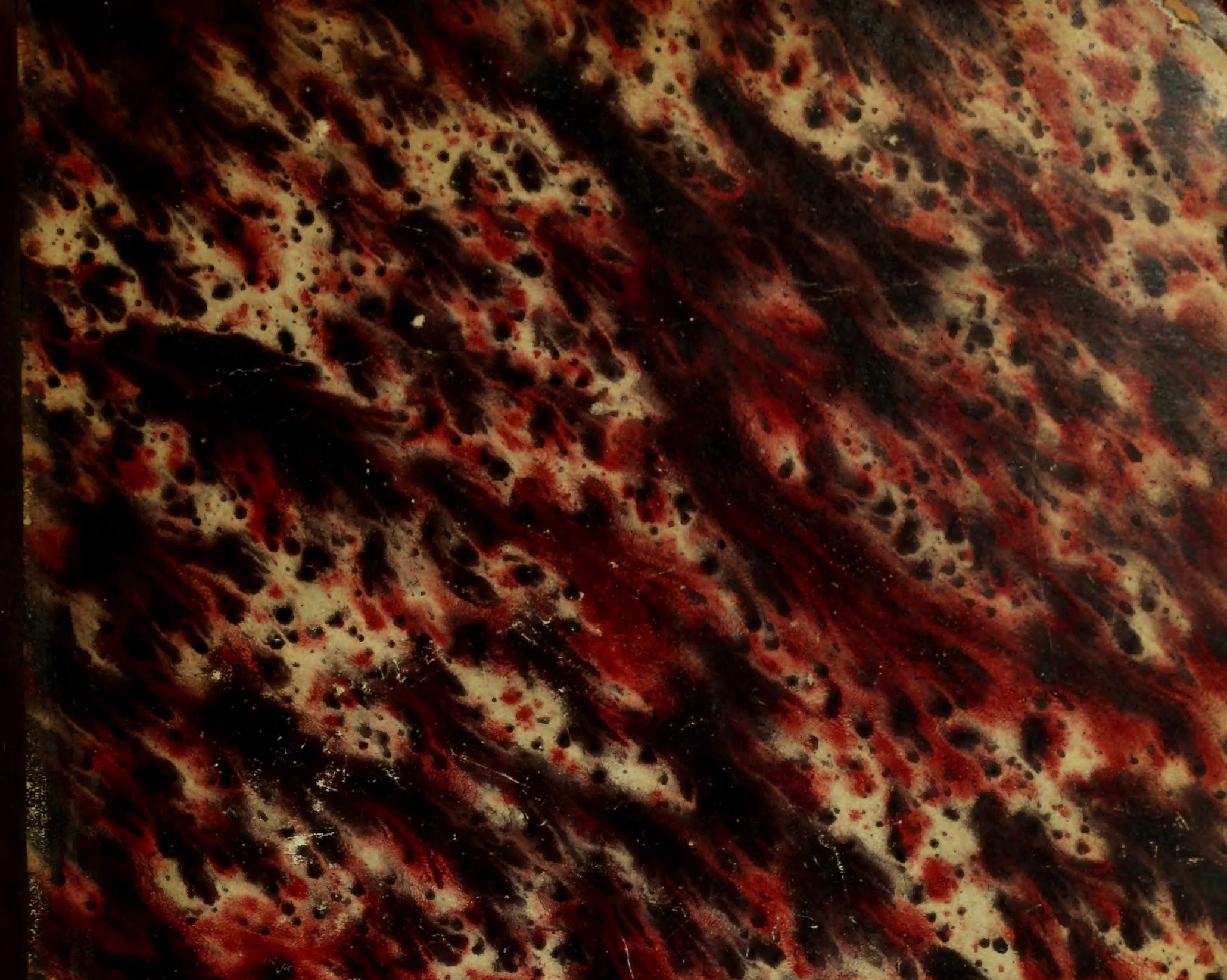

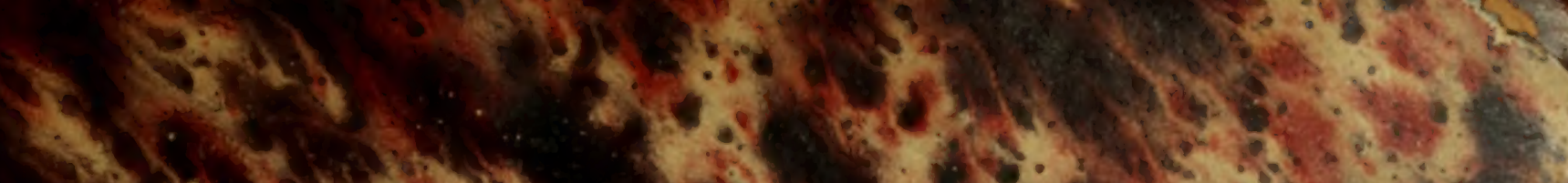

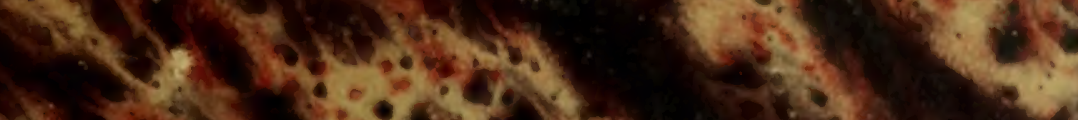




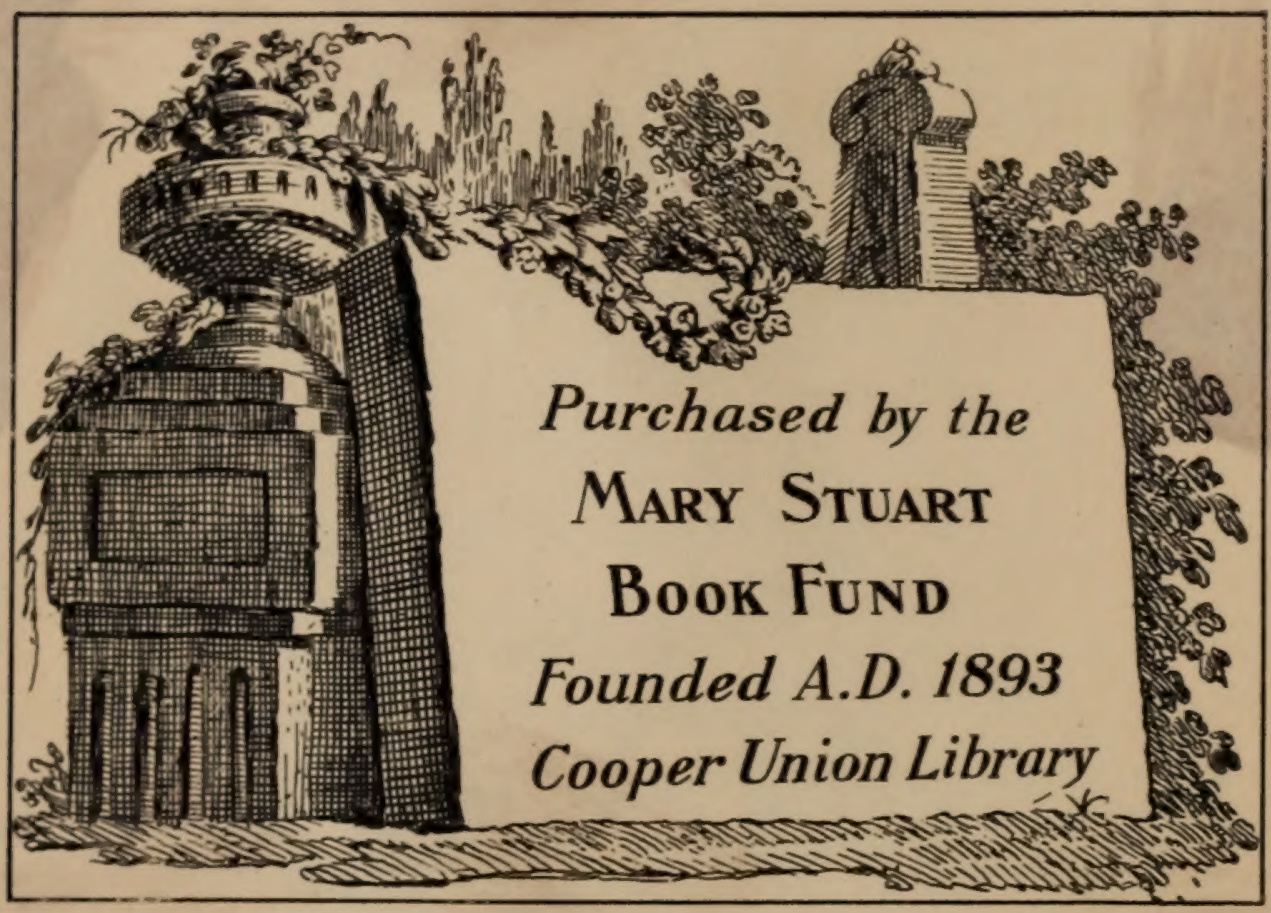




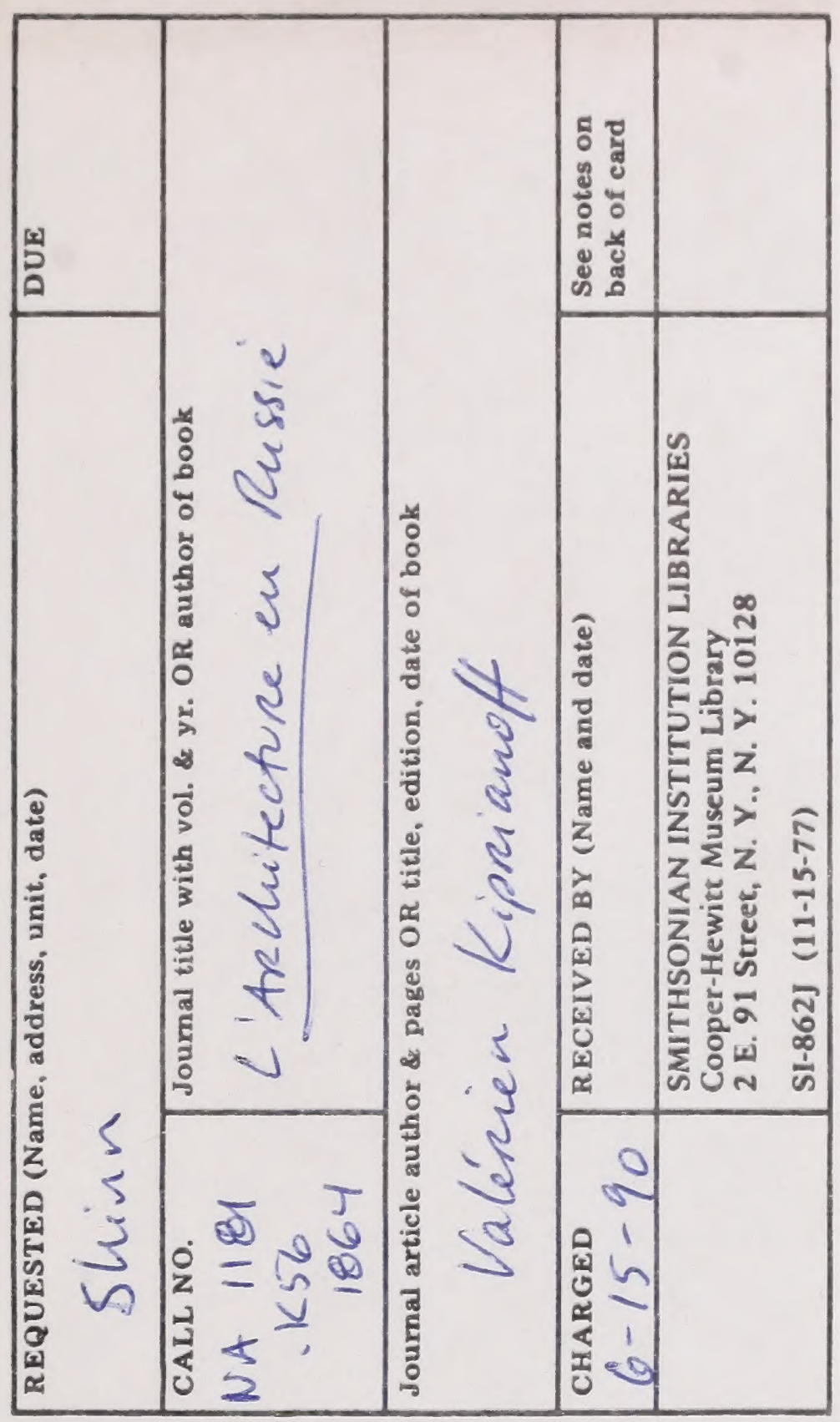






\section{HISTOIRE PITTORESQUE}

\section{L'ARCHITECTURE EN RUSSIE.}


Imprimerie du Journal de St-Pétersbourg, Gloukhoï péréoulok, n 15.

Les dessins lithographiés ont été imprinés chez Transchel à St-Pétersbourg. 


\title{
HISTOIRE PITTORESOQUE
}

\author{
DE
}

\section{L'ARCHITECTURE EN RUSSIE}

SUIVIE D'UN APERÇU

SUR LE CLINAT, LES MIEURS ET LE DÉVELOPPENENT DE LA CIVLLISATION

DAVIS CE PAYS,

\section{PAR VALÉRIEN KIPRIANOFF,}

lieutenant-colonel au corps des voies de communication, membre des Sociétés impériales de géographie de Russie, des naturalistes de Moscou et de plusieurs sociétés savantes de Russie ei de l'étranger.

Ouvrage orné de 55 dessins lithographiés et d'une carte générale de la Russie d'Vurnme

\section{ST-PÉTERSBOURG.}

a la libratrie de la cour tmpériale (S. DUfour), aU PONT DE POLICE.

\begin{abstract}
MOSCOU, CHez W. Gautier, au pont des Maréchaux.
\end{abstract}

PARIS,

CHEZ E. MeLLIER, rue pavée St-André-des-arts, $\mathrm{n}^{0} 17$.

1864. 
Permis par la censure.

St-Pétersbourg, le 2 octobre 1863.

\section{SEP 231948 $3050 \% 7$}




\section{A SA MAJESTÉ \\ MARIE ALEXANDR0 WNA,}

IMPÉRATRICE DE TOUTES LES RUSSIES.

VOTRE MAJESTÉ a daigné agréer la dédicace de cet ouvrage, et quelque indigne que ce travail soit d'un tel honneur, j'ose espérer qu'ELLE voudra bien l'accueillir avec bienveillance, en raison des motifs qui m’ont porté à l'écrire.

J'ai eu la pensée de faire connaître aux étrangers les monuments anciens de la Russie dont VOTRE MAJESTÉ est la bienfaitrice, et de rattacher à cette étude celle des mours et des coutumes de nos aieux. 
Le nom auguste et révéré auquel est dédié ce livre sera la meilleure des protections que son auteur puisse espérer, et c'est animé d'un sentiment de vive reconnaissance et d'absolu dévouement, que je viens déposer aux pieds de VOTRE MAJESTÉ le travail dont ELLE a daigné agréer l'hommage.

J'ai l'honneur d'être avec le plus profond respect, Madame, de

\section{VOTRE MAJESTÉ IMPÉRIALE}




\section{AVANT-PROPOS.}

L'étude des monuments anciens, et plus particulièrement des monuments d'architecture, disséminés sur toute la surface du globe, est d'un intérêt puissant non-seulement pour l'artiste de profession, mais aussi pour tout homme désireux de s'instruire; elle lui offre un moyen à peu près sûr de déterminer et de préciser le développement progressif de la civilisation des générations éteintes. Témoins de la vie de nos pères, les monuments sont les jalons de la route que l'humanité a parcourue, et donnent à qui sait les étudier le fil du développement des idées nationales. Quel est l'homme qui, à la vue d'une de ces belles créations de l'ancienne architecture qui font l'admiration du monde entier, ne se sent pénétré d'un profond respect pour ces glorieux survivants de l'art, qui nous ont révélé tant de faits de la vie intime et politique de nos aïeux?

'Aussi les monuments du moyen âge sont-ils devenus depuis quelque temps l'objet d'études sérieuses et approfondies. Avons-nous besoin de rappeler les immenses services que ces 
études ont rendus à l'histoire 't l'influence décisive qu'elles ont exercée sur les progrès de l'art moderne? Dans tous les pays de l'Europe, en France, en Angleter're, en Allemagne, en Italie surtout, les monuments des temps passés furent cousciencieusement étudiés dans leur's moindres détails, et de nombreux et excellents ouvrages d'architecture furent publiés à la suite de ces recherches.

Le numbre des monuments de l'art ancien en Russie ne correspond pas à la grande étendue du pays ni à l'origine antique de quelques-unes de ses villes. Les commencements de l'histoire russe sont pleins de ténèbres; tout y est obscur. et les amnales nationales ne parlent que d'époques relativement peu anciemnes. Les Russes ne possèdent donc point de renseignements positifs sur l'existence de leurs ancêtres; les monuments que ces derniers nous ont légués sont peu nombreux et ne sauraient rivaliser de beauté ou d'âge arec ceux dont se glorifient à juste titre les peuples occidentaux, qui ont toujours derancé les Slaves dans la carrière des arts et des sciences.

Toutefois, splendides ou simples, vieux ou non, les monuments de l'art russe sont remarquables en ce qu'ils appartiennent à une nation qui s'est librement et originalement formée. Considérés sous ce point de rue, ils sont dignes d'une attention sérieuse de la part des étrangers, qui n'ont en jusqu'à ce jour qu'une connaissance superficielle, sourent même erronée, des productions de l'art russe.

Voulant remédier à ce mal, et pénétré de respect pour les curres de nos aïeux, nous arons cru utile de publier quelques uhservations sur l'ancienne architecture de notre patrie et les monuments qu'elle nous a légués. L'étude des arts et des sclences est d'un intérêt général et commun à toutes les 
nations; on nous saura donc peut-être gré d'avoir cherché à domer aux étrangers, dans un rapide aperçu, une juste notion de l'art russe.

Pour donner plus de valeur à notre publication et pour faire mieux commaître nos monuments, nous arons fait accompagner notre texte de quelques plans et dessins dans le choix desquels nous arons dî nous borner à la reproduction des constructions les plus remarquables, de celles surtout qui ont le mieux résisté aux ravages du temps. Par cette raison, nous n'arons eu que peu de mots à dire de Novgorod, de Vladimir, de Pskow, bien qu'après Kiew ces villes soient les plus anciennes en Russie.

Nous nous sommes efforcé de présenter nos observations dans un ensemble systématique et de classer les monuments dont nous avons eu à parler dans l'ordre chronologique; mais il ne nous a pas été donné de rester constamment fidèle au plan que nous nous étions tiracé.

Nos aïeux, qui se contentaient pour eux-mêmes de simples habitations de bois, et qui, à ce qu'il paraît, ne songeaient nullement à la postérité, ne nous ont laissé que fort peu de monuments de l'architecture profane; les monuments sacrés absorbaient à cette époque toute l'activité de l'art, et même, pour ce qui concerne la construction des églises et des couvents, les contemporains nous ont transmis des renseignements si vagues et si abrégés que nous ne pouvons nous faire une idée exacte de la manière dont ces édifices ont été construits et de l'histoire de leur architecture. Les chroniqueurs se trompaient quelquefois non-senlement d'années, mais de siècles et de règnes, et confondaient sourent la date de la construction avec celle de la restauration ou de la reconstruction. 
L'art de fortifier l's vill's at d'élever des forteresses ne date chez nous que de l'époque où la Russie s'était rapprochée de l'Europe occidentale, c'est-à-dire au dix-huitième siècle. Jusqu'au neurième siècle nos aïeux ne connaissaient pas d'autre moyen de mettre leurs habitations à l'abri de toute attaque que de les entourer de palissades et de remblais de terre, et à la fin du dix-septième siècle ils ne possédaient encore que de faibles connaissances en matière de fortification.

A partir du dix-huitième siècle, tous les soins des souverains russes sont voués à l'embellissement de leur nouvelle capitale. Tandis que Moscou, l'ancienne résidence des Tsars, ne voit désormais s'élever dans ses murs que quelques simples bâtiments dans le goût hollandais, Pétersbourg se couvre de superbes édifices imités des constructions de l'Europe occidentale.

Les églises construites en dernier lieu par M. Thon rappellent seules le style russo-byzantin. Les plans de ces églises récemment publiés sont d'une grande importance non-seulement comme recueil d'architecture, mais aussi et surtout comme matériaux d'une valeur inestimable pour l'étude du caractère de nos vieux monuments. Tout l'esprit de l'ancienne architecture russe, saisi en ses moindres détails par notre habile artiste, y revit dans la reproduction hardie de ses formes les plus élégantes. 
La vie primitive des Slaves septentrionaux, ancêtres des Russes, nous est entièrement inconnue. Après avoir erré dans les vastes plaines du Dnieper et du Volga, ils ont disparu sans laisser de traces de leur existence. Nous ne nous occuperons donc point de la période antéhistorique de la vie des Slaves; nous ne parlerons point des cabanes (povalouchi) et des cavernes (petchoury) de leur existence nomade, ni des chaumières qu'ils ont dû construire à l'époque où les familles s'étaient peu à peu agglomérées et transformées en communes. La tradition nous apprend toutefois que dès le septième et le huitième siècles, les habitants des régions centrales de la Russie avaient commencé à tailler grossièrement la pierre, à sculpter le bois, à façonner des ustensiles de ménage en argile et à forger des armes de fer. L'art de fondre les métaux leur était connu avant le neuvième siècle $\left.{ }^{1}\right)$. La vie des Slaves devenait de plus en plus sédentaire; leurs chaumières, groupées en villages d'une étendue souvent considérable, se disposaient en posady, c'est-à-dire en rangées

(1) On voyait à Kiew une idole de Peroune et différents objets en métal; on à trouvé de nos jours, sur les bords de la Lakchenka, près du bourg Tourovsky, dans le district de Galitch, gouvernement de Kostroma, un vase renfermant une idole en cuivre. 
formant des rues. La charpenterie devint l'art dominant en Russie. A cette époque, la chaumière pouvait déjà présenter une cage asse\% solide, plafomnée, percée d'ouvertures en guise de fenêtres et entourée d'un r'emblai de terre; la fosse revêtue de pierre, qui servait anciennement de foyer, y était remplacée par un ître.

C'est aussi à cette époque qu'il faut rapporter la construction des cabanes russes et des masures de la Petite-Russie (mazanti), formées d'une cage de poutres minces et peu solides, quelquefois même de haies de branchages enduites d'argile et blanchies à la craie, à peu près comme on le fait encore aujourd'hui dans ces contrées. (Fig. 2 et 3.)

Quant à la disposition des villages, les chaumières de la Petite-Russie sont isolées ou groupées en petit nombre, quelle que soit l'étendue du village, tandis que celles de la Grande-Russie sont disposées en rangées, comme nous l'avons dit plus haut, et alignées l'une à côté de l'autre. Grâce à cette circonstance, les villages de cette dernière partie de la Russie ont un aspect sombre et monotone et les incendies y font de terribles ravages. Les villages de la Petite-Russie, dont les maisons sont disséminées sur un grand espace, sont beaucoup moins exposés au feu; leurs blanches chaumières jetées cà et là sur les rersants des collines et dans le fond des ravins, noyées dans la verdure, caressent la vue par leur aspect riant et pittoresque.

De tout temps les Slaves ont entouré leurs habitations de murs de clôture et de remparts le terre, et ont bâti des villes fortifiées; mais ce n'est qu'à partir du neuvième siècle qu'ils commencent à entourer leurs villes de murs en bois et à creuser de profonds fossés secs ou pleins 
d'eau, non-senlement autour des forteresses, mais anss autour des camps retranchés; ces derniers étaient protégés de plus par d'épaisses haies de branchages. I Les murs en bois s'éleraient sur des remparts de terre rapportée, rarement très-élevés au-dessus du sol. L'enceinte de la ville de Toula, bâtie bien plus tard, sous le règne du granc-duc Vassili Iranovitch, offre un exemple de la construction la plus compliquée de ce genre de murs. Cette enceinte est formée de deux murs, les tours qui la flanquent en ont quatre, sauf la tour circulaire de Krapivna, qui a six murs, des portes de fer et trois embrasures ('). Selon Nestor, l'enceinte de Novgorod fut élevée par Rurik. La tradition attache au fort Staroladojsky (vieille Ladoga), dont la fondation est antérieure à celle de Novgorod, le nom de château de Rurik $\left(^{2}\right)$.

Dès le neuvième siècle le gouvernement commence à s'occuper des fortifications. Les habitants de Novgorod acquièrent la réputation de bons charpentiers; ceux de Pskow excellent dans la maçonnerie. A cette époque on fabriquait déjà en Russie deux espèces de briques: la brique brute séchée au soleil et la brique cuite au feu. Dans le cours du neuvième

(1) Ces embrasures, appelées bö̈, boïnitsy, étaient percées dans le mur pour laisser passer la bouche du canon.

(*) Quelques historiens reportent la date de la fondation de Novgorod au quatrième siècle. En 1114, au temps du prince Mstislaw, la ville de Ladoga fut transportée plus près du fleuve et entourée d'un mur en pierres de taille et en cailloux, percé d'embrasures; ce mur est encore aujourd'hui en assez bon élat. En 96ว, sous le gouvernement de la grande-duchesse Olga, fut bâtie la ville de Pskow. En 990, le grand-duc Vladimir fonda plusieurs villes le long des fleuves Desna, Vystra (Oster), Troubèje, Soula et Stougna. Les villes de Korsoun, Bogouslaw et Youriew (Dorpat) furent bâties sur la Rsia, en 1032, sous le règne d'Yaroslaw. Le grand-duc Vsevolod fonda la ville de Pereyaslavl-Zaleski. 
siècle on éleva à Kiew (') un palais pour servir de demeure aux princes, un palais (terem) pour la grande-duchesse Olga et un autre palais pour cette même princesse dans la partie de Kiew nommée ville haute ( $T y$ chgorod). Kiew a été tant de fois dévastée par le fer et le feu que pas un ancien édifice d'architecture profane n'y est resté debout. D'ailleurs, comme nous l'avons déjà dit dans notre avant-propos, l'activité de nos premiers architectes s'appliquait entièrement à la construction des églises et des couvents. Il existe cependant à Kiew un vieil édifice qui peut donner une faible idée de ce qu'y était l'architecture à cette époque. Nous voulons parler de la maison d'Artémise (Artemikhine dome), ainsi appelée du nom de sa première propriétaire, qui arait vécu à l'époque des grands ravages de la peste. Connu aussi sous le nom de maison des parents de saint Démétrius de Rostof, cet édifice est construit en pierre de taille et couvert de tuiles. (Fig. 4.)

A cette époque, les Russes étaient encore peu habiles dans l'art d'élever des fortifications. Nous rencontrons cependant, dès le règne d'Yaroslaw, dans l'armée russe un corps spécial de constructeurs militaires appelés gorodniki, mostniki et maîtres parotchny $\left({ }^{2}\right)$, et auxquels on ne peut refuser une certaine instruction, car c'est par leurs soins que fut bâti en 1115 , sous le règne de Vladimir Monomakh, le pont sur le

(') Kiew a été fondée en 430 ; quelques historiens prétendent qu'elle avait dejà existé du temps d'Hérodote.

$\left(^{2}\right)$ On appelait gorodniki (du mot gorod, ville) les gens chargés de la construction des villes et des forteresses; mostniki (du mot most, pont), ceux qui bâtissaient les ponts et tout ce qui était nécessaire pour le passage des rivières; enfin les maîtres parotchny (parotchnyié mastera) étaient ceux qui confectionnaient loutes sortes de machines pour lo siége des villes et pour la guerre en rase campagne. 
Dnieper; ce sont eux également qui, lors du siége de Tver, sous Démétrius Donskoï, jetèrent deux ponts sur le Volga, et plus tard un pont sur le Don pour donner passage à l'armée russe envoyée contre les Tartares. Les annales de Novgorod font aussi mention de plusieurs ponts flottants à Novgorod et d'un pont sur le Volkhow. - Toutefois la théorie de l'art des ingénieurs ne prit naissance en Russie qu'à l'époque du tsar Vassili Ivanovitch Shouïsky, qui fit traduire en 1607, de l'allemand et du latin, un règlement pour la conduite de la guerre, "afin que les Russes fussent instruits, 》ainsi que le dit la préface de ce livre, "de toutes les nouvelles ruses "de guerre dont se prévalaient l'Italie, la France, l'Espagne, "l'Autriche, l'Angleterre, la Hollande..... et qu'ils fussent " à même d'opposer avec succès non-seulement la force à la "force, mais aussi le savoir au savoir.»

$\mathrm{Au}$ dix-septième siècle, Pierre le Grand organisa un corps spécial d'architectes militaires sous la dénomination d'ingénieurs. 

L'ar'chitecture sacrée s'est formée de bonne heure en Russie; le style byzantin y pénétra avec le christianisme au dixième siècle, et lorsque la nation tout entière fut convertie à la doctrine du Christ, l'architecture avait déjà atteint les proportions véritables de l'art, ainsi que le témoignent quelques monuments sacrés élevés à cette époque à Kiew, tels que l'église en bois de St-Nicolas, bâtie par la grande-duchesse Olga sur la tombe d'Askold, et l'église de St-Elie, également en bois. - La première église en pierre, connue sous le nom d'église de Dîme (dessiatinnaya), fut érigée en 989 à Kiew, à l'endroit où fut versé le sang des premiers martyrs Théodore et Jean, Varègues, convertis au christianisme ( ${ }^{1}$ ). Cette église, fondée par le grand-duc Vladimir sous l'invocation de la sainte Vierge, fut achevée en sept ans; consacrée en 996, elle subsista jusqu'en 1240, c'est-à-dire jusqu'à l'époque de l'invasion des Tartares, qui, sous la conduite de Baty, ravagèrent le pays. - Des architectes grecs avaient

(1) Le nom d'église de Dîme ou dessiatinnaya lui vient de ce que le grand-duc Vladimir avait affecté à l'entretien de sa fabrique et de ses desservants la dìme des revenus et des biens de la ville. Avant la construction de la cathédrale de Sainte-Sophie, l'église de Dîme avait été la calhédrale de cette ville. 
été chargés de la construction de ce temple qui servit longtemps de modèle à toutes les églises russes. L'inspection des ruines de l'église de Dîme a constaté qu'elle arait des voûtes en pots creux comme on en fait encore aujourd'hui.

Les murs de fondation étaient en gros blocs de granit, en moellons et en briques; on voyait trois espèces de briques dans le soubassement des murs en élévation, à savoir : des briques d'une dimension plus grande que celle des briques de six werchoks qu'on emploie de nos jours; des briques de moindre dimension et des briques plates carrées, de sept werchoks à chaque face, sur un pouce et quart d'épaisseur. Les lits de mortier des murs avaient presque trois fois l'épaisseur des petites briques. Le ciment, d'une couleur de chair, se composait de chaux mêlée de briques cassées et passées au tamis, peut-être même moulues ou broyées entre des pierres. La ténacité de ce ciment, qu'on employait aussi à lier les briques avec le marbre, les pierres des corniches et les dalles, est telle qu'il est impossible de séparer les briques sans les briser. L'église était pavée d'ardoises d'un rouge foncé, tirées probablement des monts Karpathes; le plancher des chapelles latérales était en dalles vernies de petite dimension, espèce de carreaux de Hollande qui sont probablement les premiers produits de l'industrie faïencière (tsenina) en Russie. Les murs du sanctuaire étaient ornés de mosaïque; ceux de l'église étaient couverts de peintures. L'emplacement du maître autel dans le sanctuaire était pavé de dalles équarries; le maître autel lui-même était entouré de carreaux de mosaïque en marbre de différentes couleurs, en jaspe et en verre, d'un travail très-fin.

L'église de Dîme resta pendant plus de quatre siècles à l'état de ruines; en 1635, le métropolitain de Kiew, Pierre 
Magila, profita des matériaux de l'ancienne construction pour élever de nouveaux murs contre la partie sud-ouest du temple, qui arait survécu aux ravages exercés par les hordes tartares. L'église ainsi restaurée avait 20 archines 3 werchoks de longueursur 8 archines 12 werchoks de largeur, y compris l'épaisseur des murs. (Fig. 5.) Une petite église de bois, sous l'invocation des saints Pierre et Paul, fut construite à l'étage supérieur, au-dessus de l'église principale; en 1828 elle fut entièrement démolie, et en 1842 une nouvelle église s'éleva sur son emplacement. (Fig. 6.)

Un autre édifice, non moins fameux parmi les anciens monuments de la Russie, est la cathédrale de Sainte-Sophie à Kiew, élevée pendant les années 1017 à 1037 par le grandduc Yaroslaw Vladimirovitch, en commémoration d'une victoire remportée sur les Petchénègues. (Fig. 7.) Quelques parties centrales de cette église se sont conservées jusqu'à nos jours dans leur état primitif. Le mode de construction des murs et des piliers de ce temple, érigé également par des architectes grecs, est pareil en tout à celui qu'on avait adopté pour l'église de Dîme. A en juger par ce qui nous est resté des ornements de ce temple d'Yaroslaw, il faut supposer que tout son intérieur avait été orné de mosaïques. Saint-Olympe Petchersky, connu de son temps comme peintre d'images et maître mosaïste habile, avait travaillé à ces ornements avec les architectes grecs.

Les excavations souterraines du couvent de Kievo-Petchersk, qui datent des premières années du onzième siècle, se composent de deux parties distinctes, connues sous la dénomination d'excavaiions rapprochées ou grottes de SaintAntoine, et d'excavaitons éloignées ou grottes de Saint-Théodose. Les premiers se trouvent à une distance de 90 sagènes, 
les seconds à une distance de 200 sagènes de l'église de Veliko-I'etchersk. L'église elle-même, commencée en 1075 et acherée en 1086, est très-belle. Les contemporains, fraplés d'admiration à son aspect, ne surent micux exprimer sa beauté en leur langue fleurie qu'en la comparant aux cieux. L'intérieur du temple resplendissait de dorures et de mosaïques; les murs étaient couverts de peintures dont la réputation s'étendait au loin.

Le pavé présentait une espèce de mosaïque en verre de différentes couleurs; les dômes étaient dorés. Cette église, dérastée souvent par le fer et le feu, a été restaurée pour la dernière fois en 1729 (fig. 8); le clocher a été construit en 1745 , sous le règne de l'impératrice Anne. Les portes saintes, situées à l'entrée principale du couvent et bâties en 1106 par Nicolas le Dévot, prince de Tchernigow, qui poussa son zile au point d'exercer trois ans durant les fonctions de gardien de ces portes, sont une des plus remarquables constructions de Kiew. L'église de la Sainte-Trinité, qui s'élevait au-dessus de cette entrée, avait une grande ressemblance avec celle de l'Annonciation, qui surmonte les portes d'or d'Yaroslaw à Kiew.

Le courent de Saint-Michel aux Faîtes d'or a été fondé, vers la fin du dixième siècle, par saint Michel, premier métropolitain de Kiew. La cathédrale actuelle (fig. 9), toute en pierre, fut bâtic en 1108 par Sviatopolk II Iziaslavitch, grand-duc de Kiew, et dédiée à l'archange Nichel. Cette église avait aussi été ornée de mosaïques à l'intérieur, ses quinze dômes araient été recouverts de plaques dorées, d'où lui vint le surnom de couvent aux faîtes d'or. Barbe, fille de l'empereur grec Alexis Comnène et épouse de Sriatopolk, apporta de Byzance au couvent de Saint-Mi- 
chel les reliques de sainte Barbe. Lancieme facale de cette église est anjourd'hui masquée par des constructions modernes et des contre-forts. Les deux chapelles latérales et le clocher datent du règne do Pierre le Grand; l'enceinte de pierre fut élevée en 1758 .

La cathédrale de Sainte-Sophie à Norgorod (fig. 10), fondée en 1045 par le prince Vladimir Yaroslaritch et exécutée également par des architectes grecs, est un des plus parfaits spécimens du style byzantin. Par rapport au mode de construction et à l'emploi des matériaux, elle diffire peu des églises de Kiew dont nous avons parlé plus haut.

L'ancien couvent de Kolojane à Grodno est aussi un des plus remarquables monuments de l'architecture du douzième slècle. Bâtie par Vsévolode Davydovitch, arrière-petit-fils d'Yaroslaw ${ }^{\text {er }}$, au sommet d'une haute montagne baignée par le Niémen, l'église de ce couvent a gardé les vestiges de l'art byzantin anquel elle doit le jour. Une double enceinte, n'offrant qu'un étroit passage, entoure le sanctuaire; dans sa face extérieure on aperçoit de grosses pierres de différentes couleurs, qui sont peut-être des produits de la fabrication d'une espèce de faïence anciennement connue en Russie sous le nom de tsenina. Sur la lanterne qui supporte le dôme principal on voit des carreaux portant des croix

L'église de Saint-George à Youriew Polski, dans le gouvernement de Vladimir, bátie au commencement de la seconde moitié du douzième siècle, par le grand-duc George on Youri Vladimirovitch Dolgorouki, fondateur de Moscou. est construite en grosses pierres calcaires équarries. L'excellente conservation de toutes ses parties témoigne de la solidité de cette espèce de matériaux.

La cathédrale de la Transfiguration à Pereyaslarl (fig. 11) 
érigée en 1152, appartient au style byzantin; ses murs sont revêtus de pierres blanches arrondies aux angles. Les liens des murs sont en bois.

La cathédrale de l'Assomption à Zwenigorod appartient, par le mode de sa construction et par son architecture, à la même époque que celle de la Transfiguration de Pereyaslavl. Elle est, comme l'église de la Nativité de la SainteVierge à Stary Simonow à Moscou, un spécimen de construction carrée. Ses murs sont formés de deux pans parallèles construits en grosses pierres calcaires de couleur blanche; l'intervalle entre les pans est rempli de béton hourdé à bain de mortier. Cette espèce de construction, employ ée autrefois par les Grecs, s'appelle emplecte.

De la Grèce elle passa à Rome et en Russie. Plus tard, les architectes italiens continuèrent à se servir en Russie de ce mode de construction; il ne faut donc pas s'étonner qu'on l'y rencontre souvent et partout, depuis les murs des premières églises de Kiew, élevées au dixième siècle, jusqu'aux constructions modernes. Une triple chaîne de pierres blanches ciselées s'étend le long du mur septentrional de la cathédrale de Zwenigorod, entre l'étage supérieur et l'étage inférieur. Le professeur Roulier a vu des coquillages dans les pierres du parvis de cette cathédrale, ce qui prouve que déjà aux temps de la première construction de ce temple la pierre calcaire était extraite des bancs supérieurs de la roche voisine. On voit encore dans les murs du sanctuaire de la cathédrale les crampons de chêne qui les relient; un maître autel en pierre s'élève au centre du sanctuaire.

La cathédrale Dmitriewsky à Vladimir Zalesky, sur la Kliazma, est d'une origine plus récente que l'église de Zwenigorod; elle est construite également en pierres calcaires ci- 
selées. Les dômes sont revêtus de plaques de cuivre dore. Les plus anciennes églises de Norgorod et de Pskow sont recouvertes de plomb et rarement de cuivre; les feuilles de fer n'ont été employées pour la première fois qu'à la construction de la cathédrale de l'Assomption à Moscou, encore étaient-elles de fabrication allemande.

Pendant que les pieux souverains de la Russie érigeaient les nombreuses églises dont nous avons mentionné quelquesunes et qui se distinguaient par une magnificence peu commune à cette époque, - des particuliers, poussés par leur zèle religieux, élevaient, en accomplissement de vœux ou en commémoration d'événements remarquables, des églises en charpente destinées à leur usage particulier; ces églises, à toiture de planches, ressemblaient probablement toutes, pour la forme, à celles de Saint-Elie et de Saint-Nicolas à Kiew. Elles étaient très-petites, sans poêles; la lumière n'y pénétrait que par de petites ouvertures pratiquées, en guise de fenêtres, dans le mur, à une hauteur dépassant la taille humaine. Il est probable que quelques-unes de ces églises n'avaient ni plafond ni plancher; que plusieurs ne présentaient même qu'une cage de cabane dont la partie orientale formait le sanctuaire. La porte d'entrée était pratiquée dans le mur occidental. Cependant toutes ces églises, dont le toit aigu supportait une petite lanterne terminée en dôme surmonté d'une croix, répondaient, par leur extérieur, aux formes adoptées pour la construction des temples, dès les premiers âges du christianisme, selon l'enseignement de l'apôtre Pierre et son sens symbolique. Cette forme de vaisseau, tourné à l'orient, figurait la vie humaine et la course de l'homme vers le port céleste situé dans ces régions de félicité parfaite d'où nous vient toute bénédiction divine, comme le so- 
leil nous vient de l'orient: le temple était un symbole du monde visible; le sanctuaire, celui du monde invisible.

Aucune de ces églises ne s'est conservée jusqu'à nous, mais il existe dans le gouvernement de Vladimir, entre les villes de Loudogda et de Mourome, une petite église de SaintNicolas qui peut nous en donner une faible idée. (Fig. 12.)

Plus tard, lorsque la construction en pierre devint plus facile, les églises en charpente dont nous venons de parler furent reconstruites en brique et en pierre. Dès le onzième siècle on voit paraître en Russie des églises à deux, trois, cinq, sept, neuf et treize dômes, coupoles ou flèches. Les églises à deux dômes figurent les deux natures de JésusChrist; trois dômes sont un symbole de la sainte Trinité;cinq, un symbole du chef de l'Eglise et des quatre évangélistes, ou des cinq plaies du Christ; - sept, un symbole des sept sacrements, des sept dons du Saint-Esprit, des sept conciles æcuméniques; - neuf, un symbole des neuf hiérarchies célestes; - treize enfin sont un symbole de JésusChrist et de ses douze apôtres (i).

Malgré ces différences extérieures, les églises russes bâties jusqu'à la moitié du quinzième siècle portent toutes le cachet du style byzantin, qui, uni et subordonné à l'élément national russe, donna naissance à un style composé

(1) Nous citerons parmi les églises à trois dômes: le couvent de SaintJean le Précurseur à Toula: les églises de la Resurrection à Gontchary et de la Nativité à Poutniki à Moscou; l'église du couvent de SaintGeorge à Vladtimir et celle du couvent de Saint-Alexandre Nevsky, dans le district de Rybinsk (gouvernement d'Yaroslavl). A cinq dômes: la cathedrale de l'archange Vichel à Hoscou; la cathérrale de Vladimir, bâlie en 1159 par le prince André Géorgiévitch; la cathédrale de Sainte-Sophie a Novgorod. A neuf domes: la cathedrale de l'Annonciation à lloscou A onze dômes: l'église de la Resurreclion au Kremlin. - La première église en charpenle à Novgorod avait treize dòmes. 
russo-byzantin. Le caractìre distinctif de ce style était İ disposition de l'église en forme de croix grecque, en souvenir de ce que la croix est la seule voie de salut; les voûtes étaient en berceau; le toit était bordé de corniches; l'église contenait trois absides disposées en hémicycle et séparées par un mur transversal avec trois ouvertures; l'hémicycle central était plus élevé que les autres et avait la forme d'une tourelle; tous ces hémicycles étaient couronnés de coupoles qui figuraient le ciel. Les murs, en moellons, étaient revêtus de pierres calcaires blanches et liées par des crampons de bois; les murs épais avaient des assises de retraite; les murs moins épais étaient reliés par des chaînes en pierres calcaires blanches. Les fenêtres étaient très-étroites et se trouvaient à la naissance des voûtes; le siége de l'évêque était élevé de trois marches. Les portes d'entrée qui terminaient trois des nefs ou des bras de la croix étaient précédées de portiques; cependant, dans la plupart des églises, il n'y avait qu'un portique à l'entrée de l'ouest, près de laquelle s'élevait aussi le clocher; ce dernier se trouvait quelquefois à l'entrée septentrionale. Les fondations des églises en général n'étaient pas très-profondes et les murs étaient peu solides; il n'y a donc pas lieu de s'étonner que les anciennes constructions aient été si peu durables. Les parties basses seules se sont conservées jusqu'à nous, grâce au soin qu'on u mis à les laisser intactes lors de la reconstruction et de la restauration des anciens temples.

Dans le cours du onzième siècle, on commença à élever en Russie des murailles de pierre autour des villes et à bâtir des tours de pierre $\left({ }^{1}\right)$. Les couvents, qui servaient souvent

(') On appelait ces tours strelnitzy; elles ètaient forlifies et perrées de meurtrières. 
de refuge contre les ennemis, étaient aussi entourés de remparts de pierre flanqués de tours; les cours claustrales s'appelaient même cours de siége. Les couvents offraient donc, dans leur ensemble, la réunion des trois espèces d'architecture, civile, religieuse et militaire.

La premiere forteresse de pierre fut construite en Russie en 1030, après la soumission des Esthoniens, - sur les bords de l'Embach, à l'endroit où se trouve actuellement Dorpat, - par le grand-duc Yaroslaw (qui reçut dans le baptême le nom de George ou Youri); elle fut appelée Youriew gorod (ou ville d'Youriew). En 1037, Yaroslaw fit entourer Kiew d'une muraille de pierre et jeta les fondements du Kremlin de Novgorod. Du treizième au seizième siècle, les murs et les tours des villes étaient construits en pierres calcaires, en pierres de taille, en lourdes briques et en cailloux; des ponts s'élevaient sur les fossés, et des portes secrètes, donnant sur la campagne ou sur le fleuve, étaient pratiquées dans les murs. Les figures 13 et 14 représentent deux tours de la forteresse de Novgorod, bâtie en 1490 par l'archevêque Basile. La figure 15 reproduit une tour de pierre de l'enceinte du couvent de Saint-Serge à Troïtsa; cette tour est percée de deux rangées de meurtrières. Quelques-unes des tours de ce couvent avaient des galeries souterraines ou passages secrets (taïnili); celle du nord-est avait encore, du temps de Pierre le Grand, une galerie de quatre verstes qui conduisait au bourg Deoulino. Une galerie partant de la tour sud-est conduisait à l'enceinte et de là dans un passage pratiqué en 1608 , pour arrêter les travaux souterrains des Polonais qui assiégeaient le couvent.

Vers le milieu du douzième siècle, Moscou, dont les annales font pour la première fois mention en 1147 , devient 
célèbre. Simple village sous le nom de Koutchkowo, transformée d'abord en ville d'apanage de la province de Souzdal, puis en résidence des grands-ducs, elle devint peu à peu le siége central du pouvoir politique, qui chez nous a de tout temps protégé les arts et les sciences. Nous allons donc passer à la description des monuments que Moscou renferme dans son sein.

Un territoire nommé Bor ou Borowitchi, et couvert d'une forêt séculaire, fut, dès l'origine de Moscou, le point central de la ville. C'est là qu'à une époque où Koutchkowo était à peine connu en Russie, s'éleva d'abord l'église du Saint-Sauveur dans la forêt, la plus ancienne église de Moscou, et ensuite celle de Saint-Jean le Précurseur (fig. 16); toutes les deux avaient été bâties en bois de chêne $\left(^{1}\right)$. Borowitchi devint ensuite une ville appelée Diélinets, Kremnit ou Kremlin (kreml) $\left({ }^{2}\right)$. Le Diétinets ou ville intérieure est une espèce de fort intérieur où on reléguait les enfants pendant les attaques de l'ennemi, pour les mettre à l'abri de tout dan-

(') En 1330, Jean Kalità reconstruisit en pierre l'église du Saint-Sauveur dans la foret. Cette église, la première qui ait été bâtie en pierre à Moscou, s'appela aussi dès lors église du Saint-Sauveur dans le palais; elle fait aujourd'hui partie du palais du Kremlin. Elle est construite en lourdes briques reliées par des crampons de fer, et porce le cachet du style byzantin, accommodé déjà au goùt et aux habitudes russes. Au sud-ouest de cette eglise fut bâtie simultanément avec elle l'église de la Nativité de Saint-Jean le Precurseur, toute en bois; quelques écrivains supposent inême qu'elle est antérieure à la fondation de Hoscou. En 1461, le grand-duc Vassili Tiomry la rebâtit en pierre el ajouta une chapelle sous l'invocation de Saint-Ouare le Martyre. Elle fut la première église catbédrale de la résidence métropolitaine de Moscou. Le socle de cette église est en pierres blanches.

$\left({ }^{2}\right)$ Le nom de Kremnik vient de Krymyorod ou ville de Krym; Kremlin de krenellus, créneau, ces forteresses ayan éte entourées de nurs crénelés. 
ger. Ces forts avaient la valeur d'une citadelle ou d'une redoute. Le Diétinets de Moscou avait été entouré, par ordre de Dmitri Donskoï, d'une palissade en bois de chêne $\left({ }^{1}\right)$; comme ces sortes de construction se trouvaient ordinairement à l'endroit le plus élevé de la ville, on leur appliqua souvent le nom de Vychgorod (ville haute). Le nom de Diétinels changea d'abord à Novgorod et Pskow, et puis à Moscou, en Kremniti et plus tard en Kremlin. Bien que depuis l'établissement de la hiérarchie cléricale à Moscou les églises et les couvents y fussent devenus très-nombreux, leur style u'éprouva aucune transformation et les constructions en pierre étaient encore si rares que les chroniqueurs du quatorzième siècle en parlent avec autant d'importance que s'il s'agissait de graves événements pulitiques. Dans les premières années du seizième siècle, la ville proprement dite ne comprenait encore que le Kremlin; autour de lui s'étendaient les faubourgs, les bourgs et les villages de la ban lieue.

La domination écrasante des Mongols avait non-seulement arrêté les progrès des arts en Russie, mais avait même anéanti le peu de connaissances qu'elle arait précédemment acquises en matière de construction. Les artisans attachés en petit nombre à la maison des khans et des grands-ducs purent seuls exercer quelques métiers qu'ils sauvèrent de la ruine générale.

(1) Le grand-duc Dmitri Ivanovitch et son frère Vladimir avaient déjà songé à entourer lioscon d'une enceinte de pierre, mais le projet n'a ete mis à execulion qu'au quiazième siècle, sous le règno de Jean III. 
L'avénement de Jean III ouvrit une nouvelle ère pour les arts; l'architecture, tant sacrée que profane, fit de sensibles progrès, ainsi que nous pouvons le juger d'après les monuments qu'elle nous a légués. Jean III appela de Pskow des maçons qui avaient étudié leur métier sous la direction des maîtres allemands ('); il appela de Venise le fameux architecte et savant Aristote Fioraventi, natif de Bologne. Ce dernier apprit aux Moscovites à fabriquer des briques plus grandes et plus solides que celles qu'ils avaient employées jusque-là, à préparer une chaux plus épaisse et plus forte, à employer pour les murs en élévation la brique et non le moellon, en réservant ce dernier uniquement aux fondations; à lier les murs avec des crampons de fer, à construire des voûtes de la largeur d'une brique, à façonner des ornements en argile, en un mot à construire les édifices avec plus de rectitude et de précision.

La cathédrale de l'Assomption de la Sainte-Vierge, qui est la première bâtie en pierre à Moscou, a été érigée, sous

(1) Dans un article des Annales de la patrie (mai 1855), M. Solovief affirme, sur la foi des chroriques, que ces maçous de Pskow n'étaient pas de simples maçons, mais bien des archilectes comme Fioraventi. Lo chroniqueur les appelle aussi maitres construclers d'éylises. 
le règne du grand-duc Jean Danilovitch Kalità, par le métropolitain saint Pierre. Jean Kalità, petit-fils de saint Alexandre Nevsky, fit construire en même temps une église sous l'invocation de l'archange Michel et y désigna lui-même l'endroit où il voulait être enterré, imitant en cela le métropolitain Pierre, qui se prépara une tombe dans le mur septentrional de la cathédrale de l'Assomption. Depuis ce temps, la cathédrale de l'Assomption devint le lieu d'inhumation des patriarches de Moscou, et la cathédrale de l'archange Michel celui des souverains russes jusqu'à Pierre le Grand.

La cathédrale de l'Assomption (fig. 17), acherée en 1327, fut démolie cent quarante-six ans plus tard, pour cause de vétusté, et sur son emplacement une nouvelle église fut construite sous Jean III, avec l'assistance des artisans russes. Cette nouvelle construction fut si peu solide qu'on dut bientôt la démolir de fond en comble, et c'est alors que l'architecte Aristote Fioraventi, appelé à Moscou, érigea la cathédrale de l'Assomption telle qu'elle existe encore aujourd'hui, à quelques changements près. Commencée en 1474, elle fut achevée en cinq ans. La cathédrale de Vladimir a servi de modèle à cet édifice remarquable. Sa construction est trèssolide; les fondations ont plus de deux sagènes de profondeur; les murs sont fortement reliés par des crampons de fer; les voutes, primitivement de la largeur d'une brique, ont été reconstruites en ogive en 1626. Des contre-forts ont été élevés à cette même époque aux quatre angles extérieurs. Les dômes avaient été d'abord recouverts de lames de fer d'Allemagne attachées à des arcs de bois, mais elles furent remplacées en 1684 par des feuilles de cuivre doré, étendues sur des arcs de fer et doublées de fer-blanc. Mal- 
gré les changements que nous venons d'indiquer et ceux qui eurent lieu à la suite de l'incendie de 1737 et des dévastations de 1812, la cathédrale de l'Assomption conserve encore à peu près sa forme primitive. Les voûtes, couronnées de cinq dômes, sont soutenues, au centre de l'église, par quatre piliers circulaires d'ancienne construction; la lumière pénètre dans l'église par les fenêtres étroites de la rotonde du dôme et les dix-sept fenêtres murales. Le sanctuaire se compose de cinq hémicycles dont les intervalles sont remplis de pilastres liés entre eux par des arcades. La disposition des parties intérieures de l'église porte les traces du symbolisme sacré; l'architecture est un mélange des styles byzantin et lombard; les formes sont massives et simples.

L'iconostase du maître autel de cette cathédrale (cloison qui ferme le sanctuaire), d'après les explications de Sa Haute Eminence le métropolitain Philarète, est fait en l'honneur de l'Assomption de la Vierge; il est composé de cinq rangées superposées d'images. Dans ce travail se reflète dans toute sa plénitude l'idée de l'Eglise œcuménique.

La rangée supérieure représente l'idée de l'église primitive jusqu'à Moïse, et l'union de cette Eglise avec celle du Nouveau Testament. Une suite de pères de l'Ancien Testament et de patriarches tels qu'Adam, Enoch, Noé, Sem, Abraham, Isaac, Jacob et autres, se trouvent des deux côtés de l'image de Dieu le Père, qui, de son sein, donne naissance au Verbe éternel. Plus bas, c'est l'Eglise de l'Ancien Testament, à partir de Moïse jusqu'à l'apparition du Christ, apparition qui était annoncée; c'est pour cela qu'au milieu se trouve l'image de l'Apparition de la sainte Vierge avec l'Enfant éternel entouré de prophètes tenant en leurs mains les chartes de leurs prophéties. 
La troisième rangée représente les douze fêtes principales de l'amnée. La quatrième est un tableau de l'Eglise chrétienne dans lequel le: Christ, roi de gloire, est représenté sous la figure de l'érêque éternel assis sur son trône, entouré de la Vierge et de saint Jean-Baptiste; plus loin sont tous les apôtres, et à leur tête saint Pierre et saint Paul. La cinquième rangée renferme les images qu'on pose habituellement dans les iconostases et qui sont en harmonie avec les idées religieuses ou les événements en mémoire desquels. le monument a été construit. Ces images portent le nom d'images locales.

La cathédrale del'ar'change Michel, dans sa forme actuelle (fig. 18), a été construite en commémoration de la délivrance de la Russie de la famine; la cathédrale de l'Assomption lui a servi de modèle: aussi est-elle moins originale que la cathédrale de l'Annonciation (fig. 19), qui, par son style, se rapproche des églises du mont Athos ou de l'église de Kertch, qui date du dixième siècle. Achevé en 1416, ce bâtiment est de forme carrée; le sanctuaire a trois hémicycles; un parvis couvert à deux entrées entoure l'église de trois côtés, c'est-à-dire des côtés sud, nord et ouest; quatre chapelles d'un style oriental s'élèvent aux angles au-dessus du parvis et communiquent entre elles au moyen de terrasses établies à découvert sur la toiture du parvis. Le faît? de la cathédrale se compose de doubles lanternes superposees; les dômes, couverts de cuivre doré, sont au nombre de neuf; celui du centre est surmonté d'une croix supportée par un croissant. Les murs de fondation sont en pierre blanche; les murs en élévation sont construits en brique. Les voûtes, en anse de panier, sont soutenues par des piliers carrés auxquels aboutit le chour, posé sur des arcades en plein cintre 
et entouré d'une balustrade. Malgré les changements faits dans les temps modernes, malgré la capricieuse fantaisie de son architecte, ce temple présente encore aujourd'hui dans toutes ses parties un ensemble imposant et original. Il est pavé de carreaux de jaspe et d'agate qui, selon Karamzine, avait été enlevés des cathédrales de Rostof et de Souzdal; la tradition dit qu'ils y avaient été apportés de Constantinople.

C'est ainsi qu'à partir de la fin du quinzième siècle, 'Moscou se rapproche visiblement de l'Europe occidentale et que sou architecture passe de son ancien état de simplicité à une ornementation souvent même trop recherchée. Parmi les monuments de cette époque nous citerons les églises de l'Epiphanie, de Nicolas Gastounski, de Cosme et Damien, vis-àvis le couvent de Tchoudow, de la Sainte-Vierge de Grebenskoïe, érigée par Jean III en commémoration de la conquête de Novgorod.

L'époque de l'érection de l'église du bourg de TroitskoïeGolenistchewo, situé entre les montagnes des Moineaux (Vorobiévy gory) et le mont Poklonnaya, est inconnue; mais, à en juger par le mode de construction et le style, elle doit avoir été construite au commencement de lapériode des patriarches. Au quatrième siècle, cette localité devint célèbre par le séjour qu'y fit saint Cyprien le métropolitain.

L'église de la Nativité de la sainte Vierge au couvent de Saint-Sabbas, disciple de saint Serge de Radonége (près Zwenigorod), est, par son ancienneté et ses belles formes, un des plus remarquables monuments de l'ancienne architecture russe. Elle est tout entière en pierre blanche.

L'église inférieure de la Nativité, restaurée en 1837, est aussi un monument des plus curieux. Par la construction de ses murs en pierre blanche, sans liens de fer, et par la dis- 
position de ses parties intérieures, elle semble appartenir au quatorzième siècle; l'église qu'on voit au-dessus d'elle, à l'étage supérieur, a été construite beaucoup plus tard. Les voûtes de l'église inférieure, faites partie en brique et partie en pierre blanche, sont en ogive avec pendentifs et s'appuient, dans la nef, sur deux larges piliers circulaires. Les deux autres piliers correspondants sont carrés et reliés par des arcades qui séparent le sanctuaire de la nef. La nef, qui touchait à l'ancien palais des grands-ducs et aux appartements des Tsarines, est éclairée par une seule fenêtre pratiquée dans le mur septentrional; le sanctuaire, séparé par des cloisons en trois parties, est éclairé par trois étroites fenêtres. Le maître autel et la table d'autel sont faits en lourdes briques; un pilier de pierre s'élevait derrière le mâtre autel, probablement pour recevoir le retable. Cette église était réservée à l'usage des grandes-duchesses et des Tsarines russes.

Vers la moitié du quinzième siècle, le métropolitain Jonas éleva dans la cour de sa maison un édifice en pierre (une espèce de palais, palatium, en russe palaty), qui contenait une église sous l'invocation de la sainte Vierge de Petchersk, construite en brique. Les dessus des portes et l'étroite chaîne qui liait les murs étaient taillés en pierres calcaires blanches. Le métropolitain Zosima le Barbu ajouta à ce bâtiment trois cellules avec des carreaux au niveau du sol. En 1475, le métropolitain George életa une maison de pierre avec quatre caveaux, et en 1487 l'architecte Marc Friazine bâtit le premier palais de pierre à Moscou. En - 1491, les Friazine, Pierre, Antoine et Marc, construisirent sur la place du Kremlin un grand bâtiment en pierre (Granovitaya Palata) pour le grand-duc (fig. 20); les por- 
tes Frolorskié (Spaskié) datent de la même année. Suivant le récit de Krekshine, on ajouta en 1492 aux anciemnes fortifications de pierre du Kremlin deux nouvelles tour's à meurtrières, avec galeries secrètes; plusieurs édifices fur'ent élevés en même temps au Kremlin, arec des galeries souterraines voûtées et des conduits d'eau en pierre, traversant le Kremlin de long en large, "pour lecas de siége.» A cette époque on connaissait déjà à Moscou l'usage des conduits d'eau en pierre et en plomb. Ces aqueducs et ces galeries secrètes forment le Kremlin souterrain dont on a découvert par hasard quelques parties. En 1516, par ordre du grand-duc Vassili Ivanovitch, des étangs furent creusés et un moulin en pierre établi à la Néglinnaya. Imitant l'exemple du souverain, plusieursparticuliers riches se mirent aussi à bâtir à Moscou des maisons en pierre. Les plus remarquables d'entre ces maisons étaient celles de Basile Obrazets, du boyard Dmitri Khovrine et du marchand Tarakane; la dernière avait été terminée en un seul été. Enfin, en 1499, l'architecte Alevise bâtit pour le grand-duc un palais de pierre (terem) au Kremlin (fig. 21), qui, selon Karamzine, s'est conservé jusqu'à nous. 

En 1473 fut fondé l'arsenal à Moscon, et dès lors on se mit à y fondre des canons et des cloches.

Les germes des arts, transportés sur le sol de la Russie par les Italiens et les Allemands, poussaient peu ì peu des racines jusque dans la vie sociale du peuple russe. Vers la fin du seizième siècle, Moscon avait déjà des cathédrales à dômes d'or, entourées d'épaisses murailles, des forts flanqués de tours à meurtrières; mais elle n'avait encore que très-peu de maisons en pierre. La ville proprement dite ne comprenait que le Kremnik; toutes les parties qui forment aujourd'hui le Beligorod et le Zemlianoy-gorod n'étaient alors que des faubourgs entourés de murailles en bois et de tours ou défendus par des grilles et des chevaux de frise. An quinzième siècle, les murs et les tours du Kitay-gorod (') furent rebâtis en briques. En 1586 on commença, par ordre du Tsar Théodore, la construction d'une enceinte de brique autour du Beligorod, quartier qu'on appela d'abord Krasnygorod ou ville rouge, de la couleur des briques dont ses murs étaient faits, et qui ne reçut son nom actuel de Beligorod ou ville blanche que lorsque ces murs furent blanchis.

(1) Du Cange pretend que le mot Kitay-gorod siguilie dépot des tresurs des Tsars 
Cette enceinte fut élevée par l'architecte Théodore Kononow: Tout ce qui était situé au delà du Beligorod fut compris dans le Zemlianoy-gorod ou ville de terre, qu'on appelait aussi Tchorny-gorod ou ville noire, de la couleur des remparts de terre qui l'entouraient à cette époque. A la fin du seizième siècle, les quartiers ou villes que nous renons de nommer formaient donc autour du Kremnik trois cercles concentriques. Le Kremnik était le siége central du pouvoir laïque et spirituel; Kitay-gorod était le centre ducommerce; Beligorod et Zemlianoy-gorod, centres d'industrie, étaient peuplés d'artisans et d'ouvriers.

Le Tsar Jean le Terrible forma à Moscou un bureau (prikaz) des constructions en maçonnerie, chargé de surveiller les constructions de la ville, de diriger les maçons et les fabricants de briques, et d'administrer les tuileries et les briqueteries élevées près du couvent Danilovsky, des portes de Kalouga et au quartier de Khamorniki.

Sous le règne de Boris Godounof, l'architecture profane, constamment protégée par ce souverain, fit de rapides progrès; l'architecture sacrée commença, dès cette même époque, à modifier quelque peu ses formes premières. L'église de saint Pierre le métropolitain, au couvent de Vysokopetrovsk, fondé en 1515 , est un édifice octogone posé sur un parapet de pierre. La cathédrale de la Protection de la sainte Vierge, connue aussi sous le nom d'église de Vassili Blajenny (le bienheureux) (fig. 22), bâtie en 1554 par Jean le Terrible, en commémoration de la conquête de Kasan et d'Astrakhan, présente un mélange hardi des types indien et byzantin.

Ce temple est très-solidement bâti en briques et en pierres calcaires. 
Les églises des bourgs Gorodna et Ostrowskoié dans le district de Kolomna, des bourgs Kolomenskoï et Diakonowo (fig. 23) dans le district de Moscou, et du bourg de Besedy dans le district de Podolsk, sont bâties en forme de tour. L'église de la Décollation de Saint-Jean le Précurseur à Diakonowo, construite en 1529, se distingue par une architecture originale: les murs sont en brique à soubassement en pierre de taille. L'église de Besedy a son étage inférieur construit en pierre de Miatchkowo; les murs sont extérieurement et intérieurement revêtus de pierres calcaires blanches. Le maître autel est en pierre, les liens des murs sont en bois de chêne aux deux étages inférieurs et en fer à l'étage supérieur. D'après ces indices, il est permis de supposer que la construction de l'église de Besedy remonte à une époque antérieure à la période des patriarches, et que par conséquent l'architecture friague ('), dont elle porte le cachet, avait cherché bien avant le seizième siècle à faire adopter en Russie les formes créées par son imagination hardie.

L'église de la Présentation, dans le couvent de Saint-Serge à Troïtsa, a trois siècles d'existence, ainsi que l'attestent les matériaux dont elle est bâtie, la préparation de ces matériaux et le style même de l'édifice, qui est un composé du byzantin et du lombard. Les crampons qui relient les voûtes du sanctuaire sont en bois; partout ailleurs ils sont en fer; le sanctuaire est pavé de dalles; en général la construction est très-solide.

(1) Dès la seconde moitié du seizième siècle on appelait friagues, en Russie, les catholiques occidentaux, pour les distinguer des Allemands luthériens; les productions des artistes catholiques étaient par conséquent qualifiées de travail friague, architecture friague, etc. Le mot friague dérive du sobriquet fria, que le peuple russe donnait à tout homme hautain ou présomptueux. 
L'église de l'ermitage de Gethsémanié, près le couvent de Saint-Serge à Troïtsa (fig. 24), est un spécimen de la construction des églises en charpente au seizième siècle. Cette église avait été bâtie d'abord au bourg de Podsosénié, dépendant du couvent de femmes de l'Assomption de la sainte Vierge, qui s'élevait au seizième siècle sur les bords de la Torgoma. L'ancienne église de Podsosénié ayant été dévorée par les flammes en 1616, saint Denis éleva sur son emplacement une église de l'Assomption de la sainte Vierge, qu'il consacra lui-même. En 1844, ce temple fut transporté de Podsosénié à la Korboukha, restauré et consacré par S. H. Em. le métropolitain Philarète. Cette église est un type des plus anciennes constructions russes. Les murs sont faits de poutres équarries; l'étage supérieur a la forme d'un rectangle, entouré de trois côtés d'une galerie appuyée sur des poutres fixées dansle mur de l'étage inférieur. Trois absides surmontées de tourelles (kakoshniks) sont adossées à la face orientale $\mathrm{du}$ bâtiment. La lumière pénètre dans le sanctuaire par trois fenêtres. Le dôme principal, appuyé sur des quilles (na gorodkach), est surmonté d'une antique croix à quatre branches. Les murs extérieurs sont revêtus de planches. L'espace compris entre la cloison du sanctuaire et les portes d'entrée a dix-huit archines de longueur; les murs intérieurs ont neuf archines de hauteur.

On voit aux environs de Rostof, (ville du gouvernement d'Yaroslaw) une église en charpente dont la construction remonte au treizième siècle (fig. 25). La figure 26 représente un autre spécimen des anciennes églises en bois; elle a été bâtie près de Novgorod, et on prétend qu'elle appartient au temps de Jean IV surnommé le Terrible. La partie souterraine de l'église du Miracle de l'archange Michel, au couvent 
de Tchoudow à Moscou, bâtie peut-être au commencement du seizième siècle, est formée de deux caveaux construits simplement en pierres calcaires blanches, sans crampons de fer.

Le clocher Ivanowski ou la tour d'Ivan Veliki (Jean le Grand) (fig. 27), commencé sous le règne du tsar Théodore Ivanowitch, fut achevé sous celui de Boris Godounof. Le style se rapproche du lombard. Ses fondations, de forme pyramidale, sont faites en gros blocs de pierre calcaire brute; on suppose que ces fondations s'enfoncent jusqu'au niveau de la Moskwa.

Les murs de retraite sont en pierre calcaire; les autres murs sont faits de briques et reliés par des barres de fer qui s'entre-croisent dans toutes les directions. L'édifice a la forme d'une tour octogonale jusqu'à la hauteur du cinquième étage, qui est cylindrique et se termine en dôme doré et surmonté d'une croix octaèdre. Indépendamment de son caractère sacré, ce clocher avait aussi une destination purement civile; il avait servi de vigie à une époque où Moscou était exposée aux attaques fréquentes des Tartares de la Crimée, des Lithuaniens et des Polonais. La place sur laquelle il s'élevait s'appelait aussi place Ivanowski; c'est là qu'avait lieu la proclamation des oukases du Tsar $\left({ }^{1}\right)$.

Nous devons aussi faire mention de l'église de la Décollation de saint Jean le Précurseur, au Staroe Vagankovo, bâtie en 1531, en commémoration de la naissance du tsar Jean IV; de l'église de Saint-Démétrius Selounski, érigée en

(1) La langue russe a conservé une locution qui se rapporte à ce fait: lorsqu'on veut dire, par exemple, qu'un homme a crié à tue-tête, on dit: il a crié de manière a être entendu de tous les coins de l'Ivanovskaya (кричать во всю ивановскую). 
1559 au Kitay-gorod, en commémoration de la naissance du tsarévitch Démétrius; de l'église de Saint-Siméon le Stylite, au delà de la rivière Yaouza, en commémoration de l'avénement au trône de Boris Godounof. Nous citerons aussi le nouveau couvent de femmes ou couvent Novodévitchi, élevé en commémoration de la reprise de Smolensk sur les Lithuaniens.

C'est à cette même époque qu'il faut rapporter les premiers changements dans l'architecture des églises en charpente; leurs cages, qui jusque-là avaient invariablement la forme d'un carré, sont désormais rectangulaires, circulaires, cruciformes ou en forme de tente. On voit donc que les déviations à l'ancien style russo-byzantin, qui paraissent, bien que rarement, dès la seconde moitié du quinzième siècle, deviennent très-fréquentes au seizième. Les voûtes des églises offrent plus de variété; aux anciennes voûtes en ogive viennent se joindre les voûtes en arc de cloître et le plein cintre, reposant sur le mur ou sur des piliers. Les liens des murs sont ornés de figures en faïence (tsénina) d'un dessin varié, dans le goût lombard, mauresque ou gothique. Toutefois les croisées sont encore formées de poteaux, à un vantail et à vitraux de mica dans un châssis de fer; longues et étroites, elles sont pratiquées à une grande distance du sol. Au seizième siècle on emploie déjà les pots creux non-seulement pour les voûtes, mais aussi pour les plafonds ordinaires; la cathédrale de Riazan et l'ancien palais du Kremlin, démoli en 1840, en offraient des exemples. Sou- les églises, les tours et les palais, étaient creusés des caveaux ou des cryptes pour la sépulture des morts ou la conservation du trésor, de la poudre à canon, des boulets, etc.

Vers cette époque, des portiques ouverts ont commencé 
à remplacer le parvis dans nos églises, et généralement on voit paraître de nouvelles formes inconnues à l'ancienne architecture russe. Les croix qui surmontent les dômes sont tantôt à quatre, tantôt à huit branches, terminées souvent par des petites croix; elles sont fixées directement sur le dôme ou bien sur une boule; les extrémités de leurs branches sont quelquefois liées avec le dôme par des chaînes. Les croix qui surmontent les dômes oriental et occidental de l'église de la Protection de la sainte Vierge, bâtie en 1693, à Fili, non loin de Moscou, par le boyard Léon Kirillowitch Naryschkine, oncle de Pierre le Grand, portent des aigles à deux têtes; un pigeon est fixé sur la croix de la cathédrale de Saint-Démétrius à Vladimir (1194).

Parmi toutes ces innovations, la plus curieuse est l'emploi d'un croissant qu'on posait sous la croix à quatre branches des anciens dômes, et qui, selon quelques-uns, doit rappeler la victoire de la croix sur le croissant ou la délivrance du joug des Mongoles. Cette explication ne peut cependant être admise, car on sait de source certaine que l'emploi du croissant dans nos églises est antérieur à l'invasion des Mongoles. On est donc tenté de croire avec Maxime le Grec ( $\left.{ }^{1}\right)$ que le croissant devait figurer la lettre grecque $\mathrm{v}$, symbole du chemin de la croix.

(1) Mort vers la moitié du seizième siècle. 

En 1601, Boris Godounof fit élever contre la salle Dorée et celle connue sous le nom de la Granovitaya, sur l'emplament du palais de Jean IV, deux nouvelles salles, appelées salle des Repas (stolovaïa) et salle des Services funèbres (panechidnaïa). Au-dessus de la salle Dorée s'élève l'église du Saint-Sauveur à la Grille d'or, surmontée de onze dômes.

La salle Dorée diffère par le style, autant que par la construction et l'ornementation, de tous les autres monuments d'architecture civile qu'on trouve dans le Kremlin. Les restes de l'ancienne architrave et des plates-bandes des trois croisées laissent encore voir quelques ornements en pierre calcaire dans le goût lombard. L'église du Saint-Sauveur à la Grille d'or (autrement dite église Vercho-Spaski) s'élevait d'abord à l'endroit où le métropolitain Jonas avait autrefois construit une maison ; l'église actuelle (fig. 28) a été bâtie en 1634, sous le règne du tsar Michel Féodorovitch. La corniche principale, l'attique et les pignons des dômes sont revêtus à l'extérieur d'ornements en relief, en faïence de couleur (tsénina) dont une partie est encore fraîche et transparente comme si elle était toute neuve.

Après l'incendie de 1591, sous le règne du tsar Théodore, Moscou fut rebâti par les architectes italiens et allemands 
et par leurs élèves russes; à la place des ảnciennes chaumières sans tuyaux de cheminées, les gens riches commencèrent à élever des maisons régulières avec un perron, un vestibule chauffé et deux ou trois ou même plusieurs chambres, qui portaient différents noms caractéristiques, tels que gridnid (гридня), térème (теремъ), povaloucha (повалуша), odrina (одрина), vychka (випка) et smotrilnitsa (смотрильница) (1).

La construction de ces maisons ne différait probablement en rien de celle que présentent aujourd'hui les cabanes des paysans riches; car le peuple russe, qui ne renonce pas facilement aux usages des temps passés, est resté fidèle au caractère des anciennes constructions de sa patrie. - Pour donner à nos lecteurs une idée de ces constructions, nous donnons les figures des façades de quelques chaumières en charpente du bourg Ivanovski, situé dans le district de Chouya du gouvernement de Vladimir (fig. 29); - d'une maison centenaire, appartenant au paysan Kobyline et située dans le mềne bourg Ivanovski (fig. 30), et de la façade des

(') Selon Katchenovský, gridnia êtait une chambre chauffée par un poêle ou une chemiliée, chóses longtemps inconnues dans les contrées sep:entrionales, où elles étaient remplacées par un âtre.

On appelle encore povaloucha, dans le district de Kassimow, des chambres froides, pareilles à celles qu'on construit en face des cabanes, de l'autre cùté du vestibule. En admettant cependant que le terme povaloucha dérive du verbe russe povalitsa (se coucher ou tomber), il pourrail bien avoir désigné une chambré de repos ou un endroit pour serrer les effets, une espèce de garde-robe, qui pouvait so trouver également à l'étage inférieur ou à l'élảgo supéricur; un ancien proverbe russe qui dit: le térème est haut, mais ta povaloucha est'encore plus haute, semble confirmer celle dernière supposition.

Odrina ètait la chambre à coucher, vychka êtait une chambre tout en haut de la maison, une espèce de pignon.

Smotrilnitsa était une petite tourelle ronde qui s'élevait au-dessus des maisons des princes et des boyards el qui permettait d'et examiner les alentours. 
chaumières communes de la Grande-Russie (gouvernement de Kostroma), construites en charpente (fig. 31).

Les poêles de ces maisons étaient revêtus de carreaux de faïence; les vitraux étaient de mica. Moscou avait imité cet usage de Pskow et Novgorod, où l'emploi du mica datait de très-loin. Ces maisons n'étaient cependant pasbasses. Les écrits du temps font du reste mention de fenêtres étroites et petites et de portes basses. L'usage s'était introduit à cette époque de faire le plancher en carreaux de chêne, ressemblant beaucoup à nos parquets. A l'extérieur les maisons étaient ornées de différentes figures en bois découpé et travaillé à jour, comme on en voit de nos jours aux maisons de riches villages. La couverture des maisons de bois était de chaume ou de planches; les maisons de pierre étaient souvent couvertes de tuiles et avaient au-dessus des portes et des croisées des ornements moulés en argile. - Les habitants nécessiteux des villes ne se laissaient cependant pas entrâ̂ner par ce luxe et, fidèles aux coutumes deleurs pères, continuaient à vivre dans des cabanes enfumées sans tuyaux de cheminée, et à employer pour les croisées, en guise de mica, de la toile imbibée d'huile ou des vessies de bœuf. Les figures 32 et 33 représentent l'intérieur d'une cabane sans tuyaux de cheminée, avec quelques fenêtres et des ouvertures servant de fenêtres. La première de ces vues est prise du côté droit, la seconde, du côté gauche de l'entrée. Les figures 34 et 35 représentent l'intérieur d'une maison à poêle et à tuyaux de cheminée; la première de ces figures donne le premier plan de la chambre, la seconde représente le fond. Pourquoi la cabane enfumée, sans tuyaux de cheminée, était-elle préférée à la maison à poêle, et n'est-il pas étrange qu'elle domine encore à peu près dans toute l'étendue de la 
Russie? Certes, à la première vue, il serait difficile de trouver à cette préférence d'autre raison que celle du bon marché relatif de la construction de ces cabanes ; mais en examinant le fait de plus près, on finit par se convaincre qu'elles ont réellement un certain avantage sur les maisons à poêle; quelque singulier que cela puisse paraître, on est cependant forcé d'en convenir. L'installation du ménage dans une simple cabane sans tuyaux de cheminée est moins coûteuse que dans une maison à poêle; ses murs enfumés se détériorent moins facilement et les insectes ne s'y logent point. De plus, un âtre sans cheminée sert en même temps d'étuve au paysan russe; vivant dès l'enfance dans une pareille cabane, le paysan s'habitue facilement à ses défauts et mène une existence semblable à celle de ses pères, sans vouloir changer de moeurs ou de coutumes. Il est toutefois à désirer que les anciens âtres, si nuisibles à la santé, cèdent enfin la place aux poêles à tuyaux, d'autant plus que la construction de ces derniers n'est pas coûteuse non plus et qu'ils peuvent aussi servir d'étuve aux paysans.

La fabrication de l'espèce de faïence connue sous le nom de tsénina avait pris en Russie un grand développement dès le seizième siècle et finit par devenir très-commune. On commença alors à comprendre sous la dénomination générale de tsénina le vernis des poteries, le verre liquide, l'émail et la faïence de couleur. Nous croyons devoir dire quelques mots au sujet de cette fabrication qui n'est actuellement représentée que par la fabrication des carreaux de faïence et en partie de la faïence ordinaire.

Nous ne nous chargeons pas de donner une définition exacte de ce que nos ancêtres appelaient tsénina (Ценина). Etait-ce un produit spécial ou bien n'était-ce tout simple- 
ment que la faïence ou la porcelaine de couleur? C'est ce qu'il nous est impossible de décider. Il nous semble cependant que la fabrication de la tsénina devait consister dans la confection par des ouvriers spéciaux de divers objets en argile couverts d'une couche de verre liquide, et pouvait être un art distinct et indépendant des autres fabrications de ce genre. En essayant de nous rendre compte de cette fabrication, nous y distinguons trois procédés distincts : 10 la confection de divers objets en argile ornés de figures pressées ou moulées au moyen de formes et de presses; $2^{\circ}$ l'imagerie et la peinture en couleurs métalliques qui couvraient ces objets d'images de saints, de figures d'hommes, I'oiseaux, d'animaux, d'arabesques variées, etc.; $3^{\circ}$ la fabrication de la tsénina proprement dite, qui consistait dans l'application sur ces objets d'une couche de verre liquide.

Des ouvriers spéciaux étaient employés à chacun de ces trois procédés. Les premiers produits de la fabrication de la tsénina, dus aux artisans de Byzance, parurent en Russie dès le dixième siècle; mais ce n'est qu'à partir du douzième siècle que les ouvriers russes commencent à orner de tsénina les murs et les planchers des églises et les ustensiles de ménage. Les traditions conservées dans le peuple et l'étude des anciens monuments nous apprennent qu'il y a eu en Russie un temps où chacune des villes dont les habitants fabriquaient de la tsénina avait ses couleurs favorites qu'elle employait invariablement dans la préparation du vernis. C'est ainsi que Rostof employait de préférence le bleu et le vert; Moscou, le vert et l'azur, etc. La tsénina de Vladimir se distinguait par la peinture originale des figures et des plantes.

La fabrication de la tsénina, que les Russes apprirent 
des Grecs, non-seulement s'adapta, en tant qu'imagerie et ornement architectonique, au goùt russe, mais subit aussi l'influence mongole. Comme tout autre art, elle a eu ses époques de transformation et de développement successif. Les petits carreaux vernis retrouvés dans les décombres de l'église de Dîme et quelques objets ayant appartenu au couvent de Saint-Irène ('), fondé en 1040 à Kiew par le grand-duc Yaroslaw, sont probablement les premiers produits russes de cette fabrication, car il est peu probable qu'ils aient été importés de la Grèce.

Nous avons dit plus haut que les murs de la cathédrale de Novgorod et de l'église du couvent de Kolojane portent aussi des ornements antiques en tsénina de Byzance. Nous remarquerons ici que dans la partie méridionale de la cathédrale de Saint-Démétrius à Vladimir, qui date de la fin du douzième siècle, on voit une image en tsénina représentant saint George à cheval écrasant un dragon. Le mur extérieur de cette même cathédrale porte un carreau de faïence avec l'image de Jésus crucifié. Ces objets ont peut-être servi de modèles aux ornements des églises de Moscou, où l'influence mongole se fait sentir dès le treizième et le quatorzième siècle.

Dans les contrées occidentales de l'Europe, la fabrication de la faïence connue chez nous sous le nom de tsénina, et importée en Espagne par les Maures, ne commença qu'au quatorzième siècle et n'acquit de la célébrité qu'au quinzième. Quoique supérieure par le travail et les couleurs à celle qu'on fabriquait en Russie, la tsénina n'en disparut pas moins dans l'occident de l'Europe à l'époque où l'on commença à y importer la porcelaine de

(') L'ancienne bâtisse de ce couvent n'existe plus. 
Chine. On voit cependant chez les peuples occidentaux quelques spécimens de cette fabrication du quinzième siècle sur la vaisselle, sur les poêles et dans l'ornementation des églises et des maisons, principalement aux corniches et aux murs; ce sont pour la plupart des figures de saints, des armoiries et des figures d'animaux et d'oiseaux en relief.

Le seizième et le dix-septième siècle furent l'époque du plus grand développement de la fabrication des émaux et de la tsénina en Russie. Vers la moitié du dix-septième, des artisans spéciaux, compris dans le service de la cour sous le nom de maîtres faïenciers, s'occupaient exclusivement de ce métier. On voyait parmi eux des potiers qui fabriquaient aussi des carreaux de faïence ou des carreaux de poêle.

Anciennement les poêles étaient revêtus de carreaux bleus et verts, lisses ou façonnés, et ornés de dessins en couleur, quelquefois même de figures en bosse produites au moyen de la pression, et de différentes inscriptions. Les assises des poêles reposaient sur des carrés de bois laissant entre le plancher et le poêle un espace vide d'une demi-archine environ (fig. 35), ou sur des supports en faïence. Les poêles étaient circulaires ou bien ils avaient la forme d'une armoire à colonnettes avec corniches et glaces; quelques-uns étaient imités des poêles tartares; en guise d'ornement on réunissait parfois les carreaux avec des clous à tête de cuivre.

$\mathrm{Au}$ dix-huitième siècle on commença à fabriquer dans les villes septentrionales de la Russie des carreaux à la hollandaise, qui se distinguent par leur dessin original et par les figures d'oiseaux et d'animaux qui les couvrent. 
Yaroslaw est de toutes les villes russes celle qui possède actuellement le plus grand nombre d'anciens poêles; les églises y conservent encore leurs vieux poêles ornés de carreaux. Parmi les poêles conservés dans les autres villes, les plus remarquables sont ceux qu'on voit à Novgorod, dans l'église connue sous le nom de palais d'Yaroslaw, et à Moscou, dans les appartements de l'ancien palais appelés térèmes.

On fabriquait les carreaux en argile purgée des parties calcaires et couverte d'un vernis dont la composition et la préparation ne différaient point de celles de l'émail ; seulement ce dernier était appliqué sur des objets métalliques, tandis que le vernis servait à recouvrir les objets façonnés en argile; les substances qui entraient dans la composition du vernis étaient moins chères et par conséquent plus grossières que celles dont on faisait l'émail. Ce dernier était appliqué à l'état de pâte épaisse; le vernis, au contraire, était toujours liquide et s'appliquait par infusion. L'essence du vernis était une masse formée d'étain et de plomb fondus et mêlés avec du verre pilé et de la potasse; cette masse recevait différentes couleurs par l'adjonction d'oxydes métalliques. Les ouvriers employés jadis à cette fabrication possédaient plus d'un secret au moyen duquel ils parvenaient à donner à leur travail un certain degré de perfection; mais la propriété de ces secrets ne leur était garantie par aucun privilége : aussi se gardaient-ils bien de les divulguer. Grâce à cette circonstance, la plupart de ces secrets ne nous sont point parvenus, et nous ne connaissons aujourd'hui de cette fabrication que la composition des couleurs, dont l'emploi avait été commun au dix-septième et au dix-huitième siècle. 
La porcelaine tendre paraît à Moscou en 1700, mais la première fabrique de porcelaine n'est fondée qu'en 1744 à St-Pétersbourg. Il faut croire qu'en Russie, comme dans l'Europe occidentale, la porcelaine a remplacé dans l'usage la vaisselle de tsénina, dont la fabrication cessa dès lors. Il serait d'ailleurs plus juste de dire que cette fabrication a perdu son nom technique plutôt qu'elle n'a disparu, car de nos jours encore il n'est pas rare de voir des objets en faïence recouverts d'un vernis bleu et ne différant de l'ancienne tsénina que par un travail plus élégant et plus solide. 



\section{VII}

Il est à remarquer que le trait caractéristique de toultes les villes russes anciennes consistait d'abord dans la préférence donnée pour les bâtir à la rive haute des ririères, ensuite dans leur division bien distincte en trois parties.

Au milieu de la ville se trouvait le château dit kremlin ou dietinetz. La partie entourant le kremlin s'appelait passad, et avait quelquefois une enceinte de murailres ou un rempart en terre.

En dehors des limites des passad étaient construits les slobodi, ainsi nommés à cause de certains droits ou franchises dont jouissaient les propriétaires, et desquels étaient privés ceux des autres bourgs ou villages.

Les slobodi portaient des noms qui faisaient allusion à la profession et à l'industrie de leurs habitants, tels que Yamskaïa (des yamchiks), Ribnaïa (des pêcheurs), Streletskaïa (des streltzi), Kosatskaïa (des cosaques).

Dans le kremlin et une partie des passadi, les maisons, construites en poutres non équarries, étaient alignées en rues.

Au centre de la ville étaient groupés les bâtiments de l'Etat, tels que les prikasnié isbie (tribunaux et adminis- 
trations diverses), le voevodsky dvor (palais du gouverneur), le trésor, les magasins aux grains de l'Etat, la turma (prison), etc.

Là se trouvaient aussi les ossadnidvori ou habitations dans lesquelles venaient loger, lors d'une invasion, les propriétaires voisins.

Les marchands et les artisans avaient ordinairement leurs habitations dans les passadi.

Parmi ces maisons en bois on voyait aussi quelquefois s'élever des églises et des couvents, dont quelques-uns étaient bâtis en pierre.

Le kniaze et sa drougina (garde) habitaient le kremlin, et les smerdi (gens du peuple) demeuraient dans les passadi.

A cette époque on n'avait aucune idée ni du pavage ni de l'éclairage des rues.

Moscou, ainsi que les villes dont nous venons de parler, se compose de parties distinctes:

$1^{\circ}$ Le Kremlin et le Kitaï-gorod;

$2^{\circ}$ Le Bely-gorod, qui entoure ces deux parties de la ville ;

$3^{\circ}$ Enfin le Zemlianoy-gorod, qui s'étend au dehors de l'enceinte du Bely-gorod.

Au commencement du dix-septième siècle, les principaux quartiers de Moscou, le Kremlin, le Kitay-gorod et le Bély-gorod, étaient déjà entourés de murailles de pierre; le Zemlianoy-gorod (земляноӥ городъ) avait une enceinte de bois qui lui valut l'appellation de ville de bois. Cette enceinte fut brûlée par les Polonais dans le courant du même siècle. Il n'existait de ponts de pierre que sur les fossés du Kremlin; tous les autres ponts, flottants ou 
bâtis sur pilotis, étaient de bois. On voyait encore jusqu'en 1678, non-seulement dans les rues du Bély-gorod et du Kitay-gorod, mais aussi dans celles du Kremlin, les cabanes des mendiants et des perclus, qui plus tard reçurent un asile dans les hospices établis à côté des églises. Dans le Kitay-gorod et le Bély-gorod, les églises des Allemands (nommées par les Russes Kirki ou ropati, lieu de murmures) s'élevaient, jusqu'en 1657, à côté des temples russes; on trouvait encore des cimetières dans l'enceinte du Kremlin.

On voit dès cette époque que les Russes, contrairement à leurs habitudes, et malgré la préférence qu'ils accordaient aux maisons en bois et aux chaumières à cages de poutres entourées de larges galeries, commencent à élever, probablement par crainte d'incendie, des maisons voûtées en brique. De toutes les murailles de pierre qui au seizième et au dix-septième siècle entouraient les villes, il ne nous est resté qu'une partie de celle de Serpoukhow. En 1556, le tsar Jean le Terrible fit construire une muraille en pierre calcaire, de 370 sagènes de longueur sur 10 archines de hauteur; elle était flanquée de quatre tours et n'avait qu'une porte. Par sa proximité de Moscou, la forteresse de Serpoukhow était un point trèsimportant de la ligne de défense tracée par le fleuve Oka.

Le couvent de Saint-Serge à Troïtsa avait été entouré, sous le règne de Jean IV, d'une muraille de pierre haute de quatre sagènes, flanquée de huit tours et renfermant une prison (ostrog). L'ancienne cathédrale de la forteresse de Mojaïsk est bâtie en pierre calcaire. A Kolomna on voit les restes d'un mur de brique élevé en 1525 par le grand-duc Vassili Ivanovitch, et qui est formé 
de deux pans parallèles, de trois quarts d'archine d'épaisseur chacun; l'intervalle entre les pans est rempli de cailloux; les portes et les tours sont en briques. Le plus remarquable de tous les anciens murs d'enceinte des villes russes est celui de Smolensk. Il a été commencé en 1596, sous la régence de Godounof, et achevé en quatre ans, malgré que les pierres calcaires qui ont servi à sa construction aient été amenées de la ville de Staritsa, éloignée de 342 verstes de Smolensk, et que la chaux ait été cuite dans le bourg de Verkhovié, situé dans le district de Bielsk, à 200 verstes de Smolensk.

La muraille de Smolensk, percée de meurtrières, a deux rangées de créneaux; son étendue est de 5 verstes et 80 sagènes; sa hauteur, de 7 sagènes sur 2 sagènes et demie d'épaisseur. Des trente-six tours qui la flanquaient, dix-sept sont encore debout; leur partie inférieure est en pierre calcaire; la partie supérieure en brique. La solidité de ce mur est telle qu'il y a de cela quarante-cinq ans, c'est-à-dire deux cents ans après sa construction, les processions religieuses qui ont lieu autour de Smolensk pouvaient encore marcher sur le mur dans tout son parcours; les briques dont il est bâti sont d'une si bonne qualité que, malgré tous les essais faits à Smolensk, on n'est point parvenu à en fabriquer de pareilles. 


\section{VIII}

Comme l'ancien style byzantin qui avait dominé eu Russie du dixième au quinzième siècle, comme le style lombardo-vénitien que les Italiens y avaient introduit au quinzième et au seizième siècle, le style, allemand ou mauresque-gothique, que les architectes allemands firent prévaloir chez nous au dix-septième siècle, subit quelques modifications sous l'influence des éléments locaux. Les Allemands préféraient, pour la construction des églises, la brique bien cuite à la pierre calcaire, et tout en gardant dans leur architecture religieuse notre symbolique sacrée, ils adoptèrent cependant une ornementation plus recherchée. A cette époque on commença à placer dans les voûtes des pots creux (golosniki), pour en augmenter la résonnance; les sommets des voûtes se réunissaient en trois étages et formaient des tourelles ou des niches demicirculaires surmontées d'un ou de cinq dômes. Les églises à cinq dômes existaient d'ailleurs déjà à l'époque des patriarches russes.

On élevait au dix-septième siècle des églises à deux étages, dont l'un, appelé église basse ou inférieure, était chauffé et servait en hiver, et l'autre, appelé église haute ou supérieure, étant sans poêles, ne pouvait servir que 
pendant l'été. Dans les églises qui datent du dix-septième siècle on ne voit plus de galeries ou chœurs comme on en bâtissait au quatorzième et au quinzième siècle; mais le sanctuaire conserve encore son ancienne division en trois hémicycles faisant saillie du côté de l'orient. La plus remarquable des églises construites à cette époque à Kiew est la cathédrale de l'Epiphanie, au couvent Bratsky, bâtie en pierre, en 1693, par le hetman Mazepa.

Les églises en charpente du dix-septième siècle avaient le plus souvent cinq dômes et trois absides de forme circulaire, dont la principale était à trois fenêtres et les deux latérales à une fenêtre. La porte occidentale était précédée d'un parvis. Les chapelles s'élevaient sur des parvis séparés, en dehors de l'église principale, avec laquelle elles communiquaient par des portes. Les registres des maisons du Bély-gorod et du Zemlyanoi-gorod à Moscou font mention, au dix-septième siècle, de quelques églises en charpente chauffées à poêles.

Les constructions en bois étaient ornées, tant intérieurement qu'extérieurement, de différentes pièces travaillées en bois avec beaucoup de recherche, dans le goût russe, telles que planches découpées à jour, accessoires sculptés, faîtes et balustrades ouvragés, et toutes sortes de ciselures différant peu de celles qu'on confectionnait à l'époque où ce genre d'ornementation venait seulement de naître. On retrouvait ces mêmes ornements sur quelques chaumières, comme nous l'avons représenté dans les figures 29 et 31. Les dômes des églises étaient couverts d'écailles de bois ou de bardeaux; les toits, pour la plupart à deux ou à quatre pans, étaient couverts de planches. Les clochers, de pierre ou de bois, étaient construits contre le 
mur occidental, rarement contre l'oriental, comme, par exemple, le clocher de Notre-Dame Grebensky au Bélygorod. On rencontre souvent près du mur septentrional des églises, des tourelles de clochers formées d'un mur en pierre partant en triangle des bords du toit appelé Tchiptsovoy et laissant des ouvertures pour la volée des cloches. Telles sont les tourelles de l'église de Saint-Jean le Précurseur au Kremlin. On élevait aussi au dix-septième siècle des clochers séparés de l'église, non loin de sa porte occidentale, et surmontés d'un dôme en forme de couronne impériale avec plusieurs ouvertures pour le son des cloches. Les quelques clochers de ce genre restés debout jusqu'à nos jours datent des règnes des Tsars Michel Féodorovitch, Alexis Michaïlovitch et Théodore Alexéevitch ou du règne des trois souverains Jean, Pierre et Sophie, c'est-à-dire de l'époque qui vit s'élever à Moscou le plus grand nombre de monuments de l'architecture profane et sacrée. Les plus remarquables de ces monuments sont :

$1^{\circ}$ L'église du Saint-Sauveur à la Grille d'or, dont nous avons déjà parlé ;

$2^{\circ}$ L'église de Notre-Dame de Géorgie (fig. 36), située près du mur oriental du Kitay-gorod. Ce monument de l'architecture religieuse du dix-septième siècle est un spécimen d'un style original créé, dans le goût russo-byzantin, par les architectes moscovites, sous le règne des trois premiers souverains de la maison Romanof. L'excellente conservation du corps de ce bâtiment et de ces ornements en briques, en carreaux et en pierres calcaires, qui ont si bien résisté pendant deux siècles à l'action de l'air, témoigne de la solidité de sa construction; 
$3^{\circ}$ L'église de Saint-Nicolas aux Stolpy (въ столпахъ) ou église sur la tour au Bély-gorod (fig. 37), construite au dix-septième siècle, dans le même style que les autres églises citées. Le nom de tour donné à l'emplacement de cette église vient, selon la tradition, d'une tour de vigie qui y avait été construite à l'époque de la domination des Tartares et qui servait à surveiller la marche des détachements qu'ils envoyaient contre le pays. De là le nom d'église sur la tour ou d'église bâtie sur l'emplacement de l'ancienne tour;

$4^{\circ}$ L'église de Saint-Nicolas à la Biersénevka, bâtie en brique vers l'an 1656. Cet édifice indique une tendance d'union entre le style indo-oriental et le style byzantin. Les ornements extérieurs sont taillés en partie dans la pierre calcaire. Des carreaux ornés de figures d'aigles à deux têtes sont placés dans les enfoncements des murs;

$5^{\circ}$ L'église de la Nativité de la sainte Vierge aux Poutniki, remarquable par une étrange réunion de constructions anciennes avec des bâtisses plus modernes, dont les principales datent des premières années du dix-septième siècle. L'antique origine de cet édifice est attestée par les lourdes briques dont il est fait et les liens de bois qu'on voit encore dans les voûtes du sanctuaire; les autres parties de la construction sont liées par des barres de fer. Les assises des murs sont très-solides. Il se peut que cette église ait été construite peu de temps après celle de la Protection de la sainte Vierge. Quant à son style, l'élément russe y domine sur le byzantin et le lombard. La rotonde du dôme est ornée d'astragales et de bandes concaves faites au moyen de la pression, et couvertes de carreaux formés de plusieurs pièces sur lesquelles on 
voit des aigles à deux têtes entourés de plantes entrelacées. Ces bandes indiquaient un assez haut degré de perfection dans l'art de produire des figures au moyen de la pression, et prouvent qu'il fleurissait déjà au dix-septième siècle;

$6^{\circ}$ L'église de la Sainte-Trinité dans le bourg Troïtsky, sur la route de Zvénigorod, à 10 verstes de Moscou, construite en 1708 dans le style de la Renaissance, qui s'introduisit à Moscou vers la fin du dix-septième siècle;

$7^{0}$ L'église de Saint-Nicolas à la Grande Croix, dans le Kitay-gorod (fig. 38), et l'église de l'Assomption sur la Pokrovka aux Kotelniki, dans le Bély-gorod. Ces églises occupent incontestablement la première place parmi celles bâties au dix-septième siècle à Moscou, dans le style mauresque-gothique. L'église de Saint-Nicolas à la grande croix est appelée ainsi parce qu'on y garde une croix de grande dimension, qui renferme quatre-vingt-dix parcelles de reliques de plusieurs saints. L'église de l'Assomption sur $l_{a}$ Pokrovka aux Kotelniki a pris son nom de l'ancienne dénomination de l'emplacement sur lequel elle s'élève. Ces deux églises sont très-solidement bâties en briques réunies par des liens de fer; leurs murs de retraite sont en pierre calcaire, qu'on a aussi employée pour quelques ornements de portes et de fenêtres. Ces églises sont comptées sans contredit parmi les plus beaux édifices de Moscou. Pendant son séjour dans cette ville en 1812, Napoléon mit un soin tout particulier à préserver du feu l'église de l'Assomption.

$\mathrm{Au}$ commencement $\mathrm{du}$ dix-septième siècle on fabriquait déjà à Moscou de bonnes et solides briques; tous les palais et tous les bâtiments de quelque importance étaient, 
à cette époque, construits en pierre. En 1635 on construisit au Kremlin, au-dessus de la salle des Artisans, de nouveaux appartements pour le Tsar et des térèmes pour les Tsarévitch Jean et Alexis. Peu de temps avant, on avait élevé la maison synodale, connue d'abord sous le nom de maison des patriarches, avec l'église des Douze Apôtres. Restaurée sous Pierre le Grand, cette église est la première de celles consacrées par le saint-synode institué en 1723. Les portes de la maison archiépiscopale dite Kroutitskiia sont également dignes d'intérêt. C'est là que les armées russes, réunies contre les Polonais qui opprimaient la patrie, avaient solennellement juré de la défendre et de la sauver. Ces portes datent de la seconde moitié du dix-septième siècle et supportent un térème à quatre fenêtres dont la façade est couverte de carreaux verts et bleus ornés de diverses figures. Avant l'incendie de 1737 , la toiture escarpée de ces portes était couverte de tuiles et répondait parfaitement au caractère général de la construction, qui porte l'empreinte du goût russooriental.

Pour ce qui concerne l'architecture, la première place parmi toutes les constructions du dix-septième siècle, après la Granovitaya Palata et les térèmes du Kremlin, appartient à l'ancien palais Potechny (palais de plaisance), transformé aujourd'hui en hôtel du commandant de la ville. Bâti sous le règne du Tsar Alexis, en grosses et lourdes briques liées par des barres de fer, ce palais se compose de deux ailes à quatre étages, réunies par une construction à trois étages, antérieure, par le travail et le style, aux deux autres et datant peut-être des premières années du dix-septième siècle ou du règne des premiers souverains de la maison 
Romanof. De profonds caveaux et des galeries en pierre calcaire s'étendent sous les voûtes également en pierre calcaire de l'étage inférieur de cet édifice. Ces caveaux contenaient autrefois, selon le témoignage des anciens habitants de Moscou, qui avaient pu constater le fait par eux-mêmes, des appartements dont les murs étaient revêtus de carreaux vernis. On voyait encore au commencement de ce siècle les tuyaux des poêles qui chauffaient ces chambres. On ignore le nom de l'architecte qui avait construit cet édifice, dont le style est un composé de divers éléments, tels que le style gothique-allemand, le mauresque, le byzantin, le style de la Renaissance et le style dit rococo. Les pilastres, les supports, les corniches et les autres ornements conservés sur les murs extérieurs de cet édifice sont taillés dans la pierre calcaire; ils sont couverts de figures de cavaliers, de lions, d'ours, de licornes, de dragons ailés, d'oiseaux, de vases de fleurs et d'autres objets habilement entremêlés et indiquant la destination du bâtiment.

Un nouveau bazar fut construit en 1677 dans le Kitay-gorod. Quelques-unes de ses rangées de boutiques conservent encore de nos jours leurs anciennes appellations, comme par exemple les lignes Sourovskaya (Суровская) ou ligne des soieries; Panskaya (Панская) ou ligne de mercerie; Friajskaya (Фряжская) ou ligne de quincaillerie, et la ligne Vénitienne; les noms de ces rangées de boutiques étaient probablement en rapport avec les relations de commerce extérieur.

Parmi les plus remarquables maisons seigneuriales de ce temps, on peut citer la maison du boyard Artamon Serguéiévitch Matveïef, bâtie par les strélitzs dans la petite rue Stolporsky de la paroisse de l'église de Saint-Ni- 
colas sur la Tour('), et la maison du prince Basile Galitzine, recouverte de feuilles de cuivre. Cette dernière maison ne le cédait en beauté à aucun ancien palais des autres pays d'Europe.

(') Les strélitzs, voulant témoigner lour reconnaissance pour les services que leur avait rendus Matvéief, apportèrent pour la construction de sa maison les pierres qui couvraient les tombes de leurs parents. 


\section{IX}

Pendant que l'architecture civile embellissait Moscou de plus de trois mille édifices en pierre, bâtis par des architectes étrangers et des maîtres constructeurs entretenus par l'État, l'architecture nationale continuait à élever ses constructions en charpente. Les étrangers eux-mêmes rendent justice à l'habileté de nos charpentiers en consignant dans leurs récits que les Russes possédaient au dixseptième siècle le talent de bâtir à peu de frais et avec beaucoup de célérité des maisons de bois qui, pour l'élégance du travail, pouvaient rivaliser avec celles de pierre. Les cages de ces maisons en charpente avaient une forme très-variée : les toits étaient, selon le climat, tantôt trèsinclinés, tantôt à deux pentes douces; les toits à plusieurs pentes étaient appelés toits de tente (chatrovi ou épanchovia). La couverture était de planches, de tuiles ou même de gazon. Les toits à flèches et à coupoles, à quatre, six et huit pans, étaient connus à cette époque sous le nom de toits du tsar, probablement parce qu'on les employait de préférence dans la construction des palais. La disposition des maisons en charpente n'offre rien de particulier; elle était très-uniforme dans les maisons de moindres dimensions. 
Elles se divisaient en deux parties: la première était l'isbah chaude ou istopka, la seconde était la chambre froide appelée klète.

Ces deux pièces communiquaient par un vestibule auquel était adossé à l'extérieur un perron à colonnes nommé kriltso. Ce genre de construction se voit encore dans nos campagnes.

Quand la chambre froide était bien éclairée, et surtout chauffée par un poêle à cheminée, elle prenait le nom de svetlitza ou svetiolka.

Les palais des kniazes et leurs térems (étages supérieurs réservés pour les femmes), et les khoromi (ma ison $\mathrm{s}$ des boyards et riches particuliers), se distinguaient par leur grandeur, une propreté plus sévère, et par leur ornementation; toutefois ils étaient rarement construits en pierre.

Chaque maison était entourée soit d'un mur de clôture, soit d'une enceinte de pieux. La maison proprement dite était bâtie au milieu de la cour. Elle se divisait en plusieurs pièces communiquant entre elles par des seni ou vestibules couverts.

Les maisons des riches avaient un étage inférieur appelé podklet, destiné au service ou aux magasins. Ces bâtiments étaient surmontés d'un térem.

Dans la cour d'une habitation de boyard se trouvaient encore des bâtiments pour loger sa dvornia (ses domestiques), et diverses dépendances.

Les riches propriétaires de l'époque faisant faire par leurs serfs tous les travaux nécessaires aux besoins de la vie, ces bâtiments avaient une importance assez considérable. 
Derrière la grande cour s'en trouvait une autre, destinée aux équipages, à la basse-cour, à l'étable et à divers magasins.

Enfin un jardin et un bain (milnia) devaient exister de rigueur dans toute maison bien tenue.

L'ornementation intérieure et extérieure des maisons privées était peu riche et variait rarement.

A l'intérieur, la place d'honneur était réservée aux images de la sainte vierge et des saints. Ces images (ikoni) étaient quelquefois recouvertes de plaques en argent et renfermées dans des boîtes à battants (kiota). Elles garnissaient le coin situé à droite de la porte d'entrée, et à l'angle du mur de face. Une lampe était suspendue devant ces images.

Les murs étaient couverts de grossières gravures appelées loubotschni, qui satisfaisaient pleinement le goût peu difficile de nos ancêtres.

Ces peintures étaient souvent religieuses et représentaient des sujets tels que le jugement dernier accompagné de tous les supplices de l'enfer, ou autres scènes de l'histoire sainte.

Quelquefois les sujets de ces peintures étaient tirés des contes en vogue (skasoke), quelquefois même leur genre était satirique ou plaisant.

Dans ce dernier cas, l'humeur du peuple s'y trouvait bien peinte dans ses formes naïves. Je citerai, parmi les plus remarquables de ces peintures, l'enterrement du chat par les souris (allusion à la bonté du peuple russe, qui après la mort de son ennemi, oublie tout sentiment de haine à son égard), les suites de l'ivrognerie, les deux fous qui se battent et le troisième qui les regarde. Ajou- 
tons, pour caractériser la malicicuse naïveté de nos aïeux, que le troisième personnage n'est pas peint sur le tableau, et que c'est au spectateur à deviner où il se trouve.

Nos ancêtres s'asseyaient sur des barces en bois; les tables des repas étaient en chêne, et la vaisselle, très-ordinaire, était en terre ou en bois. Les ciboires même des églises des campagnes étaient en étain ou en bois. Le luxe ne se rencontrait que dans les capitales, dans les habitations des kniazes ou dans les temples.

Chaque maison avait, outre les petites fenêtres à coulisse nommées volokovimi, une grande fenêtre avec dormants percée au milieu de la façade, appelée kosiatchatime ou krasnime. Les poêles des cabanes et des maisons ordinaires étaient faits d'argile et posés sur des carrés de bois, à la manière russe, comme cela se pratique encore aujourd'hui (fig. 35).

Mais dans les habitations des personnes riches, ils étaient recouverts de carreaux de tsenina à dessins variés, avec toutes sortes de moulures, d'astragales et de colonnettes. Il faut croire qu'à cette époque les vitres étaient en usage, car, en 1634, Moscou possédait déjà une verrerie. Les forteresses construites en bois à cette époque sont les seules qui soient debout de nos jours. On voit à Yakoutsk les restes d'une forteresse (fig. 39) bâtie antérieurement à l'année 1663, probablement pour mettre les habitants du pays à l'abri des attaques des peuplades voisines. Il existe à Kola, dans le gouvernement d'Arkhangel, un vieux chateau de bois très-délabré, bâti en 1704, pendant la guerre avec les Suédois, et flanqué aux angles de quatre tours (fig. 40).

Dès 1723 on commença à construire en pierre les murs 
le fondation des maisons en charpente. Jusqu'au règne de Pierre le ${ }^{\bullet}$ Grand, les maisons scigneuriales (khoromi) en pierre et en charpente s'élevaient dans les cours; mais ce souverain ordonna, par un oukaze du 19 janvicr 1718 , de construire les nouvelles maisons et de rebâtir les anciennes en une seule rangée le long de la rue, et de paver cette dernière aux frais des propriétaires des maisons. Il a été en même temps prescrit, cn vue de la conservation des forêts, d'employer pour la couverture des maisons des bardeaux et non des planches, comme cela avait lieu jusque-là; des ouvriers spéciaux furent appelés dans ce but de Smolensk et de la Petite-Russie. Pierre mit en même temps en usage les cheminées et les poêles de Hollande posés sur des supports.

Déjà en 1643 fut commencée la construction d'un pont de pierre sur la Moskwa; c'était le premier travail considérable de ce genre : aussi le considérait-on à Moscou comme une espèce de merveille.

Jusque-là on n'avait construit sur la Moskwa que des ponts provisoires ou flottants. En 1643, on fit venir de Strasbourg à Moscou, pour exécuter les travaux du pont de pierre, un maître constructeur nommé Jean Kristler et connu en Russie sous le nom d'Anzée Jacobson.

Les travaux, interrompus en 1645 , ne furent repris qu'en 1682. Le pont (fig. 41) commencé d'après le plan de Kristler fut achevé en 1687, par un moine dont le nom n'est pas parvenu jusqu'à nous.

Ce pont a été plusieurs fois restauré pendant les cent soixante-dix ans qui se sont écoulés depuis sa construction; en 1812 , on fut forcé de le reconstruire de fond en comble et de l'étayer de piles en grès de Tatarowo. Il exista en cet 
état (fig. 42) jusqu'en 1857. Il a depuis été reconstruit avec des ares en fer, ainsi que le représente la figure 43, sous la direction de notre ingénieur de si grand mérite le général Chouberski. En 1633, un Anglais nommé Galloway, horloger de profession, parvint, au moyen de travaux exécutés à l'endroit où se trouvait le pont flottant, remplacé plus tard par le pont de pierre, dont il a été parlé ci-dessus à conduire, l'eau de la Moskwa dans la tour de Sviblow et de là dans les cuisines du palais, sitni et kormovi. 
Le palais Romanoff, où naquit le tsar Michel Fedorovitch, chef de la maison régnante actuelle, et très-probablement son père le boyard et voïevode Théodore Nikitisch, qui devint plus tard patriarche sous le nom de Philarète, est sans contredit, pour la Russie, le monument ancien le plus remarquable.

Ce palais est bâti en pierre. Il a résisté pendant plusieurs siècles aux atteintes du temps. C'est le monument le plus antique d'architecture civile du Kitaï-Gorod, et le seul modèle des maisons de boyards. A part son intérêt historique, il présente celui de faire connaître le genre de vie des grandis personnages au seizième siècle et d'être un parfait spécimen des maisons des boyards à cette époque, d'autant plus que sa restauration a été faite avec tout le soin possible et que son ornementation est complétement dans le goût de l'époque.

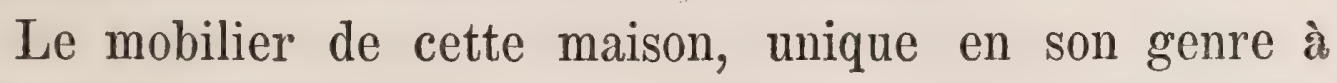
Moscou, compose à lui seul un musée remarquable d'objets des seizième et dix-septième siècles, étroitement liés à l'histoire de cette époque. Il nous montre la vie intérieure des boyards moscovites, leur ménage et l'ordre qui réglait leur vie de famille. 
La maison Romanoff est bâtic sur le versant d'une colline; clle a quatre étages du côté de la façade sud et sur la cour, et un étage sculement du côté de la façade qui donne sur la rue Varvarskaïa (fig. 48 et 49 ).

L'étage inférieur, ainsi que les caves et les glacières (figure $49 \Lambda$ ), a été bâti probablement au quinzième siècle, et en pierre de taille dite béloï-kamène ( $\left.{ }^{1}\right)$ et sans tirants en fer; les murs contiennent des excavations.

A gauche de l'cntrée il existe un large escalier en pierre qui servait à la descente des tonneaux de vin dit friagski, des tonneaux d'hydromel, de bière et de kvass, à la cave dite médoucha. Un second escalier conduit de la cuisine (prispechnaïa ou povarnia) dans la glacière, qui est à côté de la cave. Les matériaux employés et le mode de construction attestent l'antiquité de cette partie de la maison.

Les caves sont éclairées par deux fenêtres percées audessous des piédroits des voûtes en anse de panier.

Le rez-de-chausséc ou podklète et l'étage du milicu (fig. $49 \mathrm{~B}$ et $\mathrm{C}$ ) sont construits en briques dont plusieurs sont marquées aux armes du tsar Iwan Wassiliévitsch.

Les murs, les voûtes, les portes, les fenêtres et les colonnes sont reliés avec des tirants en fer.

(') Toutes les fois qu'il est question dans cet ouvrage du béloï-kamène, il faut entendre les pierres provenant des couches inférieures de la formation carbonifère. Celte pierre a été le plus souvent employée dans les constructions de Moscou. On la tire depuis longues années des environs de celte ville, et particulièrement de Miatschkovo, qui est situé sur la rive gauche de la Mloscova et à 27 verstes en aval de cette rivière. Lorsqu'il est question de pierre de grès ou de meuie, il faut entendre le grès tiré aussi des rives do la Moscova, mais dans les villages de Tatarovo, Litkino et autres. Ce grès, selon toutes probabilites, appartiont aux couches des grès verts, qui sont les couches inférieures de la formation crétacée. 
Au-dessus du troisieme étage s'élève le terem avec la vischka et la swetlitza (fig. 49 D). Cette partie de la construction est en charpente. Les murs de l'étage inféricur sont plus épais que ceux de l'étage du milieu, dont le socle est en pierres taillées à facettes. Le toit est à quatre pentes et en fer-blanc, et son arrête supérieure est surmontée d'une plaque en cuivre ciselée à jour. Les saillies de ce toit sont garnies de festons en même métal.

Les cheminées, carreaux vernis (izrastsi) contribuent ì la beauté originale du bâtiment.

Du côté est, à l'étage du milieu, il existe un balcon suspendu (gliadelnia). Au-dessus, et sur un écusson, sont les armes de la famille Romanoff; au-dessous, dans une niche et sur une pierre, est grarée l'inscription suirante:

- Par ordre du pieux sourerain l'Empereur de toutes 《les Russies Alexandre Nikolaïéritch, en mémoire de ses * ancêtres orthodoxes, et en l'année bénie de son saint * couronnement, le 26 août 1856, a été commencée la res- tauration de la maison des aïeux de la famille Rnma«noff, sise à Moscou, près du courent de la Présentation \& de la Sainte-Vierge. \&

- En cette maison naquit le tsar Michel Fédororitch «chef de la famille régnante actuelle, et y fut élevé son " père le boyard et roïerode Théodore Nikitisch Roma\& noff, derenu plus tard patriarche de Moscou sous le nom \& de Philarète. 8

- La restauration de ce monument a été terminée * en 1859.8

Le toit du parillon, côté ouest, est surmonté d'une girouette représentant un griffon ailé, qui dans une patte tient un glaive et dans l'autre un bouclier, c'est-à-dire 
une arme offensive et une arme défensive qui sont marquées sur le blason de la famille Romanoff.

Du côté de la Varvarskaïa, une porte d'entrée en fer conduit sur un palier couvert servant de vestibule. En sortant de ce vestibule et à gauche, un escalier principal conduit à l'étage du milieu; un autre descend directement à une grille en fer qui sépare le palais du couvent.

$\Lambda$ l'entrée du palais, sur l'escalier principal, est un lion en pierre, tenant un bouclier qui porte les armes de la famille Romanoff. Au bas de l'escalier est un autre lion au repos.

L'étage du bas ou podklète renferme, ainsi que le représente la figure (49 B), les communs, un garde-manger avec un petit réduit et la cuisine.

Dans cette dernière pièce il y a un poêle russe, et dans le plafond du petit réduit est pratiquée une ouverture qui donne une communication avec l'étage supéricur.

L'étage du milieu (figure $49 \mathrm{C}$ ) contient un vestibule avec chambre pour les servantes, une pour les enfants, une chapelle, un oratoire et un salon appelé boyarskaïa palata.

La chapelle, krestovaïa palata (chambre de la croix), tirait ce nom de sa destination.

Les chapelles de cette nature existaient non-seulement dans les maisons, mais encore dans les couvents. C'est là que les prêtres de paroisse, dits krestovie, célébraient les offices du grand carême ou krestii.

C'est là qu'on chantait aussi les matines, les heures ct les vêpres, et que le chef de la famille recevait les 
prêtres venant le féliciter avec la croix, à Noül, à Pâques et aux grandes fêtes. On chantait les Te Dcum, les absoutes, et toute la maison assistait à ces cérémonics.

C'est là enfin que se faisaient les festins dits zaoupokoïnie ou ponikhidnii, en commémoration des alliés et parents décédés, les festins de noce, de naissance et de baptême. La voûte de cette chapelle est une voûte d'arête gothique, dans laquelle sont ménagées des niches (pazoukhi); elle est décorée d'ornements tirés des patentes délivrées par le tsar Michel Fédorovitch.

Deux fenêtres principales (krasnoï okna) sont pratiquées sur la rue, et une troisième, avec des carreaux en mica, donne sur la cour.

Le plancher est un parquet en chêne semblable à celui des autres pièces. Cette salle est chauffée par deux cheminées ménagées dans un poêle en briques de porcelaines coloriées, suivant la mode du dix-septième siècle.

Dans l'angle saint dit perednie, à droite de la porte d'entrée, on voit des images saintes qui sont d'une époque très-reculée.

Sur une étagère appelée postavetz ou gorka, montagne (ce meuble en avait la forme), sont posés les vases en argent et en vermeil qui ont appartenu à la famille. Cette vaisselle, qui passait de père en fils, était gardée dans les familles comme des reliques. On disposait ces vases, les jours de festin, au centre de la table, en forme de montagne. C'est pourquoi de pareils repas étaient nommés pire-goroïou, festins en montagne. 
Il est à r'emarquer qu'à cette époque la vaisselle, outre l'usage auquel elle était destinée, avait aussi une signification particulière. Les Tsars donnaient à leurs sujets, comme récompenses, des aiguières et des vases précieux pour leurs bons services dits (dorodstvo), pour avoir défendu avec zèle les intérêts de l'Etat, avoir soutenu des siéges ou rempli des ambassades.

Ces présents ont été remplacés plus tard par des médailles, des décorations, des bagues ou des tabatières.

Ces aiguières avaient des inscriptions portant que, par ordre de tel Tsar, cette gosoudarskaïa milost (ce présent) avait été donnée à telle personne. En général, sur ces objets étaient gravées les armes de la Russie.

Dans la krestovaïa, le mur côté sud est percé de deux portes à un battant; l'une conduit dans l'oratoire, pièce avec voûte d'arête. Cette salle est éclairée par quatre fenêtres percées au sud et à l'est. De ces fenêtres on voit le couvent de Novospaski, lieu de sépulture des ancêtres du tsar Michel Fédorovitch. Dans une armoire vitrée remplie d'images on remarque celle de Michel surnommé Moléine; cette image date du temps où vivait le chef de la famille Romanoff, et c'est le 12 juin, qui est la fête de ce saint, que le tsar Michel Fédorovitch naquit et mourut.

Suivant la tradition, c'est avec cette même image que le métropolitain Philarète a béni son fils et que de nos jours sa H. E. notre illustre métropolitain actuel Philarète a béni sa Majesté l'Empereur Alexandre II, le jour de la bénédiction de la maison Romanoff, après sa restauration.

C'est dans cette pièce que les boyards fidìles aux usa- 
ges commençaicnt et finissaient leurs journées par des prières.

Dans les murs sont ménagés deux placards avec rayons en bois de chêne. Une porte basse donne entrée dans la boyarskaïa-komnata, qui est éclairée par quatre fenêtres, deux au sud et deux à l'ouest. On y a ménagé aussi dans les murs des placards destinés à cacher divers objets précieux.

Cette pièce est surtout remarquable par l'antiquité et la rareté des objets qu'elle contient et de divers accessoires de la vie de famille des boyards russes.

Le poêle qui chauffe cette salle est très-remarquable. Il est en tout semblable à celui qu'on trouve au couvent d'Ipatiew à Kostroma. Il donne une idée de l'imagination de celui qui a fait les briques, car chacune porte une image allégorique et une inscription différente dans le genre de rébus ou d'emblèmes : ainsi sur une brique on voit deux oiseaux se séparant avec cette inscription: "La fidélité nous unit. " Sur une autre, une tortue avec cet adage: "Il n'y a pas de meilleure maison que la sienne. "On voit que l'on voulait faire aussi servir le poêle à l'enseignement. C'est pourquoi on faisait aussi quelquefois figurer sur les briques les fables d'Esope.

Une porte donne dans la krestovaïa, d'où une autre porte percée dans le mur ouest conduit par un étroit escalier au grenier ou terem. Une seconde porte de la krestovaïa mène par un vestibule dans les chambres d'enfants et de servantes. Chacune de ces chambres est petite et a des voûtes à arêtes. Le poêle est fait avec des carreaux vernis et avec dessins. Dans la chambre 
des servantes vivaient les filles de service et avec elles la nourrice (mamouchka).

De cette chambre on montait par un escalier dérobé au grenier ou terem(') comprenant:

$1^{\circ}$ Les seni et vischka (tourelle);

$2^{\circ}$ Le terem proprement dit ou chambre à coucher;

$3^{\circ}$ La swetlitza, salon de réunion.

Les murs et le plafond dans la vischka sont revêtus de planches en sapin disposées en biais; ces planches sont à rainures. Dans un coin est un banc avec moulures.

La seconde moitié du grenier est occupée par l'opotschivalnaïa (chambre à coucher).

Les murs et le plafond de cette pièce sont couverts de boiseries en tilleul richement travaillées suivant les modèles anciens.

Le long des murs sont placés des bancs recouverts de velours à dessins, sur fond de drap d'or. Les fenêtres sont voûtées et les carreaux encadrés de châssis en fer, comme cela se voit encore dans les constructions datant du dix-septième siècle. Un poêle sortant de la troisième pièce est construit en carreaux vernis avec dessins.

Les murs de la swetlitza sont recouverts en tapisserie

(') Le mot terem n'est pas un dérivatif de harem, mot arabe, ni de thourm, mot allemand duquel probablement est dérivé le mot russe turma (prison). Terem est un mot grec qui signifie étage supérieur réservé pour les femmes. Cette assertion est confirmée par un vieil adage qui dit: " Les oiseaux dans une cage et les jeunes filles dans les terems. " La grande-duchesse Olga, revenue de Constantinople, fit élever a Kiew un terem en pierre.

Suivant les traditions et les anciennes chansons, les terems étaicnt gèéralement richement décorés. 
de cuir, genre de Cordoue, matière avec laquelle on avait aussi l'habitude de garnir les fanteuils et les chaises.

Dans le coin est est placé un petit rayon en bois cisclé, qui servait à poser les images. Sept fenêtres de cette pièce sont pratiquées vers le sud de Moscou, d'où on découvre une vue magnifique sur les quartiers situés au delà de la Moscova et de la Yaouza.

Toutes ces pièces du quatrième étage communiquent entre elles par des portes en chêne à un battant, par des vestibules et par des escaliers dérobés. Toute la distribution prouve que tous les besoins d'une existence modeste se trouvaient satisfaits dans les maisons des boyards, et qu'ils savaient se contenter de petites chambres, et jouir d'une vie tranquille et retirée dans le cercle restreint de leur famille.

Lors de la restauration de la maison Romanoff, les murs extérieurs sont restés intacts. Tout l'édifice forme un rectangle de 8 sagènes $1 / 3$ de longueur sur la rue et de 5 sagènes de largeur. La hauteur est de 2 sagènes $1 / 2$ du côté de la rue et de 4 sagènes $1 \frac{1}{3}$ sur la cour.

Les fenêtres sur la rue ont été établies plus larges que celles qui existaient auparavant et d'une forme rectangulaire. Les anciennes fenêtres sur le derrière du bâtiment ont été conservées. Elles sont étroites et voûtées.

Des changements ont été apportés à l'intérieur, bien que plusieurs pièces n'aient pas été touchées et aient conservé leur caractère primitif.

Lors de la restauration on a découvert plusieurs portes et fenêtres, ainsi que quelques parties de voûtes qui ont permis de compléter dans le même style les parties 
mancuantes ou déformées par les changements apportés précédemment.

Les fenêtres, les portes et les ornements qui sont restés intacts, ont servi à notre savant et habile architecte M. Richter, professeur de l'Académie, pour restaurer les parties détruites ou modifiées par caprice ou par nécessité. Les fenêtres et les portes sont restées disposées comme auparavant, sans symétrie et avec des ornements de différents styles.

Il paraît que le maître maçon qui a construit cette maison ne se conformait pas aux règles de l'architecture généralement adoptées, mais seulement aux conditions de solidité, de confort, surtout à une bonne disposition de l'intérieur, au goût du propriétaire et aux usages de l'époque.

La maison était bâtie sur l'emplacement le plus élevé de la cour. Sur la partie basse on avait construit l'habitation des domestiques, tcheliadi, et les communs, et on $\mathrm{y}$ avait joint un jardin et un potager.

La maison Romanoff n'a que deux fenêtres et un étage unique sur la rue Varvarskaïa, laquelle, aux seizième et dix-septième siècles, avait un tout autre aspect qu'aujourd'hui.

Tous les autres étages ont vue sur la cour, dans laquelle, avant la construction du couvent, existait l'église privée de la famille Romanoff. Dans cette cour, le boyard avait sous les yeux toutes les dépendances, le jardin, le potager, en un mot tout ce qui avait rapport aux besoins du ménage.

La façade sur la rue est simple; celle du sud donnant sur la cour est richement ornementéc. L'entrée princi- 
pale est maintenue sur la cour, suivant la coutume ancienne.

A partir du rìgne de Michcl Fedorovitch, on donna le nom d'ancienne cour à l'emplacement que ce prince tenait de son patrimoine, et qu'il donna au couvent Znamenski, qui existe cncore aujourd'hui dans la rue Varvarskaïa.

En 1611, lorsque la ville chinoise fut incendiée par les Polonais, il est probable que les constructions en bois composant les dépendances de la maison Romanoff n'ont pas été épargnées par le feu.

$\Lambda$ l'avénement au trône de Michel Fedorovitch, le inonument fut restauré, prit le nom d'ancienne cour, mais ne fut plus jamais habité par aucun membre de la famille Romanoff.

Dans cette cour il existait depuis nombre d'années une église privée bâtie en commémoration de l'intercession de la sainte Vierge. La date précise de la construction de cette église est inconnue et les actes publics n'en font mention que depuis 1517.

Il est probable que lorsque le patriarche Philarète revint à Moscou à la suite de la captivité qu'il subit en Pologne, et lors de la naissance de son fils le 'Tsar Michel Fedorovitch en 1630, il fit don de sa maison patrimoniale pour fonder un couvent d'hommes en l'houneur de l'intercession de la sainte Vierge.

L'église cathédrale de ce couvent est construite en briques lourdes avec tirants en fer. Elle fut plantée à mihauteur de la colline. Le socle est coupé en biseau et des plaques mortuaires avec inscriptions y sont scellées. Le toit a quatre pentes et est surmonté de cinq coupo- 
les. Celle du milieu porte une croix à quatre branches ciselée à jour. $\Lambda u$ pied de la croix est un croissant. Les autres coupoles sont surmontées chacune d'une croix à huit branches.

Trois faces du monument sont divisées par des demicolonnes accouplées dans l'intervalle, et sur chaque face sont trois fenêtres voûtées. Au dessus de la corniche, il y a trois arcs dans chacun desquels sont représentées des images de saints.

L'autel est composé de trois parties, et des colonnes règnent extérieurement dans l'intervalle des hémicycles.

Le 29 mai 1737 , lors d'un terrible incendie dit de Troïtsa, le toit à bardeaux de la maison Romanoff prit feu et fut reconstruit de l'épaisseur d'une seule planche. Il tomba bientôt et la voûte supérieure fut envahie par les herbes.

En 1743, l'Impératrice Elisabeth fit faire les réparations nécessaires dans le couvent de l'Intercession de la Sainte Vierge ainsi que dans la maison Romanoff.

Suivant le témoignage du professeur Tschebotareff, on voyait encore en 1776 les restes de la maison patrimoniale de la famille Romanoff, et à la fin du dix-huitième siècle, pour subvenir aux frais du couvent, ce monument fut affermé au marchand Gorgoli, qui prit à sa charge toutes les dépenses de l'entretien avec un bail de vingt-six ans.

En 1812, les ennemis saccagèrent la maison et le couvent. Plus tard, la commission des travaux de construction à Moscou s'opposa à la réparation de la maison, attendu qu'elle dépassait l'alignement rectifié de la rue Varvarskaïa, et en 1821 il fut décidé qu'clle serait dé- 
molic, mais S. II. E. l'archevêque Philarìte, aujourd'hui métropolitain de Moscou, insistant pour que ce pieux monument fût conservé, eut gain de cause et obtint qu'il restât tel qu'il était, jusqu'au jour où la restauration fut ordonnée par Sa Majesté l'Empereur Alexandre II.

Pour mieux faire connaître le système des anciennes constructions russes, nous avons pensé qu'il n'était pas superflu d'ajouter aux dessins de cet ouvrage la figure 51 qui représente la copie exacte des dessins gravés par Léon Bounine, et qui se trouvent dans le dictionnaire de Carion Istomine publié à Moscou en 1694.

Sur ce dessin nous avons ajouté une observation faite par l'auteur lui-même et qui explique le motif qui l'a engagé à ajouter ces figures à son ouvrage.

Quoique leur composition soit imaginaire, elle donne bien l'idée du caractère et du goùt des constructions contemporaines de cette publication.

Dans le dessin de l'église on retrouve quelque chose du style mauresque; dans celui du palata on voit au contraire prédominer le style occidental.

L'isbah et la gitnitsa donnent bien l'idée du système adopté pour les constructions en bois en Russie; enfin les dessins du zabor et du tine offrent un modìle de deux différentes sortes de clôtures. 



\section{XI}

L'architecture débute en Russie, au dix-huitième siècle, par une imitation servile du style hollandais, qui imprima son cachet non-seulement aux édifices civils, mais aussi aux constructions de caractère religieux.

Quelques-unes des églises construites sous le règne de Pierre le Grand ont en plan la forme d'un octogone; d'autres sont circulaires; toutes n'ont qu'un ou deux étages et un dôme. Leurs voûtes sont en anse de panier; la couverture des toits et des dômes est en tuiles plates ou concaves, quelquefois en fer-blanc. Les fenêtres s'appuient sur le socle; les trois absides en forme d'hémicycles, qu'on voyait dans les anciennes églises, sont remplacées par une abside demi-circulaire ou à plusieurs faces. Comme spécimens de ce genre de constructions on peut citer l'église de Notre-Dame de Vladimir près de la porte Nikolsky, la cathédrale du couvent de l'Exaltation de la Croix, l'église de l'Archidiacre Evple et l'église de Saint-Nicolas le Thaumaturge, à la Miasnitskaya; l'église des Saints Pierre et Paul dans la nouvelle Basmannaya, de Saint-Jean le Guerrier aux Maly-Loujniki dans la Yakimanka; de l'Ascension de Notre Seigneur, derrière les portes de Serpoukhow, etc. 
Les tours de Soukharew et de Menchilioff sont les premicrs édifices construits à Moscou par le Tsar Pierre, dans le but d'immortaliser les noms d'un régiment fidèle et d'un compagnon d'armes favori.

La tour de Soukharew (fig. 44) a été construite à l'époque où Pierre régnait conjointement arec son frère Jean. L'abolition de l'institution des strélitz était déjà irrévocablement arrêtée dans la pensée de Pierre, qui, ayant retrouvé vers ce temps dans le bourg d'Izmaïlowo une barque construite par son grand-père, mûrissait le projet de doter son pays d'une flotte.

La tour de Soukharew devait simuler un vaisseau avec son mât; les galeries du second étage figuraient le gaillard; la partie orientale était la proue; la partie occidentale, la poupe du navire. Commencée en 1692, la tour fut achevée en 1695; son style est un mélange du lombard et du gothique. Il paraît que la tour d'Augsbourg ou celle d'Amsterdam ont servi de modèle à cette construction. La tour est bâtie en briques reliées par des barres de fer; le socle est en pierre calcaire; les ornements sont en partie de cette même pierre et en partie de briques équarries. Sur la chaine supérieure au-dessous de l'escalier de la tour étaient appliqués des carreaux de couleur sur lesquels on voyait des aigles à deux têtes surmontés de deux couronnes, - circonstance qui rappelle la construction au dix-septième siècle de la tour Héraldique, détruite depuis, et qui avait aussi des ornements en carreaux armoriés de différentes couleurs. Il est probable que la tour de Soukharew avait été bâtie sur un plan dressé par le Tsar lui-même; mais on ignore le nom de l'architecte qui avait été chargé d'exécuter ce plan. 
Les portes triomphales, imitées des Romains et inconnues jusque-là à Moscou, y paraissent aussi sous le règne de Pierre le Grand, avec lcurs tableaux allégoriques, leurs portraits, leurs statues et leurs inscriptions.

En fait de monuments d'architecture civile, cette époque de réforme générale a vu s'élever l'arsenal, l'hôtel de la monnaie, converti aujourd'hui en tribunal, le palais du sénat dans le faubourg Allemand, l'hôpital, le palais de Lefort, le palais Hollandais, la maison du prince Gagarine sur la Tverskaya, qui portait l'empreinte du style italien, l'hôtel des archives du collége des affaires étrangères, etc. Parmi les constructions de la première moitié du dix-huitième siècle on peut citer les palais de Lefort, de Golovine, de Menchikoff et le palais Préobrajensky dans le faubourg Séménovsky; les palais de Pierre et de l'Artillerie et le palais Polevoy; les cours Granatny, Fourajny, Sitny, Sokolnitchi, Khamovny, etc.

Tel a été Moscou à l'époque où un terrible incendie y éclata le 29 mai 1737. (') Cet incendie, qui réduisit Moscou en cendres, se déclara d'abord dans la maison d'Alexandre Miloslavski au Lenivy Torjok, dans la paroisse de l'église de Saint-Jean le Précurseur. Lorsque après ce désastre Moscou commença à se relever de ses décombres, ses architectes adoptèrent les formes de construction des églises occidentales. C'est dans ce fait qu'il faut chercher l'explication des imitations si nombreuses en Russie de la coupole et des colonnes de Saint-Pierre de Rome et en général des portiques et des portails des

(1) La figure 52 représente le plan de Moscou gravé sur la première feuille d'une bible imprimée sous le règne d'Alexis Mikhailovitch en 1663. C'est le plus ancien plan de Mloscou que nous connaissions. 
temples grecs et romains. L'arrangement intérieur des églises russes subit aussi quelques changements par suite de ce fait. Il faut rapporter à cette même époque la construction des hautes flèches sur les églises et les clochers, et l'abandon définitif de l'ancienne division du sanctuaire en trois hémicycles; ces derniers cèdent partout la place à une abside.

Dans cette restauration et reconstruction des églises, le style de l'ancienne architecture ne fut point épargné; les hautes et étroites fenêtres et les portes basses s'élargirent et changèrent d'ornements; des portiques prirent la place des parvis couverts qui s'élevaient jadis contre le mur occidental.

Cette transformation eut donc pour résultat non-seulement d'enlever aux anciens temples de Moscou leur sens historique et leur caractère propre, mais de détruire même les inscriptions qui couvraient leurs murs et les pierres tumulaires qui pavaient leur intérieur.

Les plus remarquables constructions de l'époque à laquelle nous sommes parvenus sont: la maison des Enfants trouvés, bâtie en 1764 avec les matériaux des murs et des tours démolis du Bély-gorod, sur l'emplacement des jardins Vasilievsky, du magasin des poudres et de la cour Granatny; la maison du commandant en chef de la ville, sur la Tverskaya, et le palais de la Pretchistenka, appartenant aujourd'hui au prince Serge Galitzine.

Le pont de pierre sur la Yaouza est construit des matériaux de l'ancienne cour de la fonderie de canons. La porte Rouge a été élevée aux frais des négociants de Moscou, en 1742, à l'occasion du couronnement de l'Imıpératrice Elisabeth; elle avait la forme des anciennes portes de Rome et était ornée de figures allégoriques, 
remplacées en partie lors de la restauration de 1850 . Près de cette porte avait été construite en 1753 la cour dite Zapasny.

L'église de Saint-André (fig. 45) à Kiew, bâtie sous le règne de l'Impératrice Elisabeth, en 1744, sur un plan du comte de Rastrelli, est une des plus remarquables églises de Russie, tant par la beauté de ses formes que par l'importance historique de son emplacement, voisin de l'endroit où saint André planta la croix dans les montagnes.

L'église de Sainte-Catherine au couvent de femmes de l'Ascension ( $\left.{ }^{1}\right)\left(\right.$ fig. $46^{\mathrm{a}}$ ), construite au commencement du dix-neuvième siècle, est un spécimen du style gothique occidental, qui, du reste, n'a pas reçu de développement ultérieur à Moscou. On ne saurait même admettre que la maison du commandant (l'ancien palais Poteschny), à Moscou, ait été construite dans ce style. Nous avons dit plus haut que ce bâtiment, fondé au dix-septième siècle, a été plus d'une fois restauré dans le goût moderne; au commencement du dix-neuvième siècle, on y ajouta de chaque côté des ailes construites dans le goût gothique propre aux peuples occidentaux.

La maison du Namiestnik au Kremlin, occupée actuellement par le sénat, et le palais Golovine, transformé en

(') Le couvent de l'Ascension, important sous le rapport historique, avait existé déjà en 1387, ainsi que l'affirment les chroniques. Dévasté en 1389, pendant l'invasion de Tokbtamysh, il fut rebâti en 1393 par la grande-duchesse Endoxie, épouse de Dmitri Donskoï. La construction de la cathédrale de l'Ascension, qui se trouve dans ce couvent, se rapporte à celte même époque. La grande-duchesse Eudoxie fut la première enterrée dans ce couvent, qui fut pendant longtemps le lieu d'inbumation des Grandes-Duchesses et des Tsarines de Russie, qu'on enterrait, avant la restauration du courent, à l'église du Saint-Sauveur dans la Forêt et dans quelques autres églises de Mloscou. 
premier corps de cadets, sont aussi des monuments remarquables de l'architecture du temps de Catherine II. Nous y voyons la naissance de l'architecture civile de nos jours, qui ne tend plus qu'à rendre les bâtiments propres au but de leur construction, sans trop se préoccuper du luxe inutile et de l'ornementation superflue.

En 1834 on éleva près de la porte de Tver, en commémoration de la guerre de 1812, un arc triomphal et on jeta. les fondations du temple du Saint-Sauveur (fig. 43), dont l'exécution fut confiée à M. Constantin Thon, qui reproduisit dans ce temple l'ancien style russo-byzantin dans ses formes les plus élégantes. 


\section{XII}

En parlant de l'église du Saint-Sauveur, nous ne pouvons passer sous silence la première pensée qu'a eue l'Empereur Alexandre I ${ }^{\text {er }}$ de bâtir ce temple sur la montagne des Moineaux. Il nous est de même impossible de ne pas donner un sourenir à MI. Vitberg, architecte, qui fut chargé de le construire.

L'Empereur Alexandre attribuait à la Providence la victoire qu'il remporta sur Napoléon I ${ }^{\text {er }}$, comme le proure l'inscription qu'on lit sur la médaille commémorative de la victoire de 1812: не намъ, не намъ, а имени твоему, (non pas, non pas à notre nom, mais au tien); c'est-à-dire qu'Alexandre Ir voulait attribuer uniquement à la volonté du Dieu tout-puissant sa mémorable victoire. Le jour où le dernier soldat ennemi franchissait la frontière russe, Alexandre ${ }^{\text {er }}$, dans son ,manifeste, faisait vœu d'élever à Moscou un temple magnifique au nom du saint Sauveur.

On demanda de tous côtés des projets; tous les architectes furent invités à y apporter leur concours.

Vitberg, artiste alors dans la fleur de l'âge, renait de finir ses cours à l'Académie des arts, où ses talents en peinture lui avaient fait obtenir la médaille d'or. 
Appartenant à une famille suédoise, mais né en Russie, il avait reçu sa première éducation au corps des cadets des mines. Artiste plein d'enthousiasme, excentrique, imbu de mysticisme, il s'adonna tout entier, dès qu'il connut le manifeste, à la solution du problème qui y était proposé.

Il vint à Moscou, étudia la ville et ses environs, et lorsque le jour du concours fut venu, on trouva parmi le nombre immense de projets envoyés d'Italie, d'Allemagne et par nos artistes russes, un chef-d'œuvre dont l'auteur n'avait encore aucun renom; c'était celui de Vitberg.

Le projet colossal de ce jeune artiste, projet pénétré d'une poésie religieuse, frappa l'Empereur. Il s'arrêta devant cette ouvre et demanda le nom de l'auteur. Ensuite il voulut voir Vitberg et causa longtemps avec lui. L'artiste subjugua l'Empereur par son langage hardi et animé, par son inspiration, par le coloris mystique des croyances dont il était pénétré et auxquelles Alexandre I ${ }^{\mathrm{er}}$ rendait justice; aussi le Monarque ému lui dit : "Vous faites parler les pierres. »

Le même jour le projet fut approuvé, et Vitberg fut chargé de construire le temple et nommé en même temps directeur de la commission de construction.

De toutes les pièces composant ce projet nous n'avons réussi à nous procurer que l'élévation du temple (fig. 47).

Où sont les autres dessins de ce superbe projet? que sont-ils devenus? sont-ils perdus à jamais? Nous l'ignorons. S'ils ne doivent pas être un jour publiés, cette perte sera irréparable, en raison de l'originalité de l'idée qui a présidé à leur composition.

Il est très-vrai qu'il n'y a pas d'art plus étroitement lié au mysticisme que l'architecture; cet art tout abstrait, 
tout géométrique, impassible, ne vit que de symboles, que de figures, que d'allusions; la combinaison géométrique des lignes droites est leur rhythme; les rapports qui existent entre leur nombre présentent quelque chose de mystéricux et en même temps d'incomplet.

Un bâtiment quelconque, un temple, par exemple, ne renferme pas en lui-même un but comme une statue ou un tableau, comme un poëme ou une symphonie; un bâtiment attend l'être qui doit l'habiter; c'est un espace circonscrit, prédestiné. Il doit être fait de manière à répondre en tout au caractère et à l'essence de l'être qui doit l'habiter. Dans un temple, son enceinte, ses voûtes, ses colonnes, son portail, sa façade, sa coupole, doivent porter l'empreinte de la Divinité, à laquelle il est destiné.

Ainsi les temples d'Egypte sont des livres divins; les obélisques ne sont autre chose que des pages d'histoire réelle que les siècles reculés nous ont léguées.

Le temple de Salomon n'est qu'une Bible élevée en pierre, de même que la cathédrale de Saint-Pierre semble être une issue ouverte aux champs plus vastes du catholicisme.

Voilà pourquoi la construction des temples à toutes les époques était accompagnée de cérémonies mystiques, d'allégories, de consécrations mystérieuses; de sorte que les constructeurs du moyen âge croyaient appartenir à un sacerdoce à part, et formaient entre eux des compagnies de maçons.

Il faut avoir la foi et être placé dans des circonstances exceptionnelles pour pouvoir créer une ouvre divine. Aussi bien les circonstances daus lesquelles se trouvait 
Vitberg lorsqu'il composa son projet, son caractère et la disposition d'esprit dans laquelle se trouvait l'Empereur Alexandre, étaient tout exceptionnels.

La guerre de 1812 ébranla fortement les esprits en Russie; longtemps après la délivrance de Moscou, les idées et une irritation nerveuse ne pouvaient se calmer. Vitberg subit plus que tout autre l'impression des évenements.

Près de Moscou, entre les deux grandes routes de Mojaïsk et de Kalouga, il existe une hauteur qui domine la ville; c'est la montagne des Moineaux. La ville s'étend au pied, et la vue qu'on découvre de ce point élevé est singulièrement pittoresque.

Napoléon, en 1812, contourna cette montagne avec toute son armée; c'est là que sa force s'est brisée, c'est à partir du pied de cette hauteur que commença sa retraite.

Pouvait-on trouver un meilleur emplacement pour un temple commémoratif de 1812, que le point extrême auquel atteignit l'ennemi?

Cela n'était pas assez. D'après l'idée de Vitberg, la montagne elle-même devait former la partie inférieure du temple; le champ qui s'étend au pied devait être entouré d'une colonnade, et c'est sur cette base, dont les trois côtés sont créés par la nature elle-même, que devaient s'asseoir le second et le troisième temple, pour former un tout d'un merveilleux ensemble.

Le temple inférieur, creusé dans la montagne, avait une forme rectangulaire ou plutôt celle d'un cercueil; sa façade consistait en un portail supporté par des colonnes d'un style presque égyptien, et le monument se 
perdait dans les entrailles de la montagne, au sein d'une nature sauvage et inculte.

Ce temple était éclairé par des lampes portées par de grands candélabres de style étrusque; le jour y arrivait faiblement, et venait du second temple en traversant une image transparente de la Nativité.

Dans cette crypte devaient reposer tous les héros morts sur les champs de bataille de 1812; un service funèbre incessant devait être dit pour le repos des âmes de ces guerriers dont les noms, sans considération des rangs, devaient être gravés sur les parois des murs.

Au-dessus de ce tombeau s'élevait, en croix grecque dont les branches étaient égales, le second temple, représentant l'idée de la vie, de la peine et des douleurs. La colonnade qui y donnait accès était ornée des statues des personnages de l'Ancien Testament.

A l'entrée se trouvaient les statues des prophètes, qui n'étaient pas dans le temple même; ils semblaient indiquer la route que devaient suivre les fidèles. Dans l'intérieur du temple était réunie toute l'histoire évangélique et relatés entièrement les Actes des apôtres.

Au-dessus de ce monument, et pour le couronner, s'élevait un troisième temple en forme de rotonde. Cette partie, fortement éclairée, était le temple de l'Esprit et de l'Eternité; cette dernière idée était rendue par la forme circulaire du temple; là point d'images, point de tableaux; seulement, à l'extérieur, des archanges entouraient le monument surmonté d'une coupole colossale.

Telle était la principale idée de Vitberg; cette idée avait été étudiée par lui dans ses moindres détails, et toujours, 
en la développant, il est resté fidèle à la théodicée du christianisme et aux règles de l'architecture.

Ce projet était immense et ne pouvait être conçu que par un homme de génie; c'est pour cela qu'Alexandre I ${ }^{\text {er }}$ l'a adopté, et c'est pour cela qu'il devait être exécuté; mais on prétendit que la montagne ne pourrait supporter le poids de ce temple, et pour ce motif ou pour un autre, le projet n'a pas été exécuté.

Vitberg était un homme doué d'une énergie remarquable. Pendant tout le cours de sa vie il travailla à son projet, il y donnait tous les jours une grande partie de son temps. Cette cuvre était sa vie; elle renfermait tous ses souvenirs, toutes ses consolations, toute sa gloire. Il ne voulut jamais se persuader que son projet ne serait pas exécuté.

Il est possible qu'un jour un autre artiste secouera la poussière qui recouvre les pages de ce projet et publiera, avec un sentiment de respect, cette œuvre d'un architecte dont la vie fut si belle et éclairée par le feu sacré du génie.

Parmi les systèmes artificiels de navigation, il en fut projeté un qui avait pour but de réunir le Volga et la Moskwa à leurs sources. Ce système s'étendait aux rivières Doubna, Sestra, grande Istra et Moskwa. La grande Istra et la Sestra sont réunies à leurs sources par un canal qui constitue un point de partage pour le système entier. Ce canal de jonction coupe la chaussée de Péters- 
bourg et le chemin de fer Nicolas à 60 verstes de Moscou. Près de cet endroit se trouve un réservoir naturel formé par le lac Goutschino ou Sénége, et qui était destiné à assurer la navigation sur le canal dı point de partage et sur les canaux de dérivation de la grande Istra et de la Sestra.

Ce projet avait primitivement pour but:

$1^{\circ}$ D'abréger la communication par eau entre Pétersbourg et Moscou d'environ 1,000 verstes;

$2^{\circ}$ De remplacer le transport par terre des marchandises aux ports du Volga, par un transport par eau;

$3^{\circ}$ De faciliter le transport des bois provenant des gouvernements garnis de forêts et voisins de Moscou, ainsi que le transport des autres produits bruts d'un fort poids.

L'idée de construire le temple du Saint-Sauveur à la montagne des Moineaux eut une influence immédiate sur les travaux destinés à établir ce système, car pour la construction du temple on se proposait d'employer le granit de Finlande, lequel devait être amené à pied d'œuvre par le canal de Tikhvine et par le système dont nous venons de parler.

En examinant le système pour la jonction des rivières Moskwa et Volga à leur source, sous le point de vue d'une communication devant servir pour amener les matériaux destinés à la construction du temple, on voit de suite combien le sort de ce système était étroitement lié à celui de la construction du monument.

Inspirés par la volonté d'un monarque béni, de construire un monument superbe sur la montagne des Moineaux, en mémoire de la délivrance miraculeuse de la Russie de ses ennemis de 1812, tous concouraient pour 
réaliser cette pensée dans les dimensions les plus colossales.

Le général Miloradovitsch conseillait à Vitberg de faire les fortes colonnes du temple inférieur en monolithes de granit. A cela on lui objecta que le transport de ces pierres de Finlande coûterait très-cher. - C'est une raison de les faire venir, répondit Miloradovitsch; car si la carrière était sur la rive de la Moskwa, il n'y aurait rien de difficile à asseoir là les pierres.

C'est ainsi que pensaient les personnes qui entouraient le célèbre monarque. Mais dès qu'on eut abandonné la pensée de construire le temple à la montagne des Moineaux, on changea aussi d'idées sur les avantages de la réunion des rivières Moskwa et Volga à leur source, et la construction de ce système a été ralentie d'abord puis totalement abandonnée à la suite de l'établissement du chemin de fer Nicolas. 


\section{XIII}

Depuis 1812, les fossés qui entouraient les murs du Kremlin ont été comblés, et à leur place nous voyons de verts jardins et des boulevards.

A la barrière de Twer on a construit, en commémoration de la guerre de 1812, un arc de triomphe qui a été terminé en 1834.

Durant ces trente dernières années, on a construit sur la Moscowa un nouvean pont dit Moskvoretzky, et sur le canal d'enceinte les ponts Vissoko-Piatnitzky et KosmoDemiansky.

Le premier de ces ouvrages est établi suivant un système de voûtes en bois reposant sur des culées et piles construites en grès très-dur connu sous le nom de grès de Tatarovo; le second est bâti suivant un système de pont suspendu à un arc en fonte, et d'une seule travée; enfin le pont de Kosmo-Demiansky est composé d'arches d'une faible portée, et est entièrement bâti en pierre, avec un revêtement en grès de Tatarovo.

A la même époque, c'est-à-dire vers 1830 , entre le pont de pierre et le pont Moskvoretzky, on a construit avec 
ce même grès de Tatarovo les quais de la rivière, dont on a depuis, à plusieurs reprises, étendu la longueur.

Nous ne ferons pas la description du nouveau palais du Kremlin (Fig. 42a). Il viendra une époque où ce monument aura sa page dans l'histoire de l'architecture en Russie. Nous croyons devoir faire observer seulement que c'est à tort que l'on pense que, pour construire ce palais, on a démoli des monuments précieux; tout au contraire, plusieurs de ces monuments ont été retrouvés et restaurés dans leur véritable style.

Nous allons terminer cet aperçu sur la ville de Moscou en disant quelques mots sur les conduites d'eau de cette ville, dont l'histoire offre de l'intérêt, et qui aujourd'hui fonctionnent avec un succès complet.

Le général lieutenant van Baüer a établi les premières conduites destinées à alimenter Moscou avec une eau salubre, et ces travaux, commencés en 1779, ont été terminés en 1805 .

M. van Baüer a choisi des sources d'une eau excellente, qui se trouvent à 20 verstes de Moscou, sur le chemin du couvent de Troïtsa, derrière le bourg BolchieMitischi; elles sont au nombre de 45, se trouvent dans une vallée, et sont voisines de celles de la rivière Yaouza. Ces sources occupent un espace de 800 sag. carr., et sont toutes au même niveau, élevé à 102 pieds et demi au dessus de celui de la Moscova en ville.

La quantité d'eau fournie par ces sources ne varie pendant aucune saison de l'année, et des observations trèsexactes ont démontré que cette quantité était de 2 pieds cubiques par seconde.

Il a été observé également que la couche d'eau qui ali- 
mente ces sources est située à une profondeur moyenne variant de 17 à 30 pieds. Elle est formée du gravier que l'on rencontre dans la couche des grès argileux, appartenant probablement à la partie inférieure des terrains carbonifères; elle est recouverte d'une couche compacte de glaise diluviale se trouvant elle-même sous in banc de tourbe de deux pieds d'épaisseur.

Les principales sources de Mitischi ont été renfermées par M. van Baüer entre des murs en briques, et au moyen de petits canaux souterrains elles ont été amenées dans un réservoir unique.

De là une galerie en briques de 3 pieds de largeur et de 4 pieds et demi de hauteur, servant de conduite principale, amenait les eaux dans la capitale.

On a construit, pour franchir les rivières et les basfonds, des siphons et des ponts aqueducs. Le plus remarquable de ces derniers ouvrages est celui qui traverse la vallée de la Yaouza près du village Rastokino; sa longueur est de 350 sag.; ses piles sont construites en pierre calcaire de Miatschkovo et les socles en pierre de Tatarovo. Cette même pierre a été employée pour le revêtement des piles et des arêtes des voûtes, qui elles-mêmes, ainsi que les murs de l'aqueduc, sont bâties en briques hourdées en ciment.

L'eau de Mitischi amenée ainsi dans la capitale était répartie dans des puits à pompes, des fontaines et des réservoirs en briques, avec revêtement en grès. Ces constructions avaient la forme de pavillons ou de bassins découverts.

La longueur des conduites construites sous le règne de l'Impératrice Catherine II, depuis les sources de Mitischi 
jusqu'au bassin de la Trouba, était de 20 verstes et demi, avec une chute de 20 pieds et demi. De la Trouba on a amené les eaux au pont des Maréchaux par une conduite en fonte de 230 sagènes de longueur.

Quarante années après l'achèvement de ces travaux, l'eau commenȩa à diminuer sensiblement dans les conduites. Cette diminution eut pour cause les crevasses qui s'ouvrirent dans le radier et les parois des galeries.

Ces dégradations s'étant produites dans les parties de la galerie en briques les plus enfoncées au-dessous du sol, notamment près des forêts de Preobragensky et de Sokolniki, et près de la tour de Soukhareff, ont nécessité des réparations et des reconstructions.

On reconnut, à la suite d'une étude sérieuse, que la partie de la conduite entre les sources de Mitischi et la forêt de Sokolniki, sur une longueur de 15 verstes, pouvait être facilement réparée, attendu qu'elle n'avait pas subi de fortes dégradations; mais qu'au contraire la reconstruction de la galerie à partir de ce dernier point serait trop coûteuse, parce que cette galerie se trouvait à une trop grande profondeur et noyée dans une couche de sable fortement délayée par l'eau des sources.

On a trouvé plus avantageux d'interrompre l'ancienne conduite par un bassin près de la forêt de Sokolniki, point jusqu'auquel les eaux des sources arrivaient en quantité totale de deux cent mille védros sans déperdition. De ce bassin on fit monter l'eau dans un réservoir établi au deuxième étage de la tour Soukhareff. L'ascension de toute la quantité d'eau fut effectuée au moyen de machines à vapeur et par des tuyaux en fonte.

$\mathrm{Du}$ réservoir de Soukhareff on conduisit l'eau par des 
conduites en fonte aux cinq fontaines construites sur les places Cheremetiewskaïa, Nikolskaïa, Thểatralnaïa, Voskressenskaïa et Varvarskaïa. Cette reconstruction des conduites, projetée en 1832, fut presque complétement exécutée par le général major Janish.

Plus tard on amena l'eau arrivant la nuit et non dépensée, entre les lignes des boutiques du Kitaïgorod, pour servir en cas d'incendie, à la petite fontaine dans le Zariadie, à la maison des Enfants trouvés, à la prison pour dettes, aux théâtres, et en dernier lieu aux bains de la ville. Ces travaux ont été exécutés par le général major Maximoff $1^{\text {er }}$, en 1840.

De plus, on construisit sur la conduite un puits dans la rue Metschanskaïa, un autre dans la rue Stretenka, tous deux devant servir en cas d'incendie; enfin une fontaine dans la rue Metschanskaïa, pour les besoins des habitants.

Les deux cent mille védros fournis par les sources de Mitischi ne pouvant suffire aux besoins de la ville, Sa Majesté l'Empereur Nicolas I ${ }^{\text {er }}$ décida que toute la quantité d'eau fournie par les sources de Mitischi, qui est de trois cent cinquante mille védros en vingt-quatre heures, serait amenée en ville et répartie par la Sadovaïa dans des fontaines, aux places Samoteskaïa, Ougolnaïa, Triumphalnaïa, Koudrinskaïa et Sennaïa, près du marché Smolensky. Sa Majesté décida également qu’il serait établi une prise d'eau dans la Moskova; que cette eau, purifiée à l'aide de filtres, serait répartie dans des fontaines pour alimenter les places de la partie de la ville située au delà de la rivière, à la place Arbatskaïa, à la place Tverskaïa, ainsi que dans les quartiers situés au delà de 
la Yaouza. Enfin, que l'eau des sources Kalantschewsky et Sokolniki serait amenée à la place Bogoïavlenski, et de là au corps des cadets, à l'hôpital militaire et aux casernes des carabiniers.

306077

Le colonel baron A.-J. Delvig, actuellement généralmajor, a été chargé de l'exécution de cet ordre suprême.

Aujourd'hui, tous ces travaux ont été exécutés par lui avec un entier succès, et nous voyons l'alimentation des eaux à Moscou suffire à tous les besoins privés et publics.

Cette ville est, pour ainsi dire, le centre de la Russie d'Europe; elle est le point de départ de quatre chemins de fer, ceux de Nicolas, de Nijni-Novgorod, de TroïtsaSerguierskaïa et de Kolomna. On poursuit cette année la construction du chemin de fer de Kolomna jusqu'à Riazan, et certainement, avant peu, on construira la ligne du Sud. Moscou deviendra alors le centre principal du développement du commerce et de l'industrie en Russie.

Pour ne pas sortir des limites que nous nous sommes tracées, nous terminons ici cet ouvrage.

Le lecteur ne trouvera pas, parmi les descriptions que nous avons faites, celles des monuments de Saint-Pétersbourg. De l'époque de la fondation de cette ville date une nouvelle ère de l'architecture en Russie, et nous laissons à un autre auteur le soin de décrire les monuments de notre nouvelle capitale, qui offrent de très-beaux échantillons des styles des écoles modernes. 


\section{APERĢU}

$80 \mathrm{~B}$

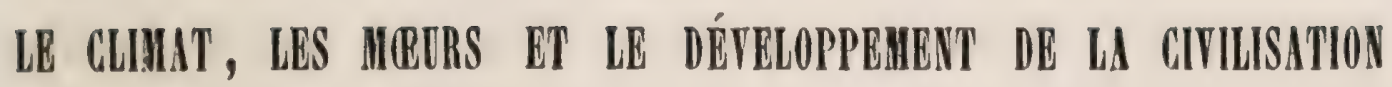
EN R USSIE.

L'Europe occidentale est traversée par des chaînes de hautes montagnes et sillonnée de vallées; son climat est tempéré par le voisinage de la mer.

L'Europe orientale, entièrement occupée par la Russie, est une plaine uniforme.

La température moyenne de son climat est basse et éprouve une forte variation de l'été à l'hiver. Cette vaste plaine orientale est baignée par quatre mers: la mer Noire, la mer Caspienne, la mer Blanche et la Baltique. Elle est séparée à l'est de la Russie d'Asie par les monts Ourals (monts d'Ougre ou Ryphei), et de l'Asie au sud par le Caucase; au sud-ouest elle est bornée par les monts Karpathes. Au milieu de cette plaine existent des mamelons élevés, nommés plateaux de Valdaï ou monts d'Alan, où prennent leurs sources les fleuves et leurs nombreux affluents qui vont se jeter dans les mers que nous venons de citer. Les plus puissants de ces fleuves sont le Volga, le Duiéper et la Dvina occidentale.

La partie sud-est de la Russie, peu montagneuse, mais abondamment arrosée, est un steppe long dont le sol. est 
une terre noire (1). Ce steppe est couvert de riches pâturages et a été habité pendant des siècles par des tribus sauvages menant une vie errante, appartenant principalement aux tribus d'Altaï, et venues de l'Asie centrale par les rivages de la mer Caspienne.

Ces tribus sauvages, connues des colons grecs sous les noms de Scythes ou de Sarmathes, habitaient les côtes nord de la mer d'Azow et de la mer Noire. Après la naissance du Christ et la retraite des Goths, ces mêmes contrées ont été habitées par les Huns, les Bulgares, les Avares, les Khosares; plus tard, au dixième siècle, par les Petchéniègues; au onzième siècle, par les Polovtzis; enfin, au treizième siècle, par les Tartares.

Le sol de la partie nord-ouest de la Russie est, sur presque toute son étendue, formé d'un mélange de glaise et de sable. Il est couvert de forêts, de marécages, et quelquefois de lacs.

La partie nord a été peuplée pendant des siècles par une tribu pauvre adonnée à la chasse et connue sous le nom de Tchoudes ou Finnois, lesquels avaient été refoulés du sud par les Slaves. Ces derniers avaient pour voisins et alliés, dans les pays du Niémen et de la Dvina occidentale, les Léthoniens, qui se distinguaient par une organisation sacerdotale toute particulière.

Les Slaves orientaux, peuple spécialement agricole comme ceux de l'occident leurs frères, vinrent des rives du Danube et s'étendirent $d u$ sud au nord, en remontant le Dniéper jusqu'à sa source, et en traversant les contrées nommées actuellement Petite-Russie et Russie-Blanche.

(1) Le pays de terre noire occupe une surface de $87,000,000$ déciatines ou $95,000,000$ hectares. 
Plus tard, ils s'étendirent autour des lacs du pays appelé aujourd'hui Novgorod; et enfin, aux onzième, douzième et trcizième siècles, ils peuplèrent les rives de l'Oka et du Volga.

Aux quinzième et dix-septième siècles ils remontèrent vers le nord en traversant les monts Ourals, et s'installèrent en Sibérie. Comme en Europe, ils émigraient en remontant toujours le cours des fleuves.

A la fin du douzième siècle et au commencement du treizième, des colons allemands (metschenostzis, porteurs de glaives) vinrent occuper le littoral de la Baltique, tandis que les Slaves occupaient les parties élevées des quatre bassins de la plaine orientale.

Sur les limites des steppes et des forêts, limites qui séparaient les peuples nomades et bergers d'Altaï des Slaves agriculteurs, et sur les confins de l'Asie et de l'Europe, se formèrent plus tard des colonies militaires pour défendre les contrées agricoles contre les invasions des tribus nomades, et particulièrement des Tartares. Au quinzième siècle, ces colonies militaires se firent connaître sous le nom de cosaques, lesquels formèrent plus tard en Russie plusieurs Oukraines (de la Petite-Russie, du Don, de l'Oural, de la Sibérie et en dernier lieu du Caucase).

A cette époque on commence déjà à distinguer le caractère commercial des quatre bassins.

Dans la partie sud du bassin de la mer Noire, les Turcs apportent l'élève du bétail, et au nord les Slaves russes introduisent l'agriculture. Au sud de la mer Caspienne commence aussi l'élève du bétail. Dans la partie haute de cette même contrée, l'agriculture se propage ainsi que l'industrie de divers métiers, qui se développe d'une manière 
toute particulière dans la période historique qui suit cette époque.

Le bassin de la mer Blanche, habité surtout par les Finnois, est couvert de forêts traversées par des lacs et des ravins très-favorables pour la chasse: aussi les habitants se livrent-ils à cet exercice.

Le bassin de la Baltique, à côté d'une industrie primitive, de l'agriculture et d'une industrie de métiers, s'enrichit par un commerce immense et actif.

Les pays commerciaux de Polotzk et de Smolensk, séparés du littoral de la Baltique par les chevaliers lithuaniens, furent privés de la possibilité d'atteindre au développement industriel et au bien-être politique dont furent favorisées les contrées de Novgorod et de Pskow, qui avaient des relations continuelles, par les eaux de la Baltique, arec l'occident de l'Europe.

Les autres fiefs gouvernés par les assemblées nationales (vetscha), et situés dans la partie supérieure des deux bassins du sud, n'atteignirent pas non plus au développement industriel et politique dont jouissait Novgorod. Les contrées telles que Kiew, la Volhyno-Galitzkaïa, Tchernigowsko-Severskaïa (du nord), Mouromo-Riasanskaïa et Souzdalskaïa, étant séparées des mers du sud par des hordes nomades, n'ont pu profiter des bienfaits qui ont rendu si florissant l'état des cités constitutionnelles (vetscheviés goroda) du littoral de la Baltique.

Nous allons essayer de donner un aperçu des traits caractéristiques de l'organisation de la société en Russie aux époques dont nous parlons, organisation qu'il ne faut pas attribuer aux populations de Pskow et de Novgorod. 
La population, bien que faible, se groupait dans les villes, faubourgs et bourgades. Les agriculteurs se groupant dans les campagnes et les industriels dans les villes, qui n'étaient auparavant que des places fortes, faisaient prospérer l'industrie ( $\left.{ }^{1}\right)$.

Vers la moitié du neuvième siècle, les peuples bergers tels que les Turcs, les Finnois et les Léthoniens, ainsi que les Slaves, peuple agricole, menaient une vie patriarcale tout en étant idolâtres.

Les tribus slaves de l'orient non nomades, telles que les Khorvates-Blancs, les Loutitschis, les Tivertzis, les P0lianés, les Drevlianés, les Dragovitschis, les Sévérianés, les Radimitschis, les Viatitschis, les Poletchanés, les Krivitchis et les Slaves de Novgorod, habitaient les forêts vierges ou sur les rives des lacs et des fleuves; ils se groupaient dans des bourgades ou villes seulement entourées d'enceintes, telles que Kiew, Lubetch, Polotzk, Smolensk, Isborsk, Ladoga, Novgorod et autres.

Chaque chef (starchina) demeurait au milieu de sa tribu et la gouvernait. A l'origine, tous les biens immeubles appartenaient en commun à la tribu, puis furent divisés entre les familles.

(1) La Baltique étant le chemin le plus court entre l'Europe occidentale et la Russie, avait pour cette contrée une grande importance.

La mer Noire ne sert à la Russie que de débouché pour les produits du s'd; seulement la navigation y est plus facile que dans la Baltique.

La mer Caspienne offre peu d'avantages au commerce, tant à cause de la nature du pays que des mœurs des peuples avec lesquels la Russie entretient des relations commerciales.

L'océan Glacial n'a aucune importance commerciale, bien qu'il baigne non-seulement le littoral de la Russie d'Europe, mais encore ceux de l'Asie et de l'Amérique. 
Les starchinis se réunissaient dans les vetchis (assemblées) des villes et des bourgades, et y discutaient de la chose publique. Les chefs des communes et des tribus portaient le titre de kniazes (princes).

La famille ainsi que les tribus étaient sauvegardées par les vengeances que ne manquaient jamais de se transmettre de père en fils ceux qui avaient été lésés.

La polygamie existait chez les peuples orientaux en même temps que l'enlèvement des fiancées (oumitschka). Le payement d'une indemnité (vena) pour de pareils rapts était dans leurs coutumes. Ils brûlaient ou enterraient les morts et donnaient des festins en leur commémoration.

Comme on l'a dit, ils étaient idolâtres ; ils adoraient les dieux blancs (divinités de lumière, divinités bonnes), tels que Svarog, le dieu de la pluie, le soleil, la lune, Peroun, Khors, Sem, Regl, Mokochi, les oupirs, les naïades, Tchourou ou Rodh (esprit familier des maisons), les Rajenitzis et autres.

Ils adoraient en même temps les divinités noires (dieux de l'enfer, divinités du mal). Ils croyaient à l'immortalité de l'âme. Les anciens des tribus faisaient des holocaustes dans l'intérieur des maisons; ils égorgeaient des coqs, brisaient des pains, et célébraient des fêtes en l'honneur du soleil et autres divinités.

Ils avaient des jours de réjouissances, tels que la Masslianitsa (carnaval), le Semik (fête du printemps), Koupalo (à l'époque de la Saint-Jean), et Koliada (à l'époque de Noël). Ils plaçaient leurs idoles sur des hauteurs qu'ils appelaient kapischis.

Ils n'avaient pas de rites publics, car les cérémonies religieuses ne se faisaient qu'en particulier. Cette circons- 
tance a été très-favorable à l'introduction du christianisme, qui comporte un rite public, mais a été cause, d'autre part, que plusieurs croyances anciennes se sont conservées trèslongtemps au sein des familles.

Les mœurs des Slaves de l'Orient étaient douces et pacifiques; ils ne s'en défendaient pas moins avec courage pendant la guerre, en même temps qu'ils se montraient hospitaliers et avaient, comme les Celtes, un grand respect pour les femmes.

Vers la moitié du neuvième siècle, ils étaient constamment divisés par des guerres intestines et ne pouvaient se constituer en forte puissance.

Peu à peu ils tombèrent sous la domination étrangère: ainsi les Slaves du Dniéper devinrent tributaires des Khosares, tandis que les peuples du Nord tombèrent sous la domination des Variagues. Après l'expulsion de ces derniers, des querelles intestines éclatèrent parmi les Slaves, et tout vestige d'ordre ayant disparu, ils appelèrent, ainsi que le prouve notre chroniqueur Nestor, les princes variagues russes, Rurik, Sinéoüs et Trouvor, pour venir occuper leur pays avec leurs vassaux. Les princes variagues répondirent à cet appel et occupèrent les pays des Slaves en l'an 6370 (862 de l'ère chrétienne); c'est cette époque qui est considérée comme le commencement de la Russie.

Jusqu'au jour où commença l'invasion des Tartares, les deux modes de la vie sociale, c'est-à-dire la vie nomade et la vie sédentaire, existaient à peu près également chez les peuples qui habitaient l'orient de l'Europe. Ensuite la vie nomade domina quelque temps; mais après l'expulsion des Tartares, la vie sédentaire devint aussi commune que la vie nomade, pour gagner toujours du ter- 
rain, grâce à la civilisation européenne, jusqu'à ce qu'elle ait été remplacée par l'état fixe de la vie sédentaire.

Pendant la guerre des Russes avec les barbares de l'Asie, sur les confins de la prairie et des steppes apparut au premier rang un nouveau guerrier, le cosaque; les Oukraines (pays habités par les cosaques) servaient toujours à l'Europe de rempart contre les invasions des peuples de l'Asie.

Voici quels étaient les produits principaux de la Russie à cette époque: les grains de toute espèce, le miel, la cire, les produits de la pêche et de la chasse, les riches fourrures apportées surtout de Sibérie et des provinces Petcherskaïa et Permskaïa. Toutes ces richesses exploitées en produits bruts pouvaient à peine suffire aux premiers besoins du peuple.

Moscou était le centre du commerce en Russie. C'est de là qu'il s'étendait de tous côtés, et plus particulièrement par le Volga, en Léthonie, vers Novgorod et vers la mer Blanche.

L'industrie des fabriques et des usines ne jouissait que d'un bien faible développement en Russie à cette époque: ainsi les fabriques de fer n'ont été fondées près de Toula, par Vinius, marchand hollandais, que lors du règne de Michel Fédorovitch, c'est-à-dire dans la première moitié du dix-septième siècle.

La vie privée était simple et toute patriarcale. Les vêtements étaient simples aussi ; le costume actuel du peuple rappelle le costume des anciens Russes. Les princes et les boyards suivaient en grande partie les modes étrangères, particulièrement celles des Grecs.

Le père était le chef de la famille, et les hommes 
avaient autorité sur les femmes; les aînés commandaient aux cadets; les femmes étaient dévotes; elles ne se mêlaient pas d'affaires sociales: toute leur attention était portée sur les soins qu'exigeait la famille et le foyer domestique; elles avaient pour leurs maris plus de crainte que d'amour; devant les étrangers elles paraissaient timides. La mère était vénérée par ses enfants qui lui devaient un respect illimité. Les parents, au lit de mort, confiaient leurs filles aux soins de leurs frères.

Dans les grandes occasions, surtout aux jours de grandes fêtes, nos ancêtres aimaient à donner de somptueux festins, à se revêtir de luxueux costumes et à étaler leurs richesses; néanmoins ils étaient économes et leurs besoins étaient très-bornés. Les boyards eux-mêmes produisaient rarement au grand jour leurs riches costumes, leurs armes et leur vaisselle d'argent; tous ces objets de prix étaient soigneusement gardés et passaient de père en fils durant plusieurs générations. Cette manière d'être de la vie sociale et de la vie de famille, enracinée profondément par les mours patriarcales et par les anciens usages, pesait de tout son poids sur chaque individu. Malgré cela, la civilisation de cette époque, quoique peu remarquable, devait agir sur le développement moral.

La civilisation nous est venue de trois côtés : au sud, de Byzance; à l'occident, de la Scandinavie et de la Germanie; à l'orient, des pays où les principes de la civilisation arabe avaient pris racine.

A l'époque dont nous parlons, la civilisation byzantine se reflétait non-seulement dans l'organisation sociale, mais même dans les arts et la littérature. Les Russes imitaient les Grecs dans la construction de leurs temples et 
dans la peinture religieuse, et cette imitation était surtout flagrante sur le littoral du Dniéper. Les traces du style de l'Occident ou du style roman se remarquent dans les contrées $d u$ nord-est telles que le pays de Souzdal; mais les évènements survenus ont arrêté les progrès de la sculpture 'en Russie. Nous avons emprunté à l'Eglise byzantine son chant original.

Le clergé avait l'instruction entre ses mains. Les écoles qui existaient à cette époque appartenaient aux couvents ; les garçons recevaient leur instruction dans les couvents d'hommes, et les filles dans ceux de femmes.

Tous les membres du clergé étaient lettrés sans exception; par contre, les princes, même les boyards, étaient rarement instruits; mais cependant les hommes l'étaient toujours plus que les femmes. Le clergé régulier tâchait d'éclairer ses ouailles par la parole et prêchait d'exemple.

La domination des Mongoles, surtout dans la partie orientale, a eu une grande influence sur la vie politique, sociale et morale: cette domination a été la cause de la division définitive de la Russie en Russie d'Orient et en Russie d'Occident. C'est de cette domination au quatorzième siècle que naquirent le royaume léthonien et le royaume moscovite; c'est elle qui a conduit le royaume moscovite à une si forte centralisation; c'est elle, enfin, qui fit naître en Russie le boyardstvo (aristocratie d'emploi et de naissance). C'est à cette même époque aussi que le clergé avait le plus d'influence.

Sous le joug des Mongoles, les mœurs et les usages de la vie privée des Russes devinrent plus grossiers, même inhumains, et ce changement eut pour résultat que les femmes des boyards s'éloignèrent de la société des hommes. 
Les Mongoles et avec eux les Livoniens, les Léthoniens et les Polonais, nous ayant séparés des contrées civilisées de l'Occident, arrêtèrent les progrès que la civilisation, la vie sociale, le commerce, l'industrie, les arts et la littérature auraient faits en Russie. Après le joug des Tartares, Kiew et le littoral du Dniéper, ainsi que le territoire de Tchernigowsko-Severskaïa, formant l'ouest de la Russie, ruinés de fond en comble, perdirent leur signification politique en cédant le pas à la Galicie, qui se fondit bientôt avec la Volhynie; mais, en 1340, les Polonais s'emparèrent de la Galicie et les Léthoniens de la Volhynie.

La Russie de l'Orient ne s'est remise qu'avec peine de ce joug. Au quatorzième siècle, elle comptait comme principautés remarquables celles de Twerskoé, Nijegorodskoé, Souzdalskoé, Riazanskoé, et Moskovskoé.

Après de longues luttes entre les principautés de Twer et de Moscou pour des droits de priorité, Moscou demeura victorieuse et domina les autres principautés; ce n'est que grâce à cette prédominance, suivie de centralisation, que la Russie a pu secouer le joug des Tartares et défendre son indépendance politique au milieu des puissants voisins qui l'entouraient.

Après avoir déraciné le système féodal inséparable des guerres intestines, la centralisation amena la paix intérieure dans la Russie orientale, paix si nécessaire au développement régulier du commerce, de la vie sociale, des arts et des sciences.

Dans cette partie de la Russie, pendant trois siècles consécutifs (aux quatorzième, quinzième et seizième), s'organisait graduellement un État placé sous un seul sceptre. Les 
fiefs, et avec eux l'état communal et l'état au service du gouvernement (c'est-à-dire celui des boyards), perdirent peu à peu cette indépendance dont ils jouissaient pendant la féodalité. L'extinction de la dynastie des Ruriks, le peu de force des nouvelles dynasties, la tendance des boyards à s'emparer du pouvoir suprême, le mécontentement des laboureurs asservis, la cupidité des cosaques de Zaporogie et $d u$ Don, l'ambition des Polonais et en partie des Suédois, d'augmenter leurs États aux dépens de la Russie, les intrigues des jésuites pour introduire le catholicisme dans la Russie orientale, furent les causes des troubles qui ravagèrent la Russie au dix-septième siècle. Il faut ajouter à ces causes la haine contre la domination moscovite des royaumes de Kazan et d'Astrakan, autrefois royaumes indépendants et professant la religion du Prophète, l'égoïsme des ambitieux, l'ignorance du peuple et la grossièreté des mœurs.

Dans la période de temps qui s'écoula à partir du joug des Mongols jusqu'à Pierre Ir ${ }^{\text {er }}$, la Russie orientale agricole, avec ses populations tartare au sud, finnoise au nord, léthonienne et germanique au nord-ouest, et slave au centre, présente deux divisions remarquables : l'une est léthonienne et l'autre moscovite. La limite qui sépare ces deux parties est le Dniéper.

Le royaume léthonien n'a jamais eu de centralisation aussi régulière que celle qu'avait le royaume moscovite. La cause du développement de cette centralisation chez les Veliko-Russes doit être attribuée à la position géographique de leur pays.

Le pays habité par les Veliko-Russes avait avec l'Asie une frontière commune et fut quelque temps placé sous 
le joug de cette contrée. Pour s'affranchir de ce joug, pour vaincre les barbares des steppes, il fallait se réunir autour d'un centre commun. Cette réunion était d'autant plus nécessaire que de puissants et d'adroits ennemis, tels que les Polonais, les Suédois, les Livoniens, nous menaçaient à l'occident.

La centralisation moscovite naquit de la nécessité de défendre contre ces voisins menaçants l'indépendance politique. D'autres circonstances concoururent aussi au progrès. Le royaume moscovite, en suivant le cours des rivières, étendait toujours ses limites; cette extension se faisait à partir des sources des rivières et en descendant vers leurs embouchures, ou du centre de la plaine orientale européenne vers sa circonférence. Les points extrêmes étaient les quatre mers déjà citées (la mer Blanche, la Caspienne, la Baltique, la mer Noire). L'occupation du littoral de la mer Blanche, habité par les Finnois et les Novgorodiens, a coûté le moins de peine.

Plus tard, pour affaiblir les Mongoles, on conquit sur eux les côtes de la Caspienne, et la crainte d'une pénible guerre avec les Turcs, puissants à cette époque, empêcha seulement la Russie, jusqu'au règne de Catherine II, de se fortifier sur la mer Noire.

Après avoir conquis le littoral de la Caspienne, pour nous rapprocher des pays civilisés de l'Europe, on s'empara, sous le règne de Pierre $1^{\text {er }}$, des ports de la Baltique, conquête déjà rêvée par Jean le Terrible, Boris Godounoff et Alexis Mikhaïlovitch.

L'influence $d u$ gouvernement moscovite agissait d'autant plus facilement qu'il ne rencontrait aucun obstacle 
physique ni aucune barrière dans la configuration plane du pays.

Dans cette immense plaine fut formé, malgré l'opposition des Oukraïnes des cosaques (sur le Don, le Dniéper et l'Oural), malgré l'opposition de la Livonie; de la Suède, de la Léthonie, et surtout de la Pologne, un grand État.

La conquête des hordes tartares entraîna à la suite la chute des cosaques. La Livonie ne pouvait nuire à Moscou; la conquête du littoral de la Baltique nous préserva contre la Suède; enfin la Léthonie, menacée au commencement par la Pologne et plus tard conquise par elle; ne pouvait nuire sérieusement à Moscou.

$\mathrm{Au}$ commencement du dix-septième siècle, époque de troubles, peu s'en fallut que la Pologne ne conquît la Russie; mais, divisée, tourmentée par des dissensions intestines, la Pologne ne pouvant trouver sur une mer l'appui si nécessaire à la puissance de tout peuple, ne put vaincre le royaume moscovite.

Tandis que la Russie occidentale, arec sa partie nord couverte de forêts, constituant la Russie-Blanche, et avec sa Petite-Russie courerte de pâturages et enrichie par l'agriculture, perdait son indépendance politique, la Russie orientale, pays agricole, industriel et commerçant, réunie sous un même sceptre, non-seulement se défendit contre ses ennemis extérieurs, mais parut encore fière et grande de son indépendance politique, et étendit ses limites depuis l'océan Glacial jusqu'à la Caspienne et la mer Noire.

L'empire russe, sous le point de vue de son étendue, 
occupe aujourd'hui la première place parmi tous les Etats existants. Il comprend toute la partic est de l'Europe, tout le nord de l'Asie et le nord-ouest de l'Amérique. Ses possessions, réunies avec les îles dans la mer de glaces et dans la partie nord du grand Océan, s'étendent sur une surface plus que deux fois aussi grande que toute l'Europe; cette surface est égale à un sixième de toute la surface terrestre. Si on en exclut les parties peu habitées, comme la Finlande, la partie nord de la Sibérie, les possessions d'Amérique et le gouvernement d'Arkhangel, la Russie occupe encore un espace plus grand que l'Europe, que les États de tout le nord de l'Amérique, que le Brésil ou que la Chine. Cette immense étendue occupée par la Russie est d'autant plus importante que toutes ses possessions sont groupées ensemble et non disséminées.

La rivière Araks (38 degré de latitude) peut être regardée comme sa limite extrême au sud, qui au nord est le cap de Taïmour ( $78^{e}$ degré de latitude) : ainsi la Russie occupe en largeur $40^{\circ}$, ce qui donne un espace de 4,200 verstes.

La distance entre ses limites d'est et d'ouest est encore plus immense; cette distance est si grande que si on établissait un chemin de fer de Kalisch, qui est sur la frontière de Prusse, au port Saint-Pierre et Saint-Paul, sur la côte orientale du Kamtschatka, il faudrait vingt jours pour parcourir cette distance, en voyageant nuit et jour sur une voie ferrée avec une vitesse moyenne de 30 verstes à l'heure. Pour apprécier encore mieux cette immense étendue, prenons la différence qui existe entre le 
lever du soleil à Kalisch et le lever du soleil au cap Oriental. Ces deux points sont distants l'un de l'autre de $175^{\circ}$; par conséquent, la différence des levers du soleil est de $11^{\mathrm{b}} 40^{\mathrm{m}}$. Cette différence augmentera encore si nous prenons comme limite orientale de la Russie le méridien passant à l'extrême limite de nos possessions en Amérique.

Après avoir suivi pas à pas le développement de la Russie jusqu'd nos jours, nous devons reconnaître que ses efforts, pendant les deux derniers siècles, pour s'étendre, ne sont que la suite de sa centralisation durant les quatre siècles précédents. De même qu'au quatorzième siècle, avec le pouvoir d'un prince moscovite, commence une révolution sociale marquée par la réunion de toutes les possessions russes sous le même sceptre, de même avec le règne de Pierre $\mathrm{I}^{\text {er }}$ commence la période des réformes morales et l'époque de la renaissance de l'homme en Russie, grâce au principe vivifiant de la civilisation apportée d'Europe. Pendant que le puissant empire russe continue, à l'aide de la civilisation européenne, à se développer, cette même civilisation donne aux hommes une plus haute idée de leur valeur, en pénétrant d'abord dans la haute classe, puis graduellement jusqu'au peuple.

Le développement de la puissance de l'empire autocrate russe a eu la plus heureuse influence sur les progrès de la civilisation, des arts et de la littérature dans ce grand pays. 
Nous croyons devoir ajouter à cet article quelques indications concernant les particularités que présente, au point de vue de la température, le climat de la Russie d'Europe.

Dans cette contrée les lignes isothermes, c'est-à-dire de température moyenne annuelle, n'ont pas une direction parallèle aux degrés de latitude; elles déclinent du nord à l'est ou du sud à l'ouest. Autrement dit la température annuelle moyenne baisse en Russie à mesure que dans la même latitude on va de l'ouest à l'est. Ainsi l'isotherme de $+3^{0}$ suivant Réaumur passe à St-Pétersbourg $\left(60^{\circ}\right.$ de latitude nord), traverse le méridien de Vladimir (56 latitude nord), celui de Samara (530 latitude nord), et traverse l'Oural sous le $51^{01 / 2}$ latitude nord; c'est-à-dire que cet isothermo s'abaisse de $801 \frac{1}{2}$ entre Pétersbourg et l'Oural. L'isotherme $+4^{0}$ Réaumur réunit la ville de Felline $\left(58^{0} \frac{1}{2}\right.$ latitude nord) à Orel $\left(53^{0}\right.$ latitude nord) et à Ouralsk ( $51^{0}$ latitude nord); de sorte que cette dernière ville se trouve à $70^{\circ}$ plus au sud que Felline. Les lignes de même degré de température pendant l'hiver et l'été ou lignes isochimènes et isotères présentent entre elles une grande opposition : tandis que les lignes isochimènes qui, du nord-est au sud-ouest, déclinent encore plus que les isothermes, les isothères, au contraire, s'élèvent du sud-ouest au nord-est; cette élévation se manifeste à une certaine distance des limites occidentales de la Russie : ainsi, par exemple, l'isochimène de $-10^{\circ}$ réunit Arkhangel (640 $32^{\prime}$ latitude nord) et Kazan ( $55^{0} 47^{\prime}$ latitude nord), et même peut-être Orenbourg ( $51^{0} 45^{\prime}$ latitude nord); l'isochimène $-8^{0}$ passe de Petrosavodsk ( $61^{0} 47^{\prime}$ latitude nord) par Riazan (54 1/s 
latitude nord) et par Saratoff (510 $1 / 2$ latitude nord). Les isothères s'élèvent de l'ouest à l'est : ainsi, par exemple, Varsovie $\left(52^{\circ} 13^{\prime}\right.$ latitude nord) et Tobolsk $\left(\begin{array}{lll}58^{\circ} & 12^{\prime} & 1 a-\end{array}\right.$ titude nord) se trouvent sur la même isothère de $+14^{\circ}$. Cela montre que plus on s'éloigne de l'est à l'ouest, en suivant la même latitude, plus l'hiver est rigoureux et l'été plus chaud, et que par conséquent la différence entre les températures moyennes de ces saisons est plus forte : ainsi, par exemple, si nous prenons une série de points entre le $52^{\circ}$ et le $62^{0}$ latitude nord, nous trouverons, comme l'indique le tableau suivant, que la différence des températures de l'hiver et de l'été varie de $17^{0} 1^{\prime}$ à $42^{0} 6^{\prime}$.

\begin{tabular}{|c|c|c|c|c|c|c|c|}
\hline NOIIS DES LIEUX. & $\begin{array}{l}\text { 总 } \\
\text { 总 } \\
\text { 总 }\end{array}$ & 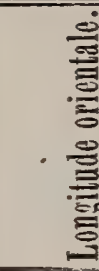 & & 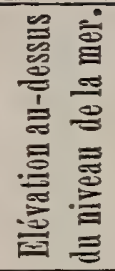 & 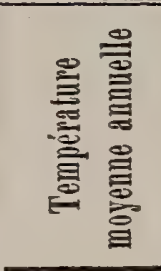 & 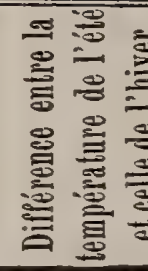 & 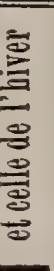 \\
\hline & & & & & \multicolumn{3}{|c|}{ RÉAUMUR. } \\
\hline Helsingfors. . . & $60^{\circ} \quad 10$ & $42^{\circ}$ & $37^{\prime}$ & 50 & $+3^{\circ} 0$ & $17^{\circ}$ & \\
\hline Pétersbourg : & $59 \quad 56$ & 47 & 58 & 10 & +30 & 18 & \\
\hline Moscou. . . & $55 \quad 45$ & 5ร & 14 & 400 & +34 & 22 & 3 \\
\hline Kazan . & รั 47 & 66 & 47 & 280 & +22 & 24 & 8 \\
\hline Ekaterinebourg . & $56 \quad 48$ & 78 & 15 & 850 & +04 & 24 & 4 \\
\hline Barnaoul .... & $53 \quad 20$ & 101 & 7 & 400 & +00 & 27 & 9 \\
\hline Irkoutsk ... & 52 & 121 & 51 & 1253 & $\begin{array}{ll}-0 & 4\end{array}$ & 27 & 9 \\
\hline Nertschinsk . & 51 & 137 & $"$ & 2230 & -34 & 34 & 与 \\
\hline Iakoutsk . . & 62 & 147 & 25 & 288 & $\begin{array}{ll}-9 & 1\end{array}$ & 42 & 6 \\
\hline
\end{tabular}

Ce tableau nous montre clairement la loi d'après laquelle la chaleur annuelle moyenne diminue à mesure qu'on s'avance dans le continent, en suivant la même latitude, 
en même temps qu'augmente la différence entre la température de l'été et la température de l'hiver. Ainsi, entre Helsingfors et Iakoutsk, les deux points extrêmes de ce tableau, qui n'ont entre eux qu'une différence de 2 degrés de latitude, il y a $12^{\circ} 1^{\prime}$ Réaumur moins de chaleur moyenne annuelle à Iakoutsk qu'à Helsingfors, et la différence entre les températures moyennes de l'été et de l'hiver est de $25^{\circ} 5^{\prime}$ plus grande à Iakoutsk qu'à Helsingfors. Ainsi la Russie d'Europe, de même que l'Asie, au nora du parallèle de $35^{\circ}$, a un climat tout à fait continental, c'est-àdire un climat composé d'extrêmes, d'excessives chalcurs et de froids rigoureux. Cette circonstance influe beaucoup sur la répartition et le caractìre de la végétation en Russie, comparativement à l'Europe occidentalc. La grande quantité de chaleur fait généralement crô̂tre plus rapidement les plantes au nord que dans le reste de l'Europe. Les plantes qui n'ont besoin que de la chaleur de l'écós sont plus variées et plus luxuriantes en Russie que dans le reste de l'Europe.

A Astrakhan, sur les bords de la Caspienne, où la température moyenne annuelle est de +8 et où les frcids en hiver atteignent quelquefois $-20^{\circ}$, il existe des vignes qui domnent un excellent raisin; seulement, pour garantir la vigne contre les effets du froid, on est obligé de la couvrir d'une forte couche de terre. Les pastèques et les melons viemnent à l'air dans la partic sud du gouvernement de Voronége, entre les $52^{\circ}$ et $53^{\circ}$ de latitude nord, tandis qu'en Allemagne on les rencontre rarement à l'air près de Stuttgart (sous le $48^{\prime \prime} 46^{\prime}$ latitude nord) et même plus au sud.

Par contre, les plantes qui resteat en terre pendant 
l'hiver et sont exposées par conséquent aux rigueurs de cette saison, sont moins nombreuses en Russie; elles offrent moins de variété qu'à l'occident de l'Europe, et parmi ces espèces il en existe qui ne peuvent venir que dans les lieux bien plus méridionaux qu'à l'occident de l'Europe.

Pour faire mieux comprendre le climat de la Russie d'Europe, nous avons annexé à la carte (Fig. 50) placée à la fin de cet ouvrage le tableau des principaux résultats de la température moyenne annuelle de l'hiver et de l'été dans les lieux les plus remarquables. 


\section{DESCRIPTION DES PLANGHES.}

Fig. 1. Vue prise en hiver dans une forêt.

Fig. 1 a. Chasse-neige.

Fig. 2. Vue extérieure des habitations communes de la Russie-Blanche (cabanes sans tuyaux de cheminée, percées de fenêtres et d'ouvertures en guise de fenêtres et couvertes de chaume).

Fig. 3. Vue extérieure des habitations communes de la Petite-Russie, enduites d'argile, blanchies à la craie et couvertes de chaume.

Fig. 4. Maison d'Artémise à Kiew.

Fig. 5. Vue de l'église bâtie à Kiew des décombres de l'ancienne église de Dîme, par le métropolitain Pierre Moghila.

Fig. 6. Façade de l'église construite en 1842 sur les ruines de l'ancienne église de Dîme.

Fig. 7 et 7 a. Plan et élévation de la cathédrale de Sainte-Sophie à Kiew.

Fig. 8. Façade et plan de l'église du couvent de Kievopetchersk.

Fig. 9. Plan et façade de l'église du couvent de Saint-Michel aux Faîtes d'or à Kiew.

Fig. 10. Vue de la cathédrale de Sainte-Sophie à Novgorod.

Fig. 11. Cathédrale de la Transfiguration à Pereyaslavl-Zaleski.

Fig. 12. Eglise de Saint-Nicolas, située dans le gouvernement de Vladimir, entre les villes de Soudogda et Mourome.

Fig. 13 et 14. Tours de la forteresse de Novgorod.

Fig. 15. Tour de l'enceinte du couvent de Saint-Serge à Troîtsa près Moscou. 
Fig. 16. Façade et plan de l'église de la Nativité de Saint-Jean-Baptiste dans la forêt (въ бору), célèbre par une chapelle sous l'invocation de saint Ouare le Martyre.

Fig. 17. Plan et façade de la cathédrale de l'Assomption à Moscou.

Fig. 18. Plan et façade de la cathédrale de l'Archange Michel à Moscou.

Fig. 19. Plan et façade de la cathédrale de l'Annonciation à Moscou.

Fig. 20. Granovitaya Palata ou grande chambre de pierre à Moscou, construite en 1491 et probablement rebâtie depuis à diverses reprises de fond en comble.

Fig. 21. Terem ou appartements des Tsars au Kremlin de Moscou, restaurés depuis 1840 .

Fig. 22. Eglise de Saint-Basile le Bienheureux ou de l'Intercession de la Sainte-Vierge à Moscou.

Fig. 23. Eglise de la Décollation de Saint-Jean-Baptiste dans le bourg de Diakovo près Moscou.

Fig. 24. Eglise de l'Ermitage de Gethsémanié, non loin du couvent de Saint-Serge à Troïtsa.

Fig. 25. Eglise située dans les environs de la ville de Rostof, dans le gouvernement d'Yaroslavl.

Fig. 26. Eglise près de Novgorod, construite du temps de Jean IV.

Fig. 27. Tour d'Ivan Veliki avant sa reconstruction à la fin du dixhuitième siècle.

Fig. 28. Eglise du Saint-Sauveur à la Grille d'or.

Fig. 29. Vue des habitations communes dans le gouvernement de Vladimir.

Fig. 30. Maison centenaire, propriété du paysan Kobyline, dansle bourg d'Ivanovskoïé, districtde Chouya, gouvernement de Vladimir.

Fig. 31. Vue d'une habitation commune dans le gouvernement de Kostroma.

Fig. 32-33. Intérieur d'une habitation sans tuyaux de cheminée, à droite et à gauche de la porte d'entrée.

Fig. 34-35. Intérieur d'une cabane avec tuyau de cheminée, - vue des deux coins opposés.

Fig. 56. Eglise de Notre-Dame de Géorgie à Mlloscou.

Fig. 3\%. Eglise de Saint-Nicolas aux Colonnes (w stolpakh) à Moscou . 
Fig. 58. Eglise de Saint-Nicolas à la Grande Croix, au Kitay-gorod, sur l'Ilinka, à Moscou.

Fig. 59. Façade extérieure et intérieure des restes d'une vieille forteresse de bois à Yakoutsk.

Fig. 40. Vue d'un ancien château de bois dans la ville de Kola.

Fig. 41. Pont en pierre à Moscou, construit en 1687.

Fig. 42. Le même pont depuis sa reconstruction en 1812, tel qu'il a existé jusqu'en 1857 , et $A$ palais nouveau du Kremlin.

Fig. 43 et 43 a. Vue du pont métallique construit à la place du pont en pierre construit en 1812, et Eglise du Saint-Sauveur.

Fig. 44. Tour de Soukharew.

Fig. 45. Eglise de Saint-André à Kiew.

$\boldsymbol{F i g . ~ 4 6 . ~ A . ~ V u e ~ d e ~ l a ~ t o u r ~ S p a s k y . ~} \boldsymbol{B}$. Eglise de Sainte-Catherine au couvent de l'Ascension (couvent de femmes). $C$. petite tour des Tsars (tsarskaya), sur le mur, bâtie dans un style indo-turc.

Fig. 47. Temple du Saint-Sauveur à Moscou. (Projet de Vitberg).

Fig. 48. Façade de la maison des boyards Romanoff après la restauration.

Fig. 49. Plans des étages de la maison Romanoff.

Fig 50. Carte météorologique de la Russie d'Europe.

Fig. 51. Fac-simile d'une gravure de la fin du $17^{\mathbf{e}}$ siècle.

Fig. 52. Plan de Moscou en 1663 (fac-simile d'une gravure du temps).

Fig. 53. Monument commémoratif millénaire élevé en 1862 à Novgorod. 



\section{BIBLIOGRAPHIE.}

N. M. SNÉGUTREFF. Antiquités russes dans les monuments de l'architecture profane et sacrée. Moscou, 1856.

TH. RICHTER. Monuments de l'ancienne architecture russe. Moscou, 1851.

J. SNÉGUIREFF. Anciens monuments de Moscou. 1842.

WELTMANN. Antiquités de l'empire russe.

A. SA VELIEFF. Matériaux pour servir à l'histoire de la fortification en Russie. 18553.

P. S. MAKSUTINE. Aperçu de l'histoire de l'architecture en Russie.

J. S. SAKHAROFF. Notice sur la fabrication de la faience et de l'émail. (Voir les mémoires de la section d'archéologie russe et slave de la Société impériale d'archéologie. Tome $\mathrm{I}^{\text {r }}$. 1851.)

A. GLAGOLEFF. Description sommaire des anciens édifices et monuments russes. (Voir les ma-
H. М. СНЕГИРЕВЬ. Русская старина въ пачятникахъ щерковнаго и тражданскаго зодчества. Москва, съ 1856 года.

Ө. РІХХТЕРЬ. Паиятнпп древняго русскаго зодчества. Москва, съ 1851 г.

И. СНЕГИРЕВЬ. Пауятнићи московской древности съ 1842 года.

BEЛЬтманЂ. Древности Россіисскаго Государства.

А. САВЕЛЬЕВЂ. Матеріалы къ псторіп пнженернаго пскусства въ Россіп. 1853 года.

II. С. МаксюТИнъ. Очергі псторіп зодчества въ Россіп.

И. ПI. САХАРОВЬ. Записка о финіпртяноуь п ценинноуъ пронзводствь. (Записки отдыленіз русской и славянской археологіИ ИМператорскато археологическаго общества, т. I. 1851 года).

А. ГЛАГО.ЕВЬ. Краткое обозрьніе древнихъ русскихъ зданій внихъ отечеси дретвенныхъ 
tériaux pour servir à la statistique de l'empire de Russie, publiés par le ministère de l'intérieur. 1839.)

L'ARCHIMANDRITE EUGENE. Description de l'église et de la hiérarchie de Kiew. 1815.

J. FOUNDOUKLEY. Description des antiquités de Kiew. 1847.

J. ZABIÉLINE. Aperçu historique de la fabrication et de la faience de Russie. (Voir les mémoires de la Société archéologique. Tome VI. 1853.)

Notice pour servir à la connaissance des antiquités russes. St-Pétersbourg, 1851.

OZERSKI. Histoire des fabriques de porcelaine. (Voir l' Abeille du Nord de 1851, $\mathrm{n}^{* \mathrm{~s}} 65,66,67,70$ et 71.)

Visite aux antiquités et aux curiosités de Moscou. 1792.

Nouveau guide à Moscou. 1833.

A. DEMIDOFF. Voyage pittoresque et archéologique en Russie, exécuté en 1839.

A. MARTINOFF et H. SNEGUIREFF. Couvent de Znamenski et maison Romanoff. Moscou, 1861.

H. PAVLOFF. Millésime de la Russie. (Note publiée dans le Calendrier de 1862.)

D. ILOVAISKI. Abrégé de l'histoire de Russie. Moscou, 1861.

V. LIADOFF. La Russie européenne sous le rapport physique et ethnographique. St-Pétersbourg, 1861 . памятниковъ. (Матеріалы для статистики Россійской Имеріи, изданные министерствомъ внутреннихъ дыљъ 1839 года).

АРХИМАНДРИТЬ ЕВГЕНІЙ. Описаніе кіевскаго собора и кіевской іерархіи. 1815 года.

И. ФУНДУКЛЕЙ. Обозръніе Кieва в' отношеніи къ древностямъ. 1847 года.

И. ЗАБФЛИНЬ. Историческое обозръніе финифтянаго и цениннаго ды'ла въ Россіи. (Записки археологическаго общества T. VI, 1853 года).

Записка для обозр'ьнія русскихт древностей. С. Петербургъ, 1851 года.

ОЗЕРСКПП. Исторія фарфоровыхъ заводовъ. (Съверная пчела 1851 года. 칯ํㅡ 65, 66, $67,70$ и 71.$)$

Путешествіе къ древностяиь достопауятностямъ Московскимъ. 1792 г.

Новый Путеводитель по Москвъ 1833 года.

A. DEMUDOFF. Voyage pittoresque et archéologique en Russie, exécuté en 1839.

А. МАРТЫНОВЬ И Н. СНЕГИРEВЂ. Знаменскій монастырь и палата боярь Романовыхъ. Москва, 1861 года.

Н. ПАВЛОВЂ. Тысячелбтіе Россіи. (Приложеніе къ мұсящеслову на 1862 г.)

Д. ИЛОВАЙСКІЙ. Очерки русской исторіи. Москва, 1861 г.

В. ЛЯДОВЬ. Европейская Россія въ физическомъ и этнографическомъ отношеніяхь. С. Петербургъ, 1861 года. 
V. PUTZA. Traduction de l'allemand par $\Lambda$. Téléguine. Géographic comparative. Cahier n" 2 de la géographic de l'empire russe. Moscou, 1862.

Note explicative des cartes statistiques et agricoles de la Russie d'Europe. Edition publiée par le département du ministère des domaines. (3 édition.) St-Pétersbourg, 1857.

S. ZABELLNE. Description de la vie domestique des tsars russes

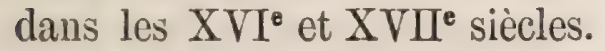
Moscou, 1862.

N. I. KOSTOMAROFF. Description abrégée de la vie et du caractère des habitants de la Grande-Russie dans les XVI et XVI" siècles. St-Pétersbourg, 1860.

N. I. KOSTOMAROFF. Du commerce en Russie. (Voir le journal le Contemporain de 1857.)
В. ПюТЦА, переводъ съ пьмецкаго А. Тельгина. Сравительнал географія, выпускъ II, Геоrрафiя Россіиской Изперіп. Моства, 1862 г.

Хозяіственно-статистическй атдасъ, изданый департаментомь сельскаго Хозлйства минпстерства государственшыъ пууществъ. Нзд. 3-е. С. Петербургъ, 1857 года.

И. ЗАБъЛИНТ. Дохашній быть русскихъ царей въ XVI и XVII ст. Москва, 1862 года.

Н. И. КОСТОМАРОВЬ. Очеркъ дохашней жпзни и нравовъ великорусскаго народа въ XVI п XVI стольтіяхъ. С. Петербургъ, 1860.

Н. И. КОСТОМАРОВЬ. 0 торговл'в въ Россіи. (Современншіъ, 1857 года). 



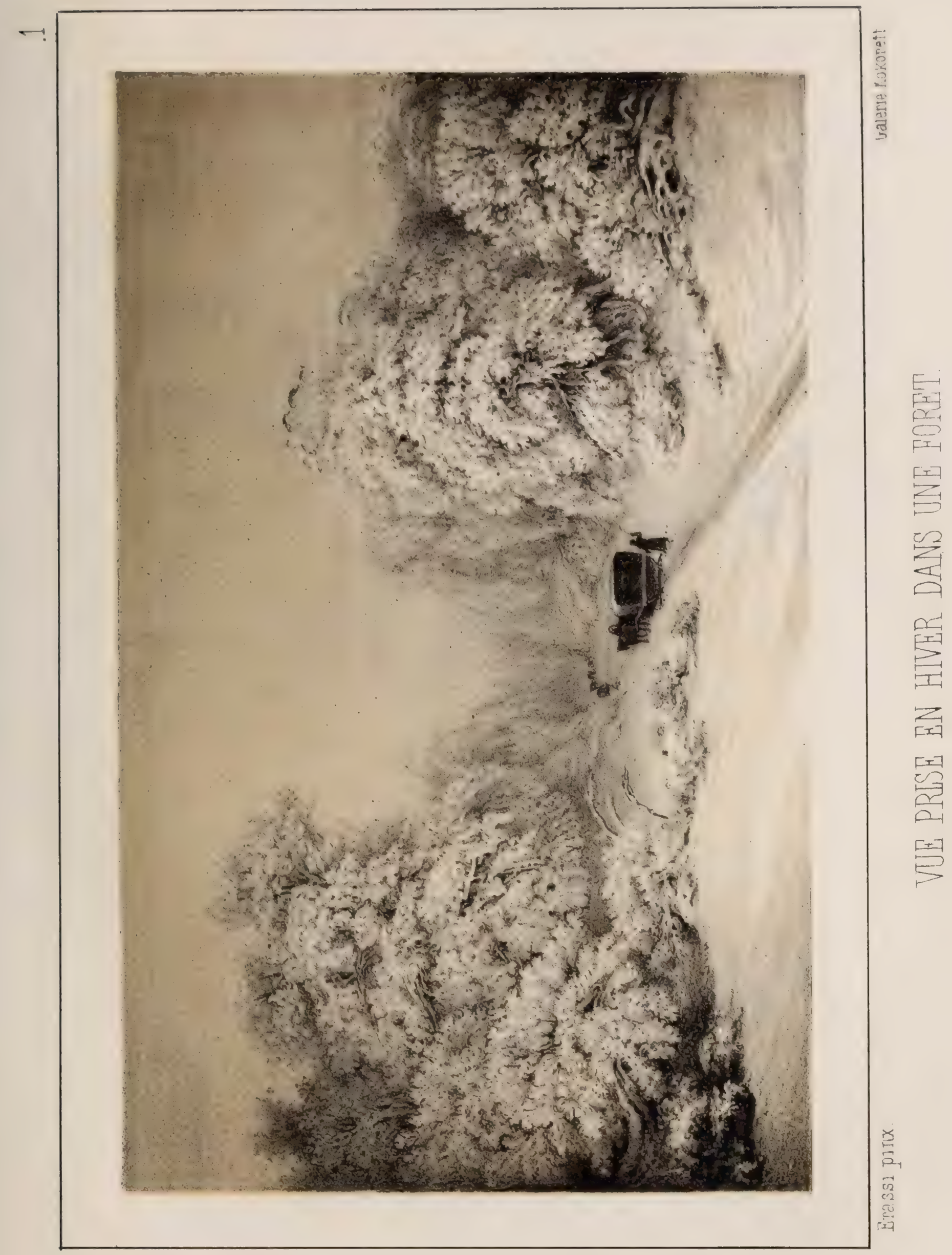





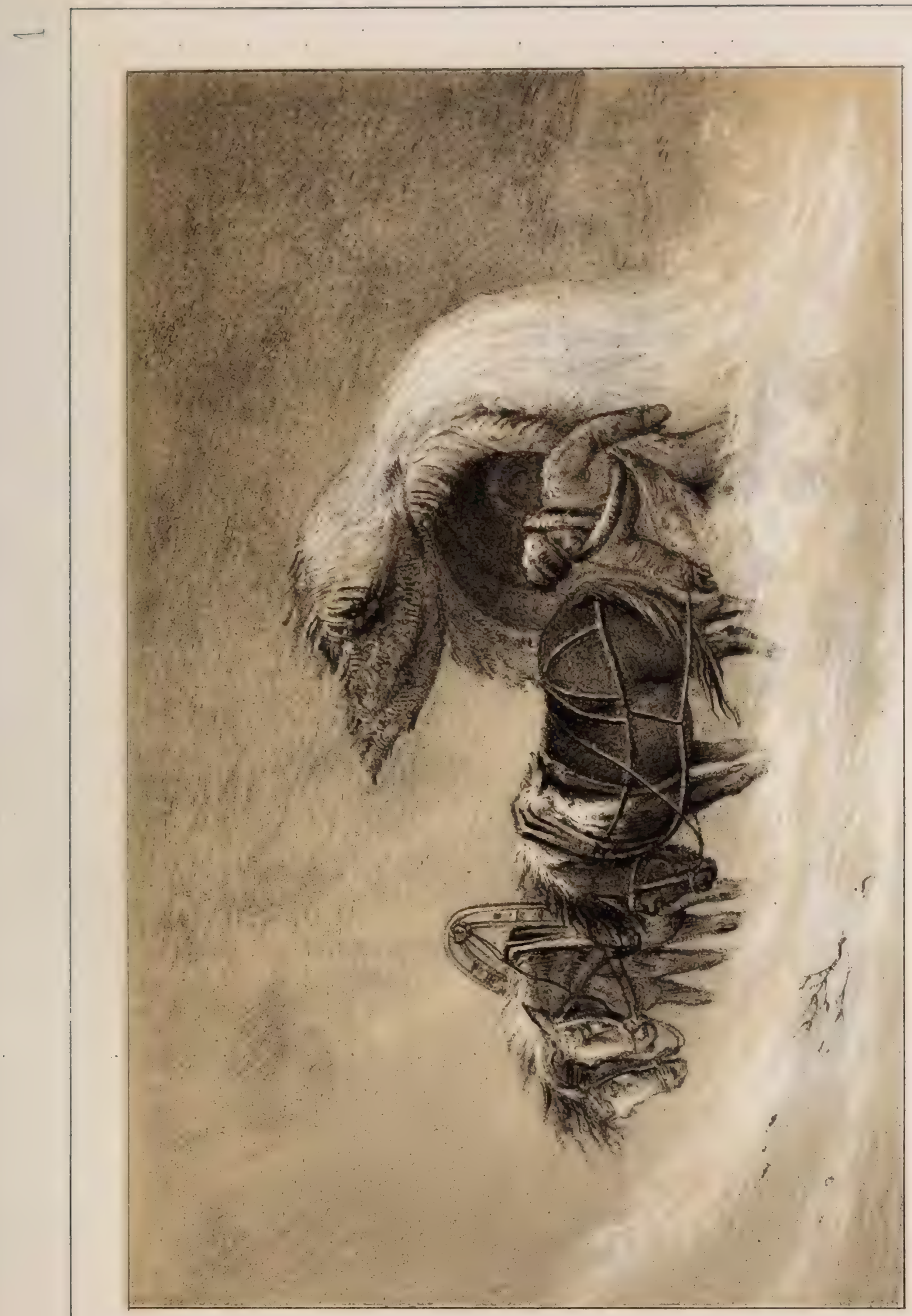





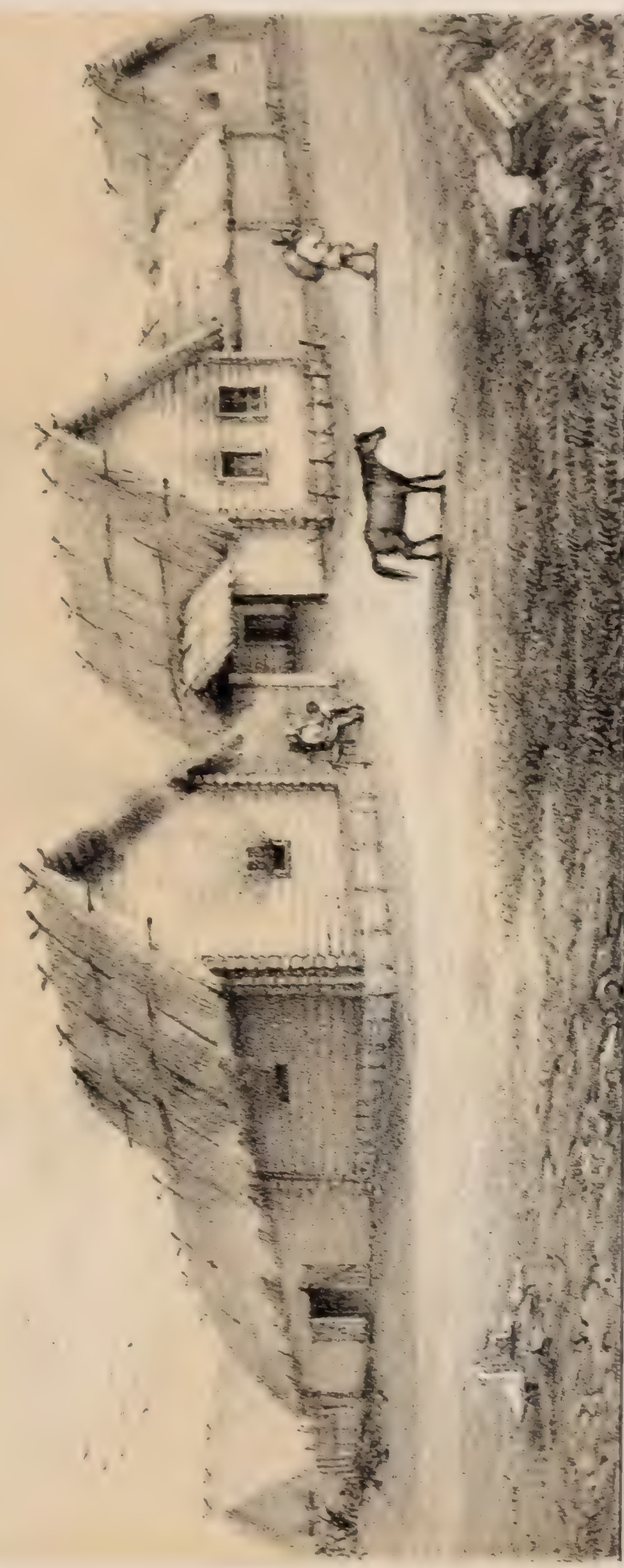

ב 



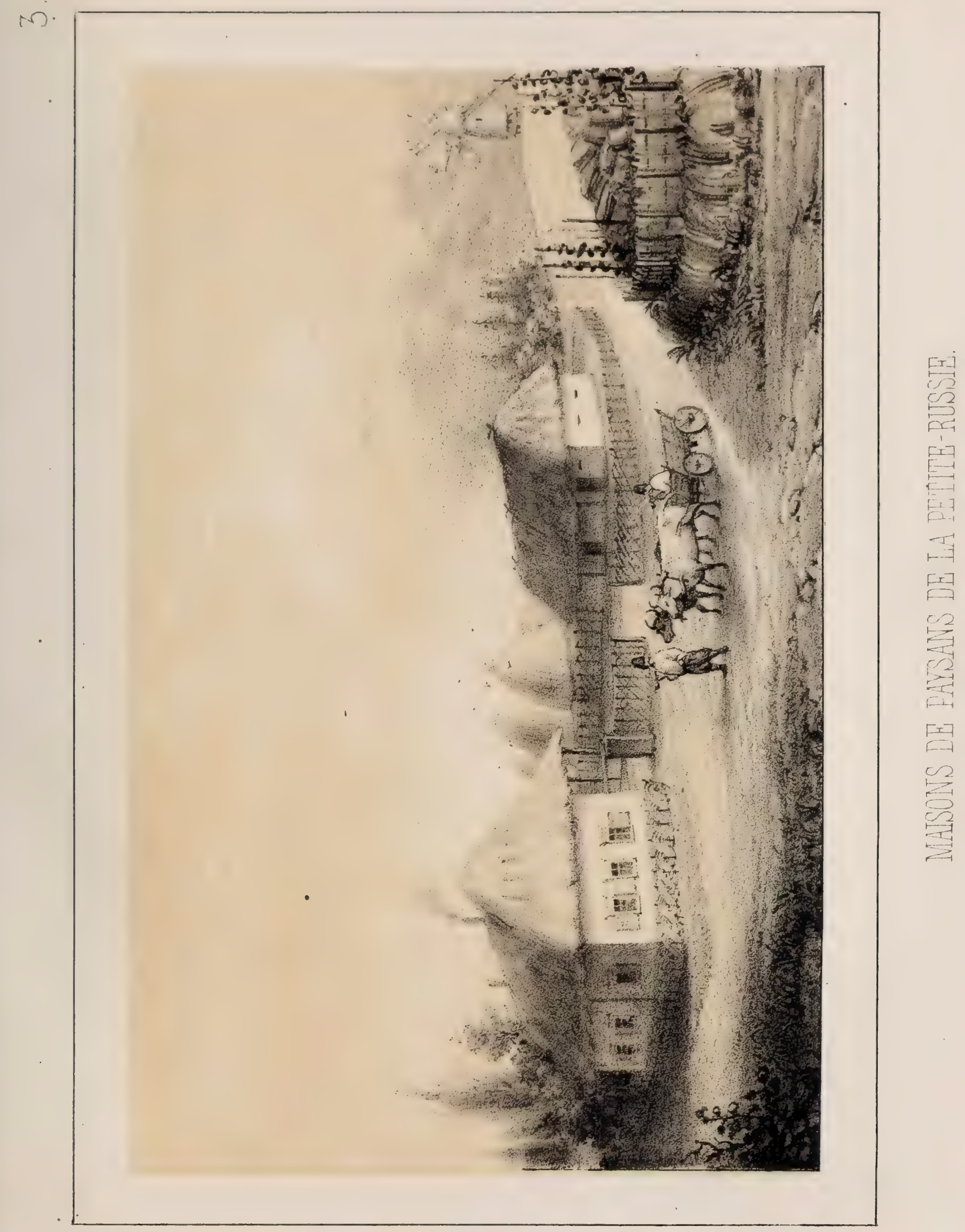






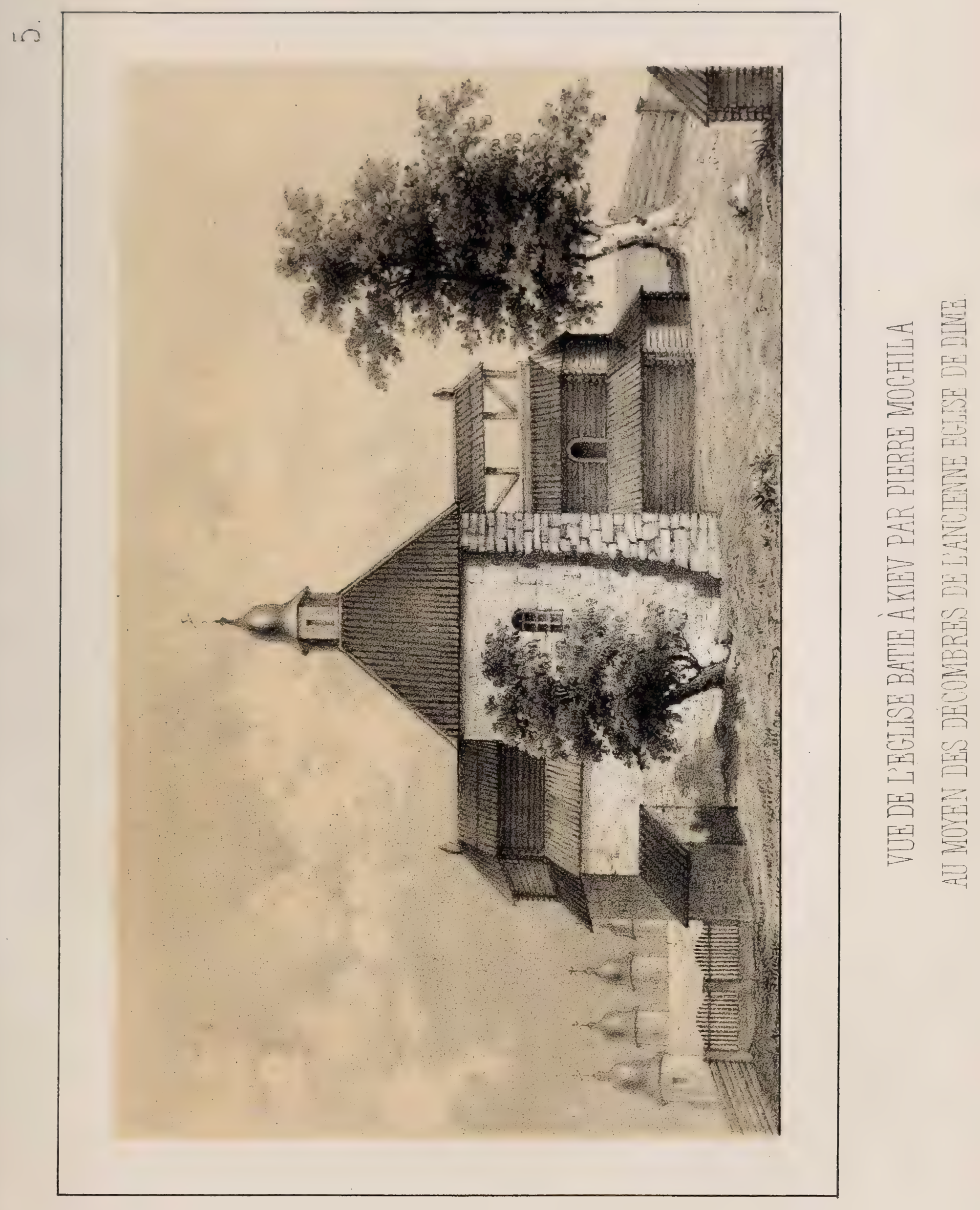





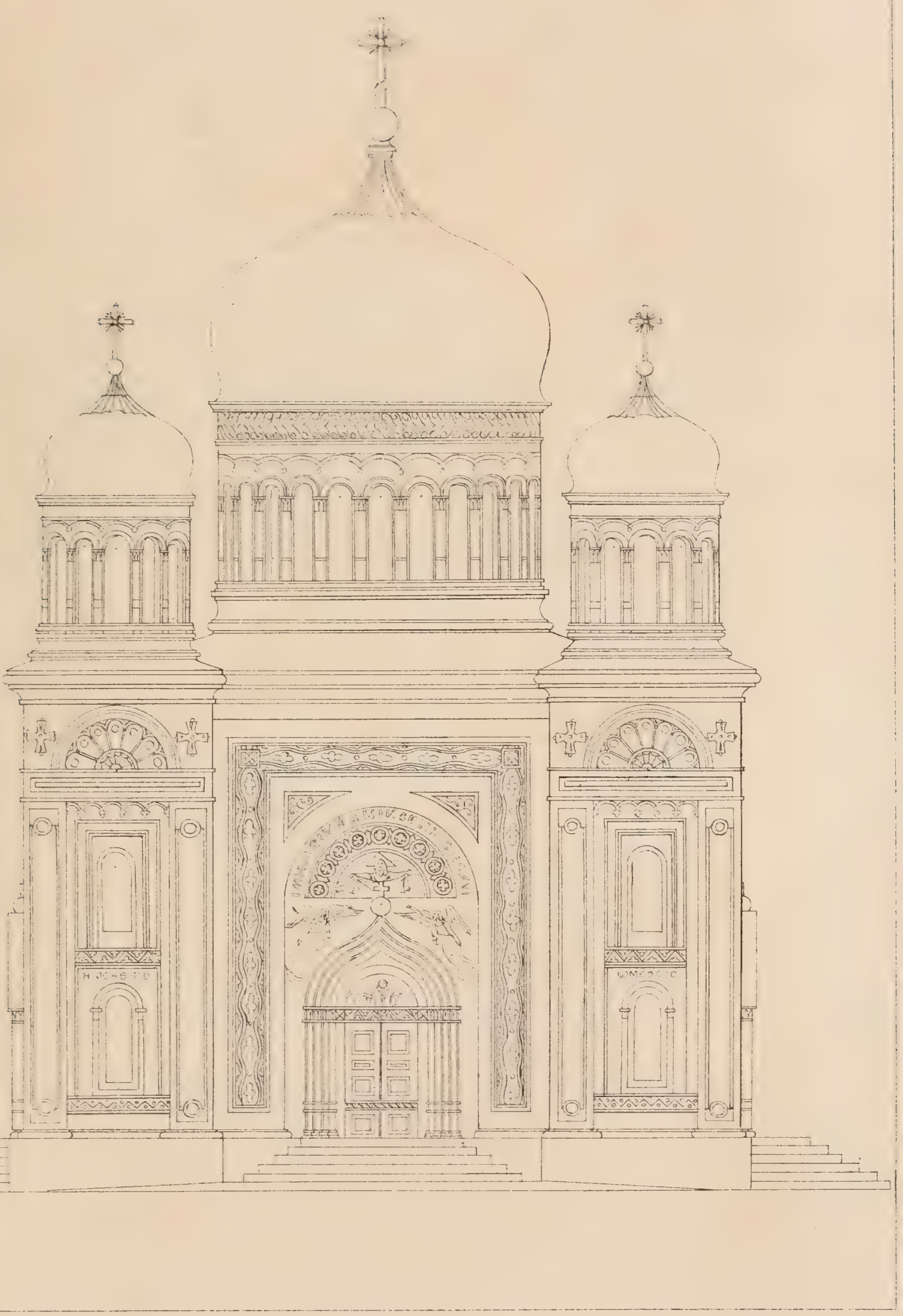

FACADE DE TÉGTISE CONSTRUTTE STIR LES RUNRES

DE LANGTENIE ÉGTSE DE DINE 


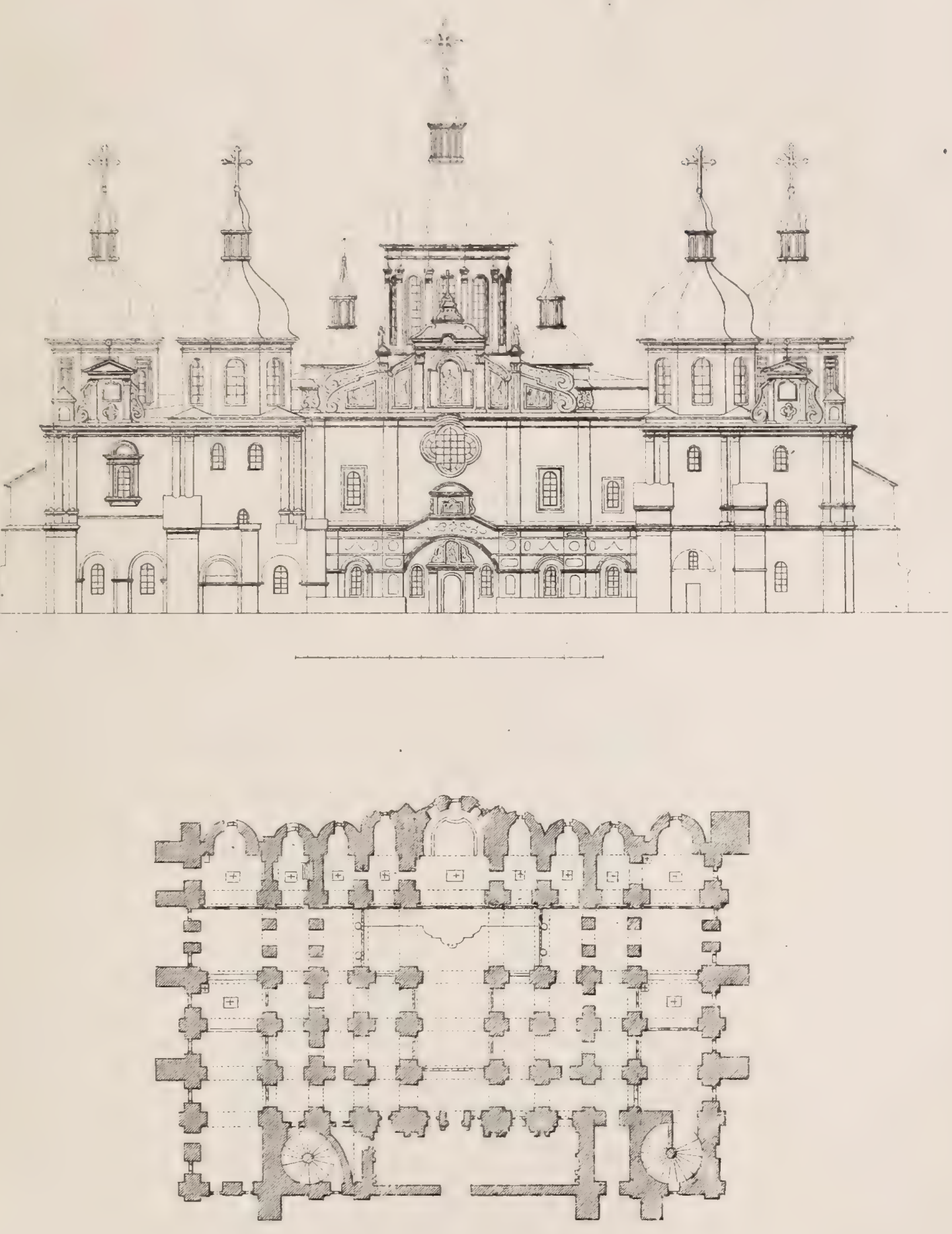

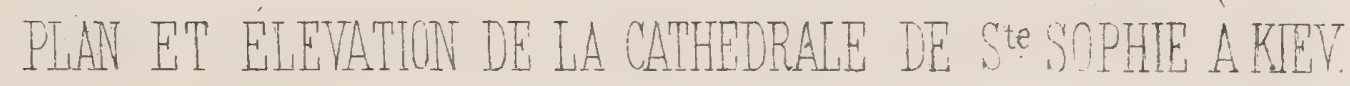





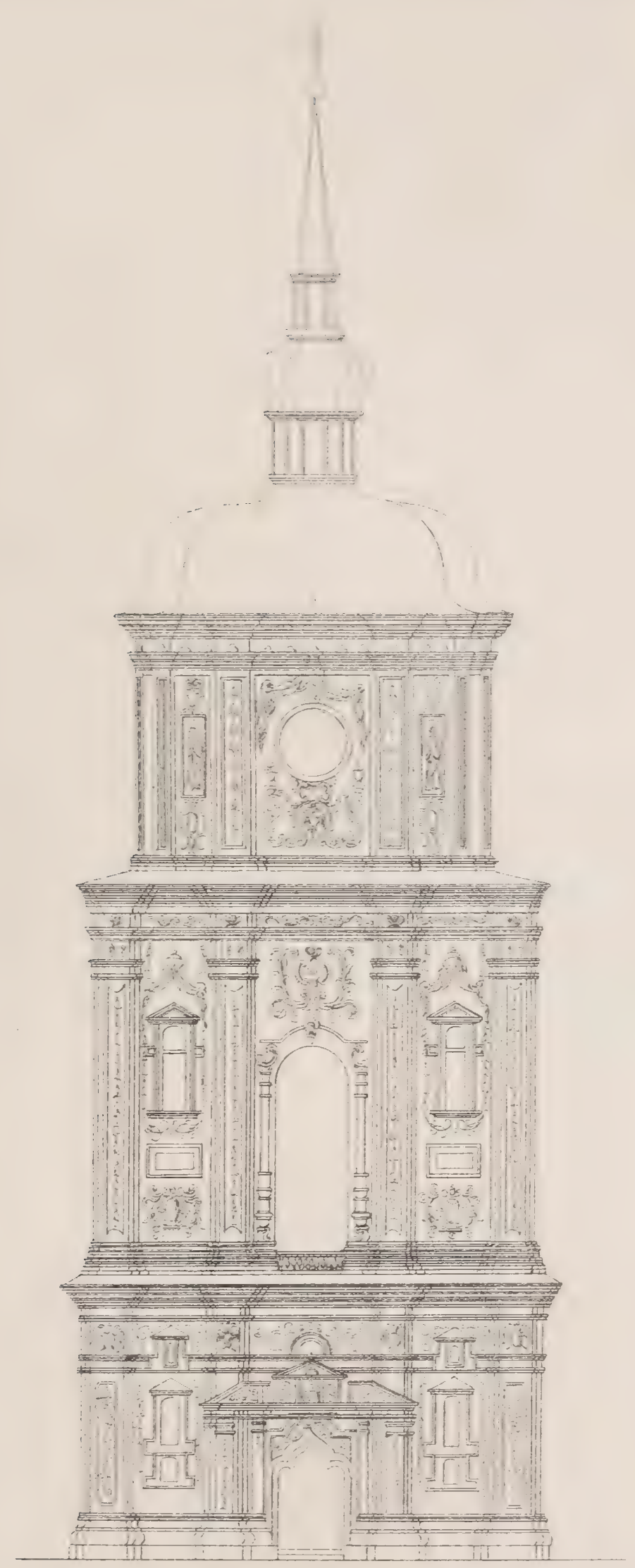

TOOIER DE L OATHETT A. 



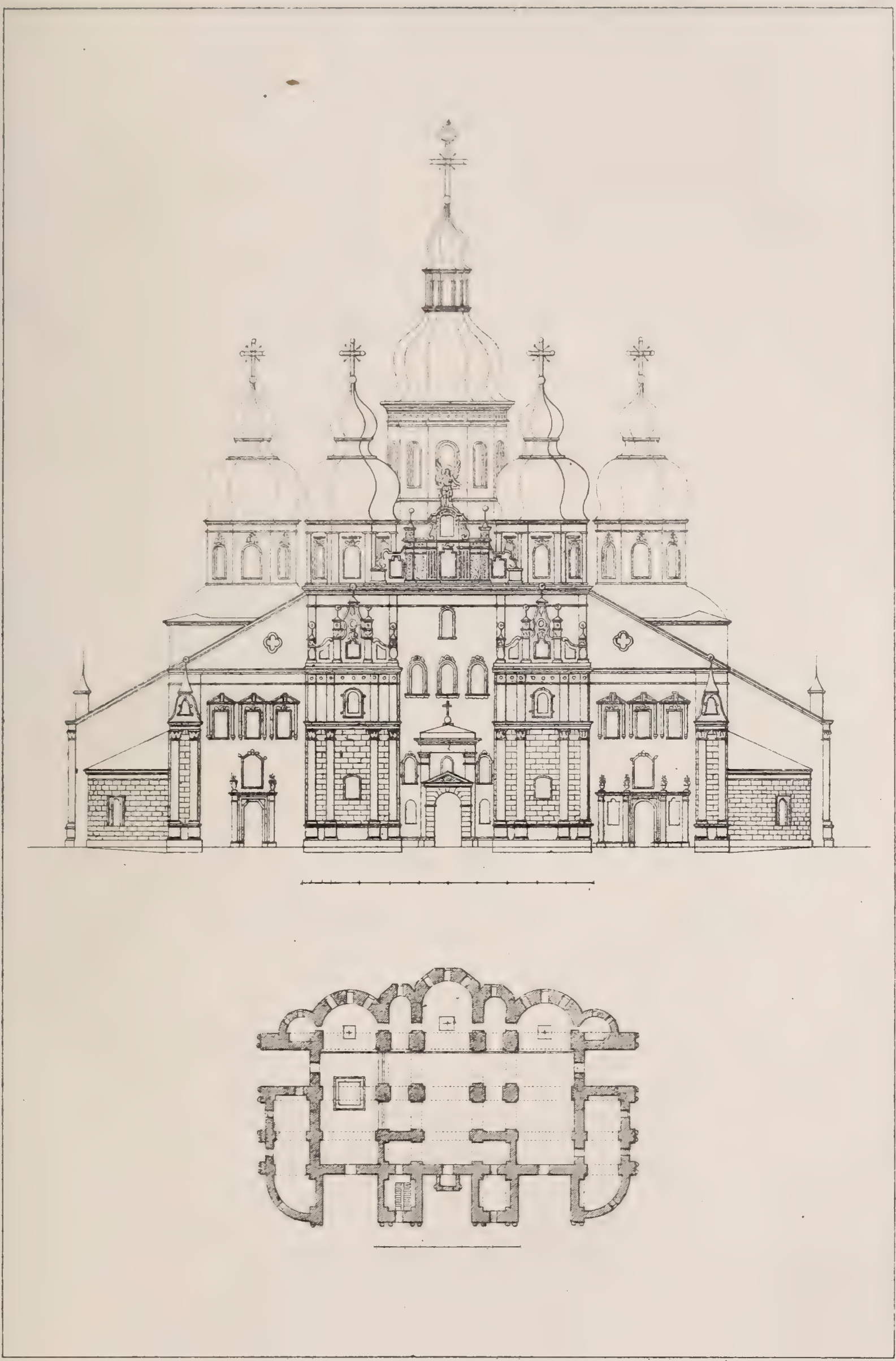

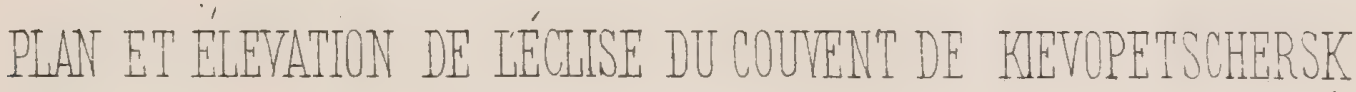




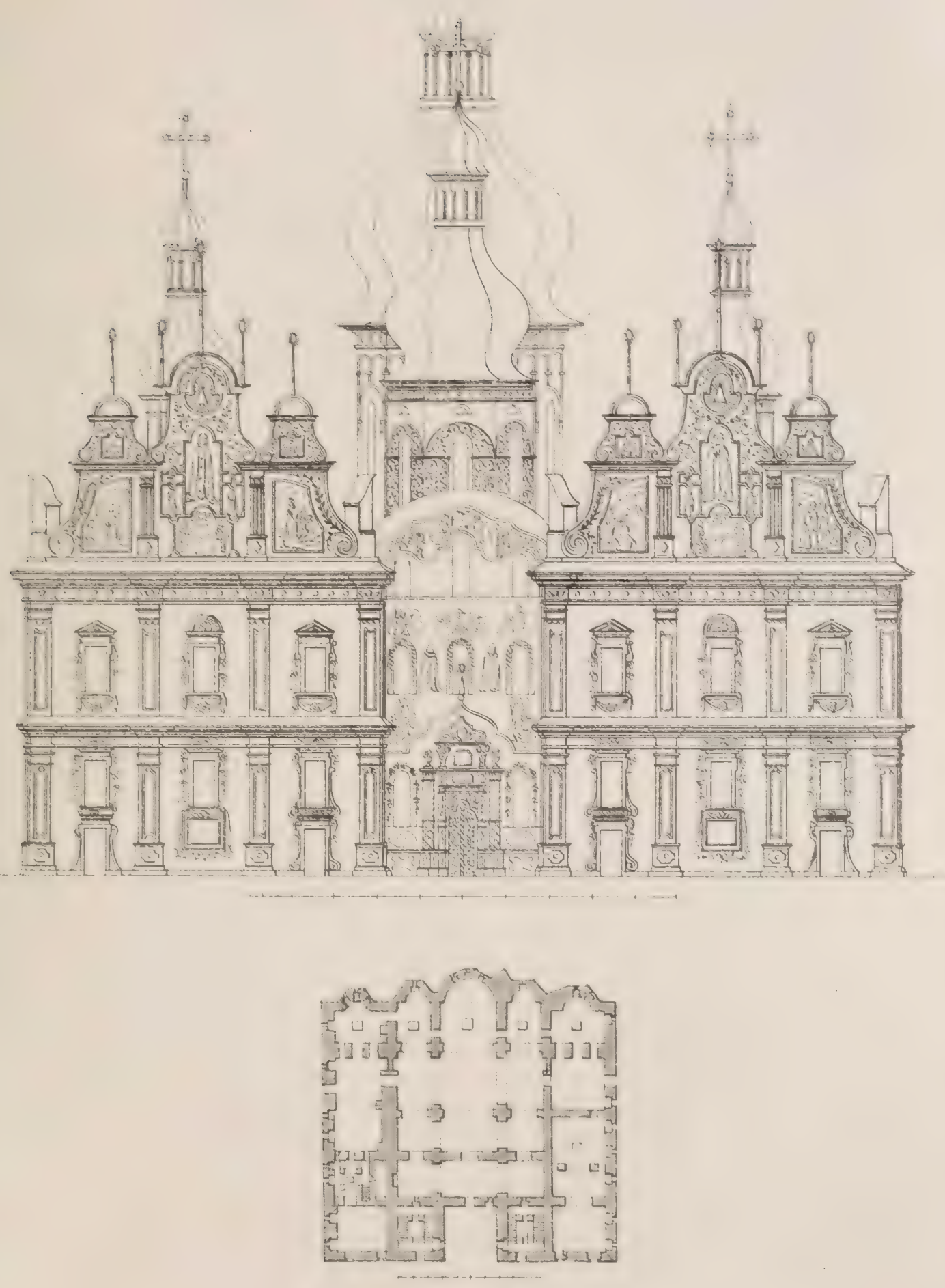

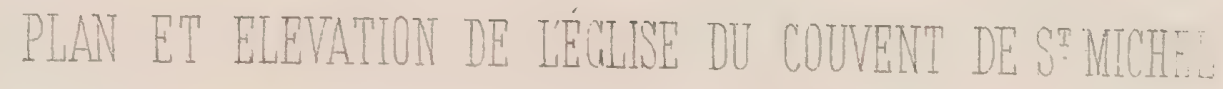





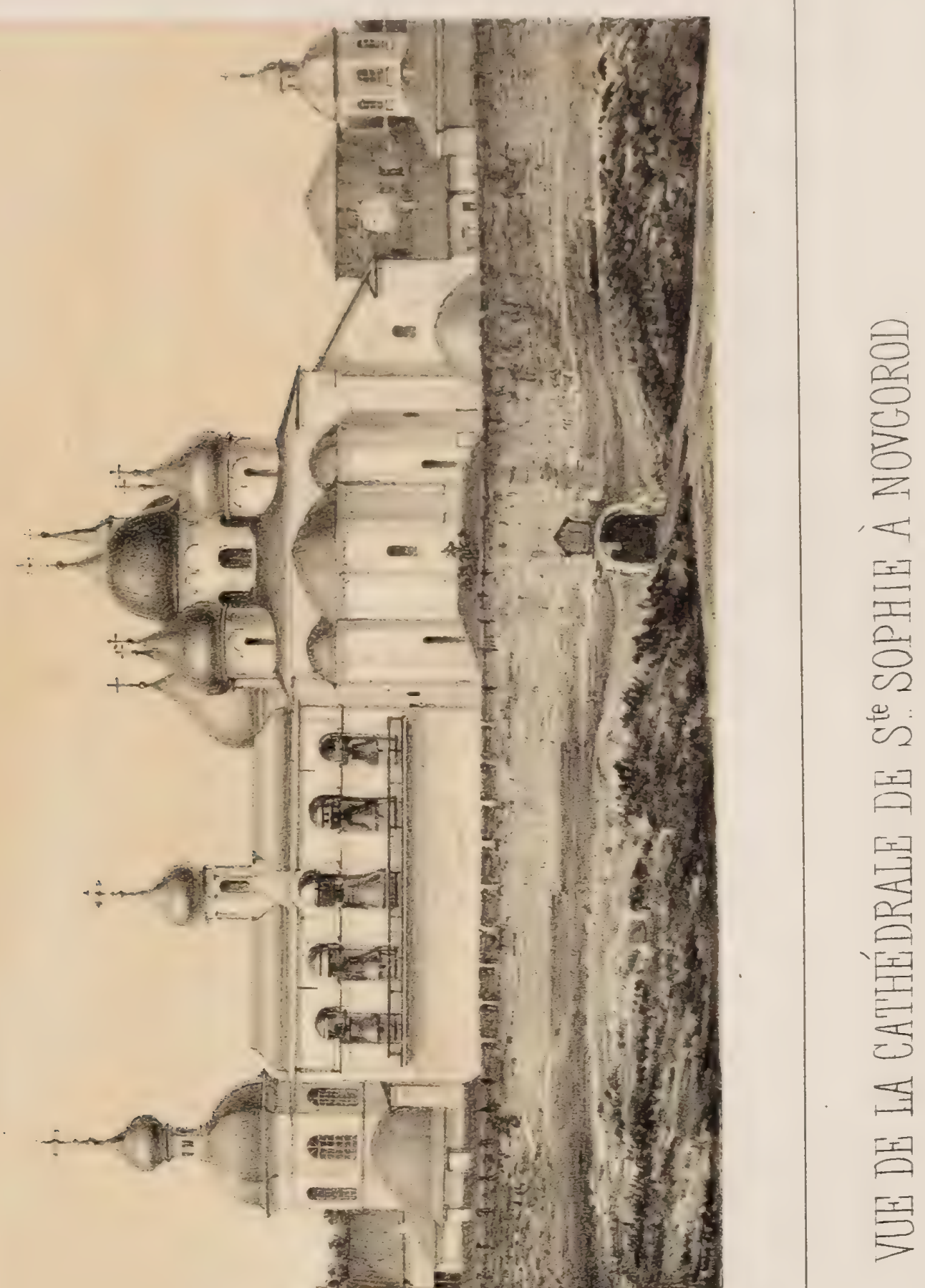





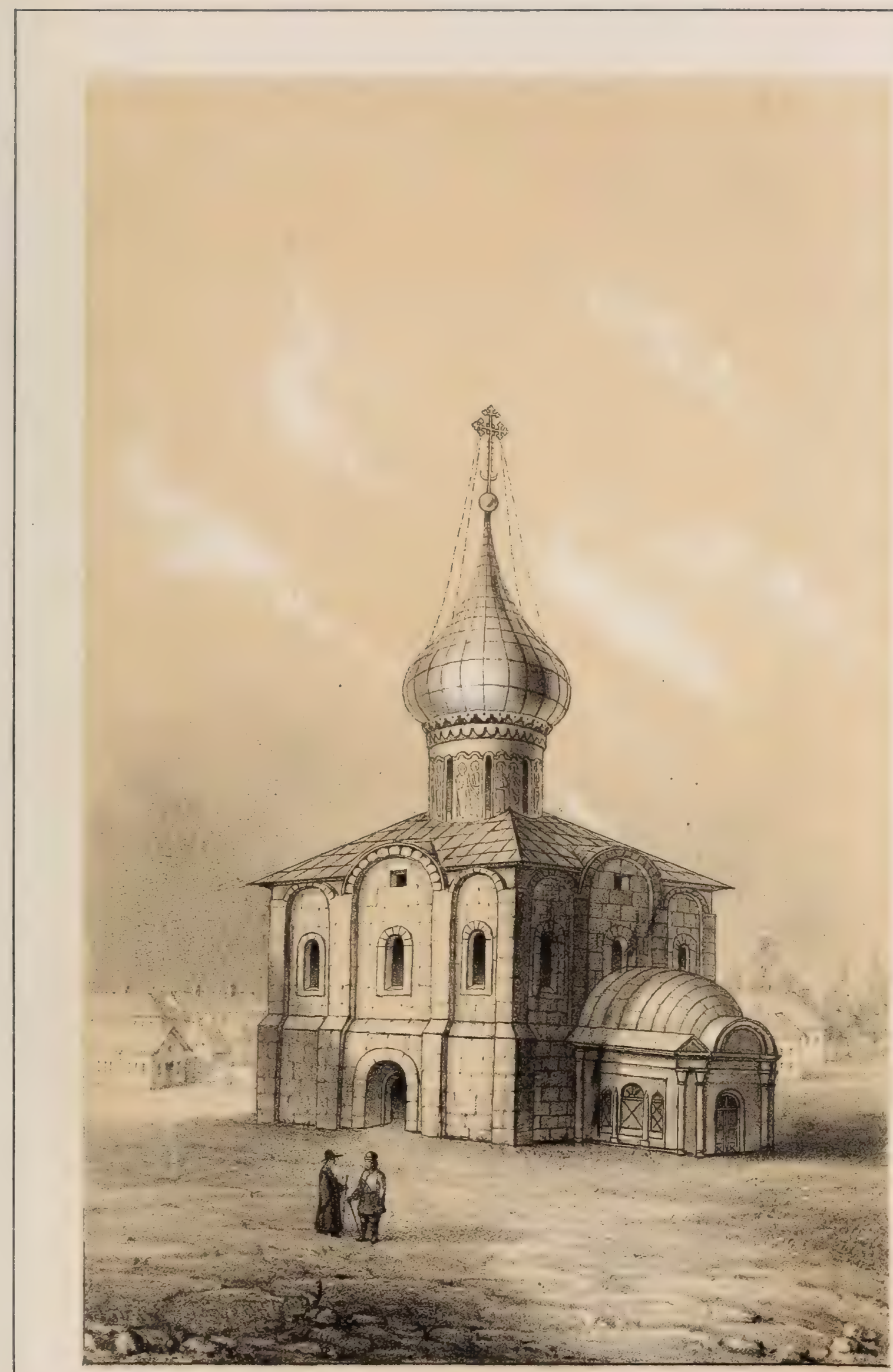

CATHEDRALE DE LA TRANSFIGURATTON

A PFRTASLAVI - TIALESSKYY 



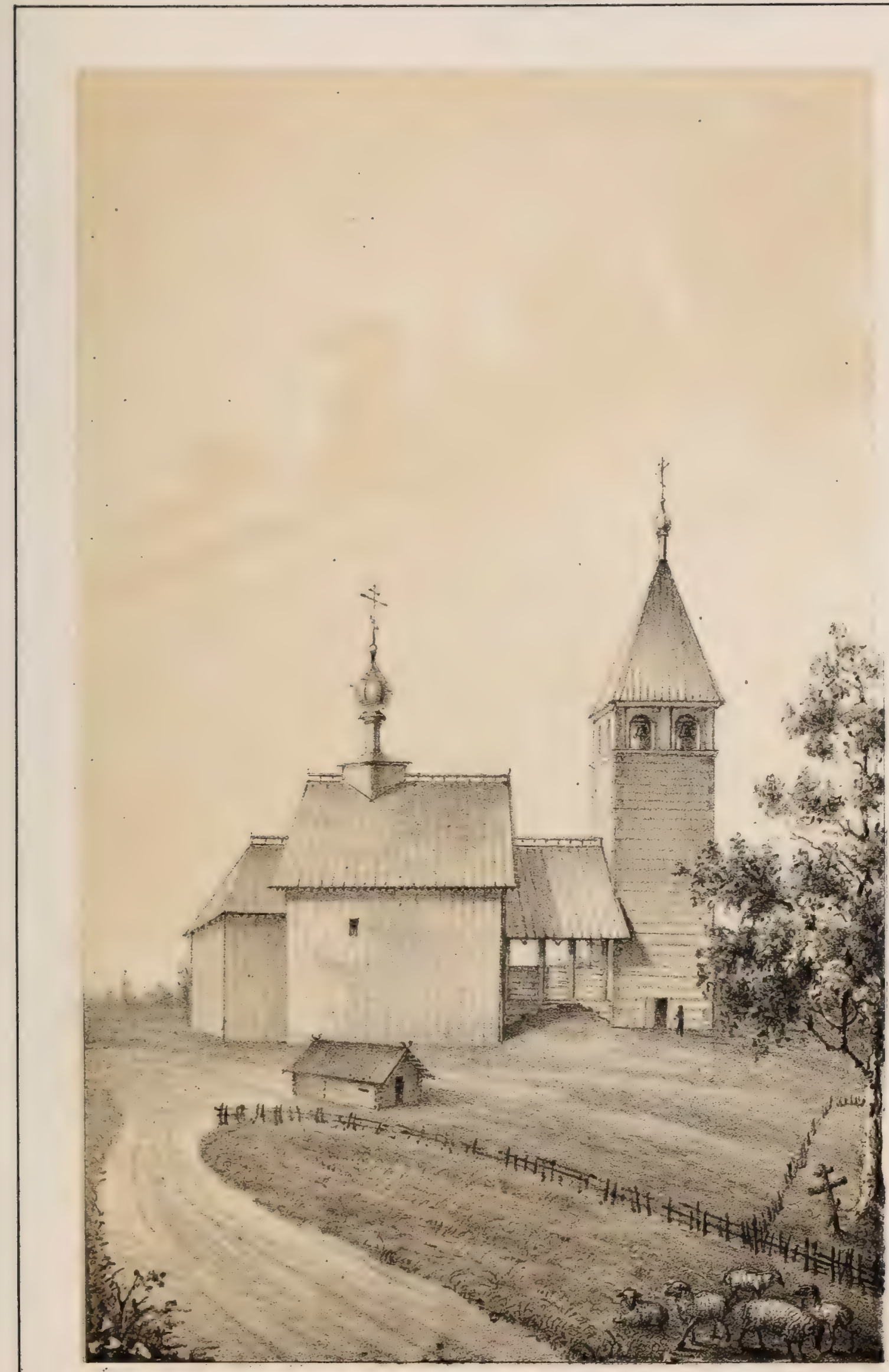

EGLISE DE SE NICOLAS

ENTRE SOUDOGDA ET MOUROM. 



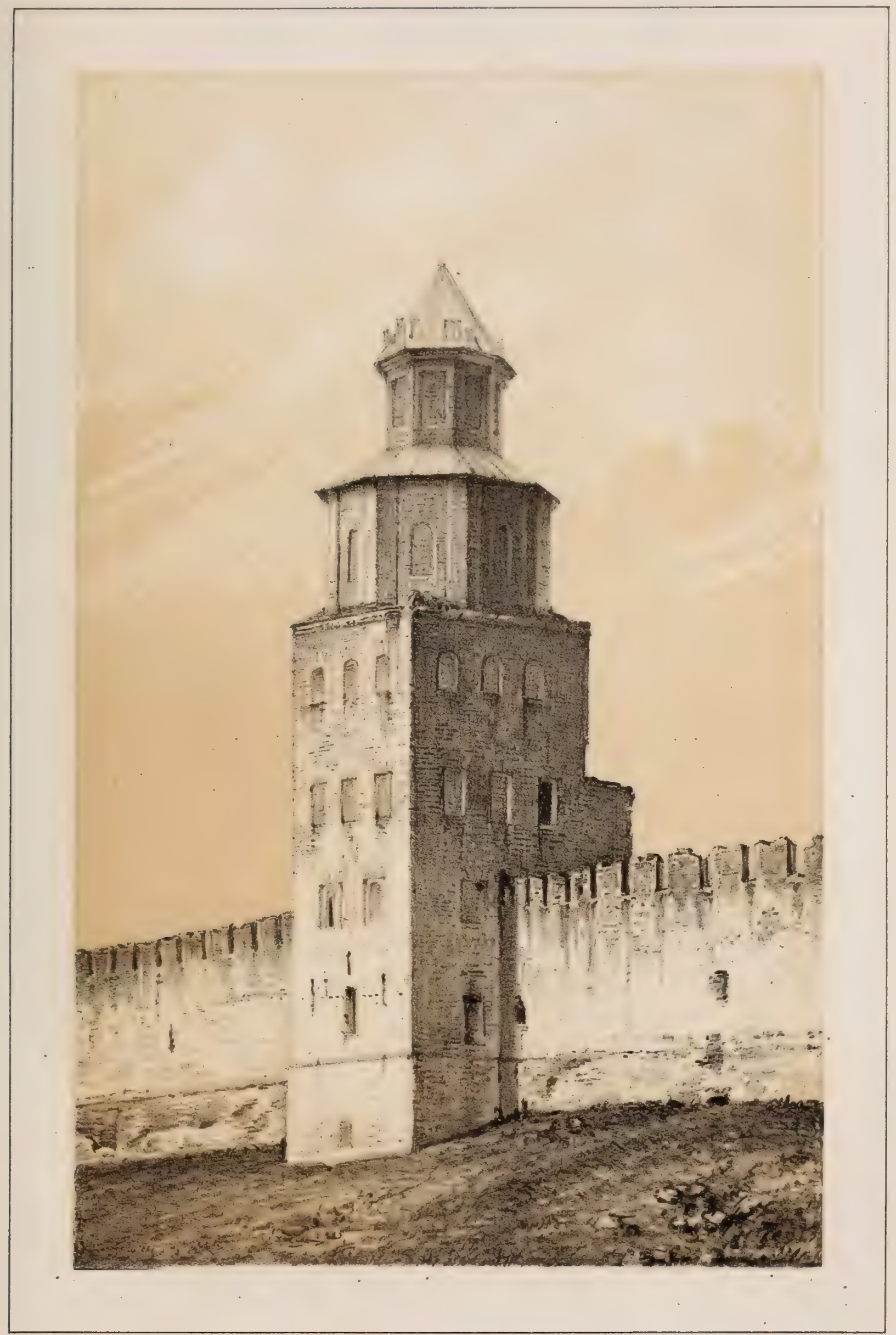

TOJR DE LA FORTERESSE DE NOVGOROD 



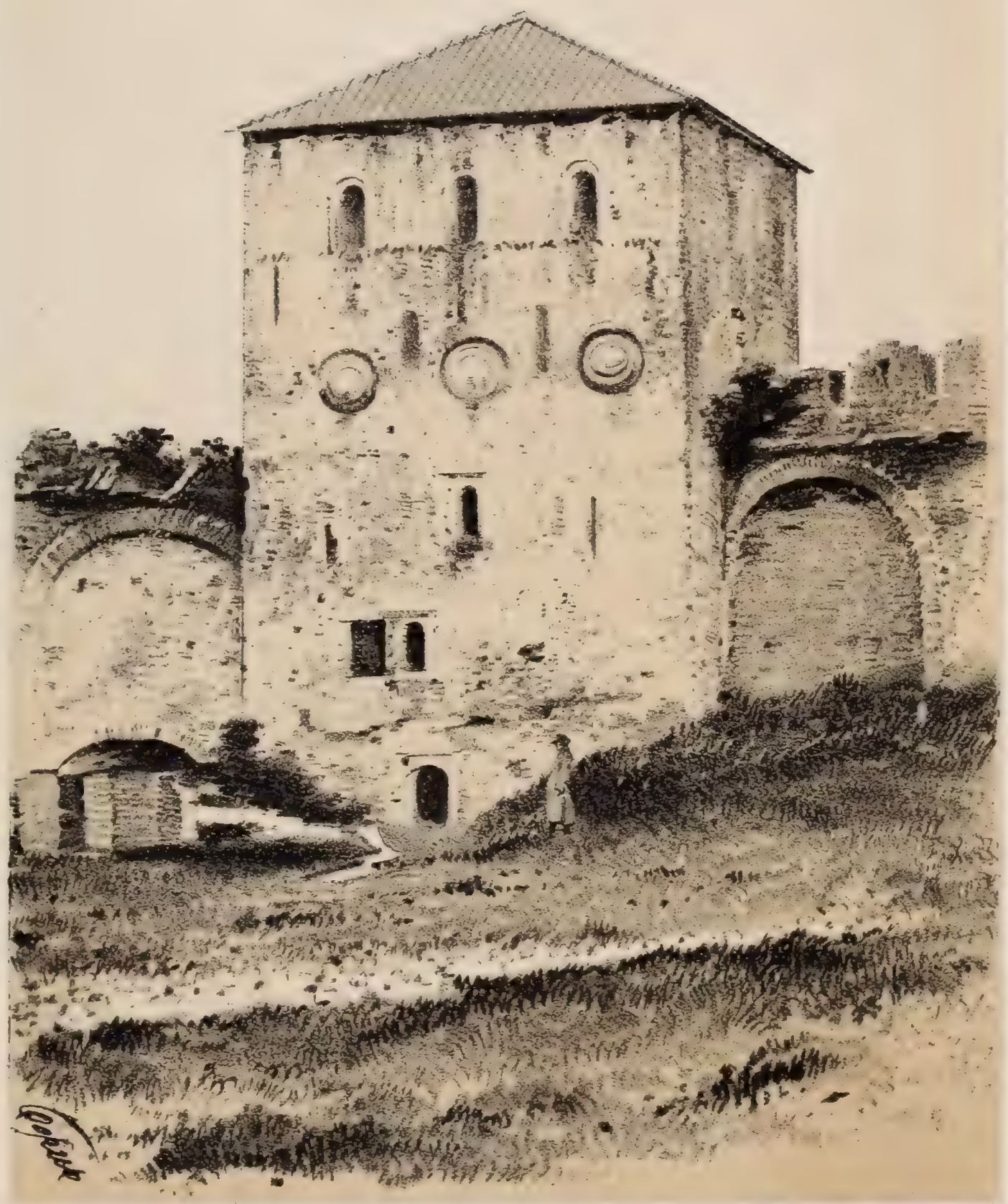





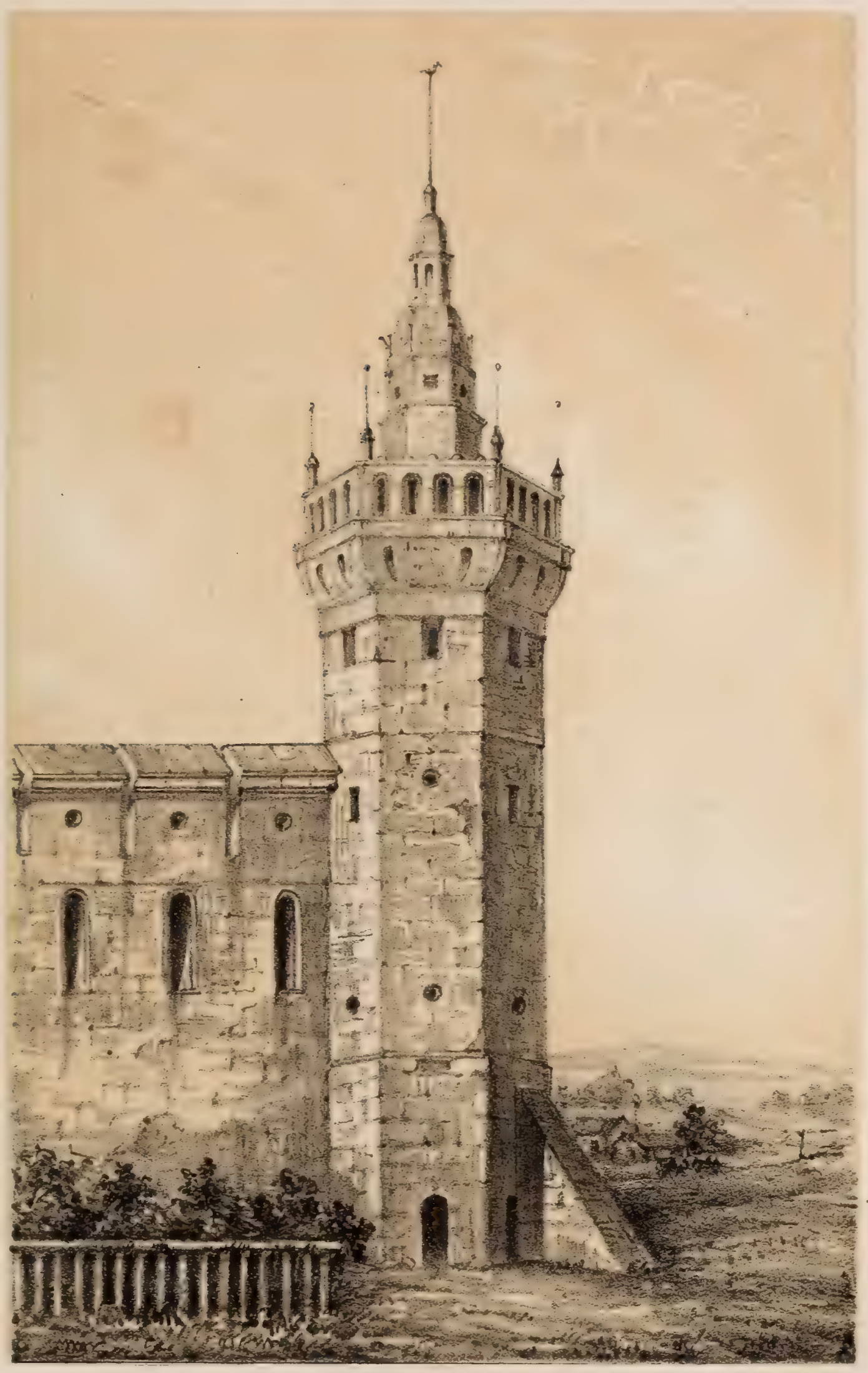

TOUR DE LENCEINTE DU COUVENT DE SE SERGR

A TROTTZA, PRES DE MOSCOU. 



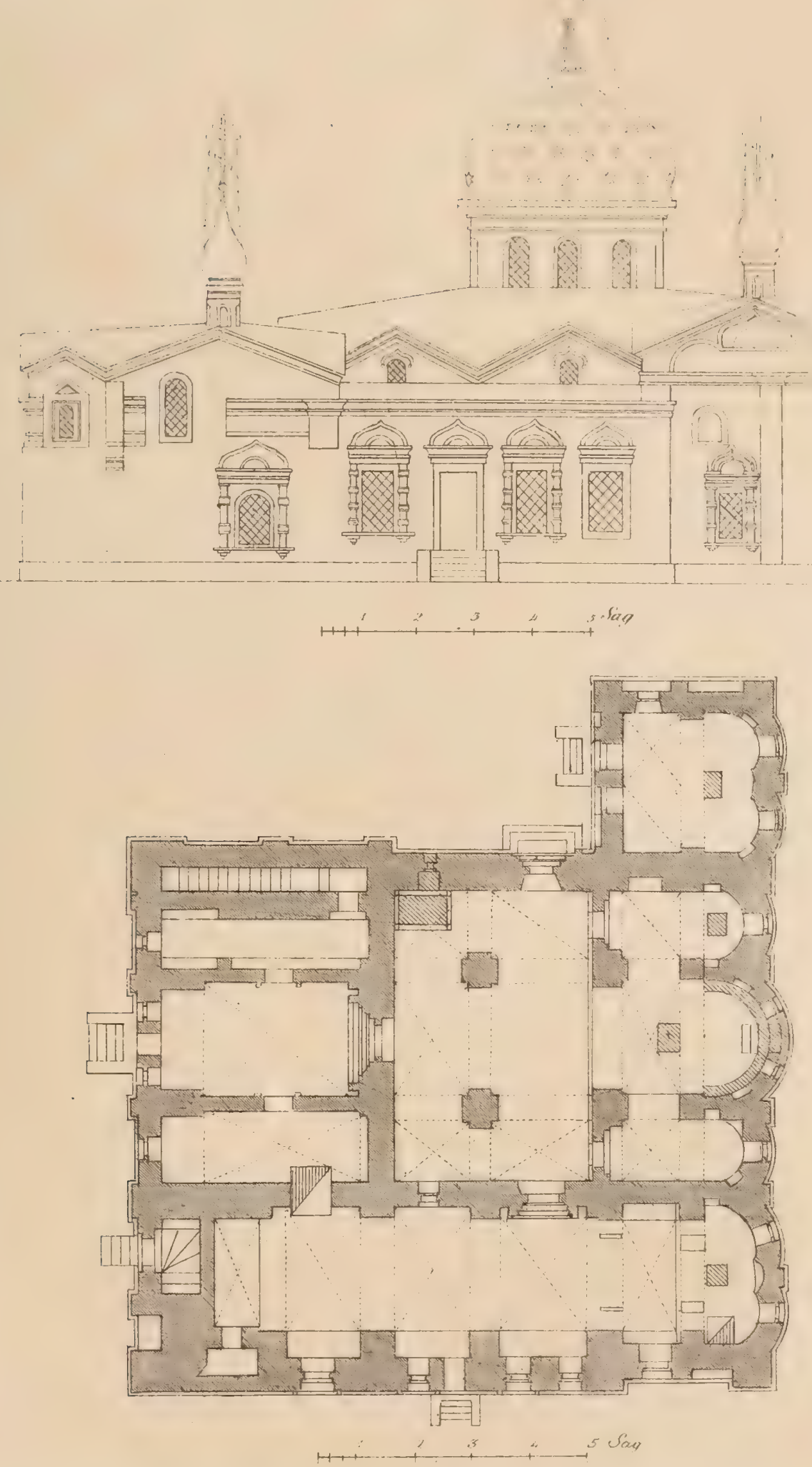

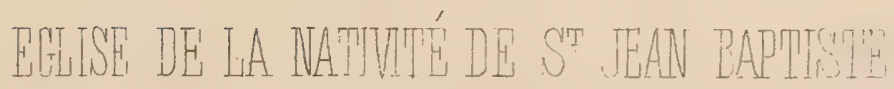

A MOSGGOT. 



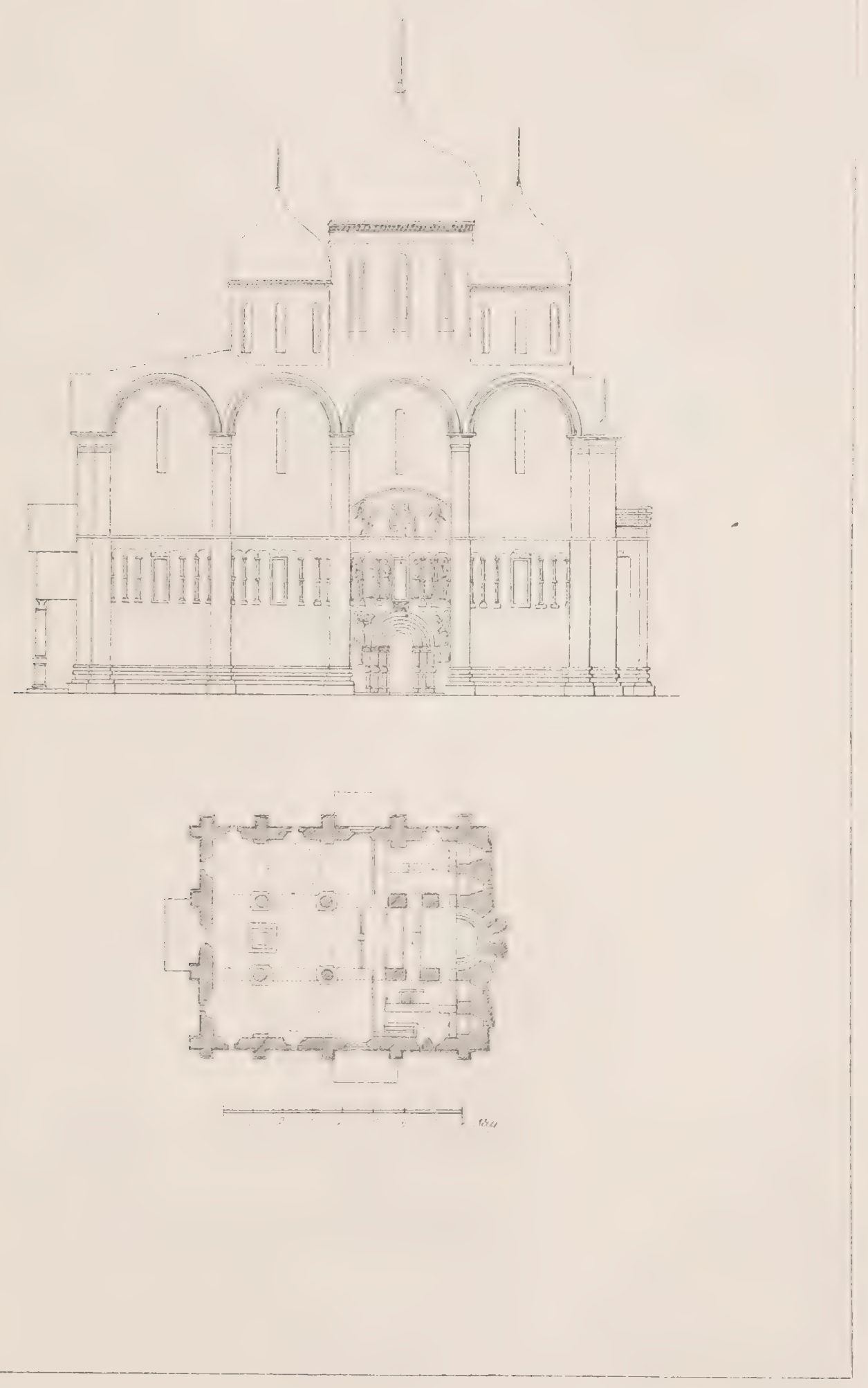

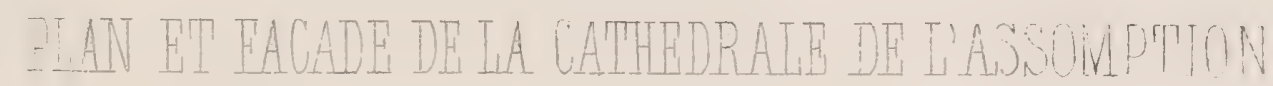





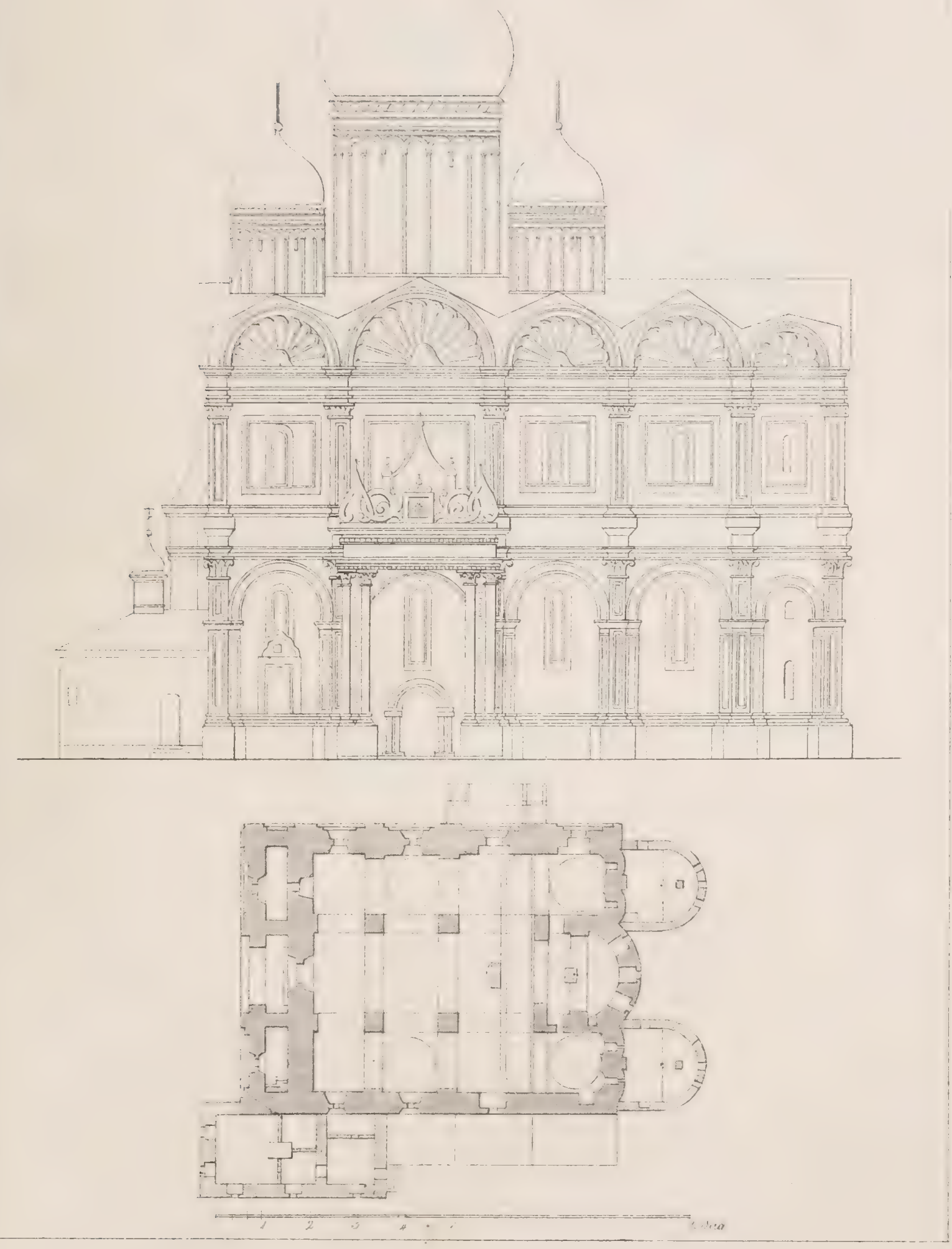

PTAN ET FACADE DE IA CATHEJRATE DE LARCHANGE MTCHEL 


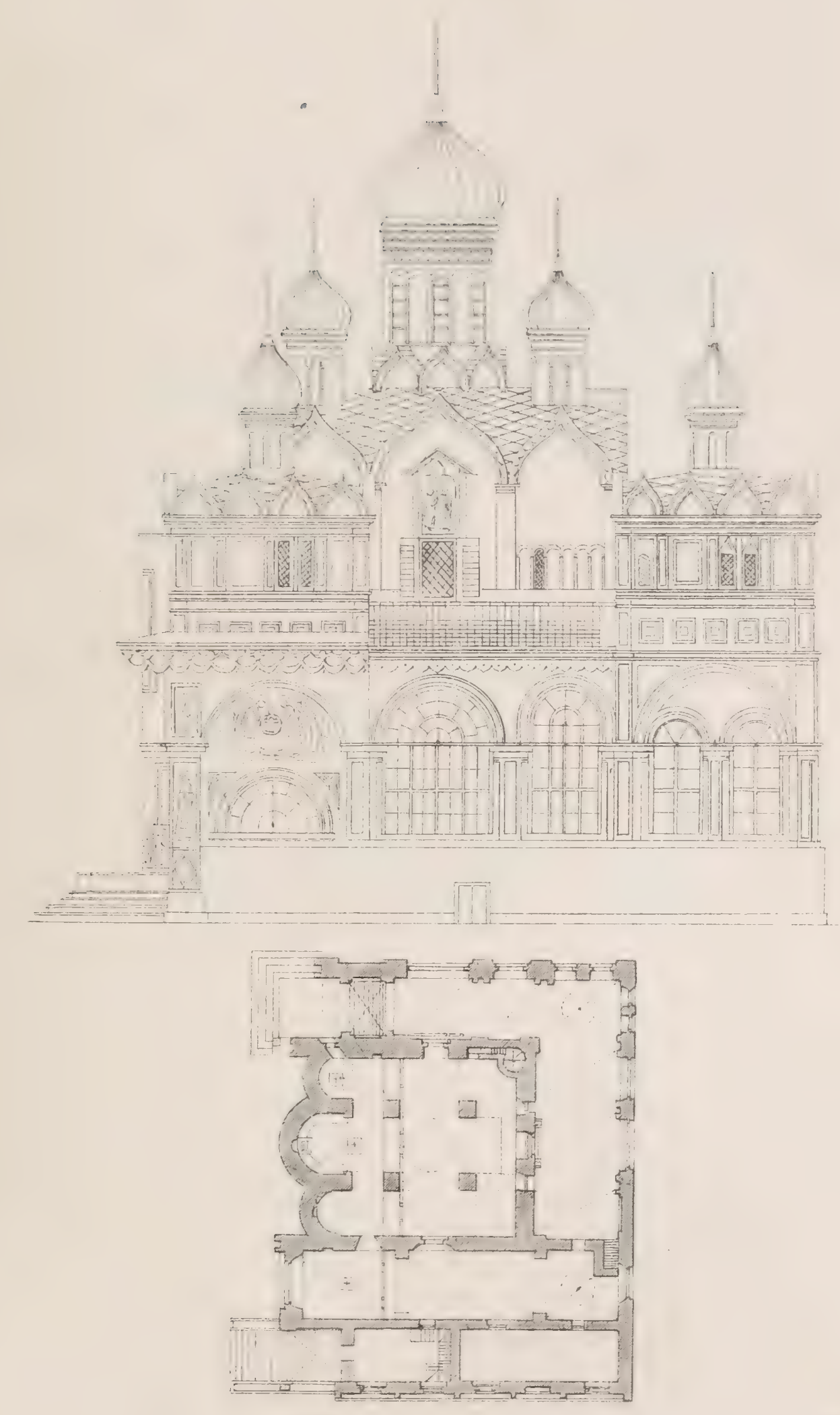

(

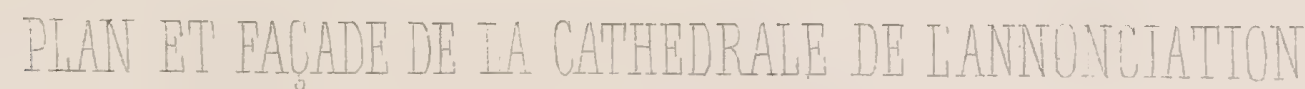

A Moscot 


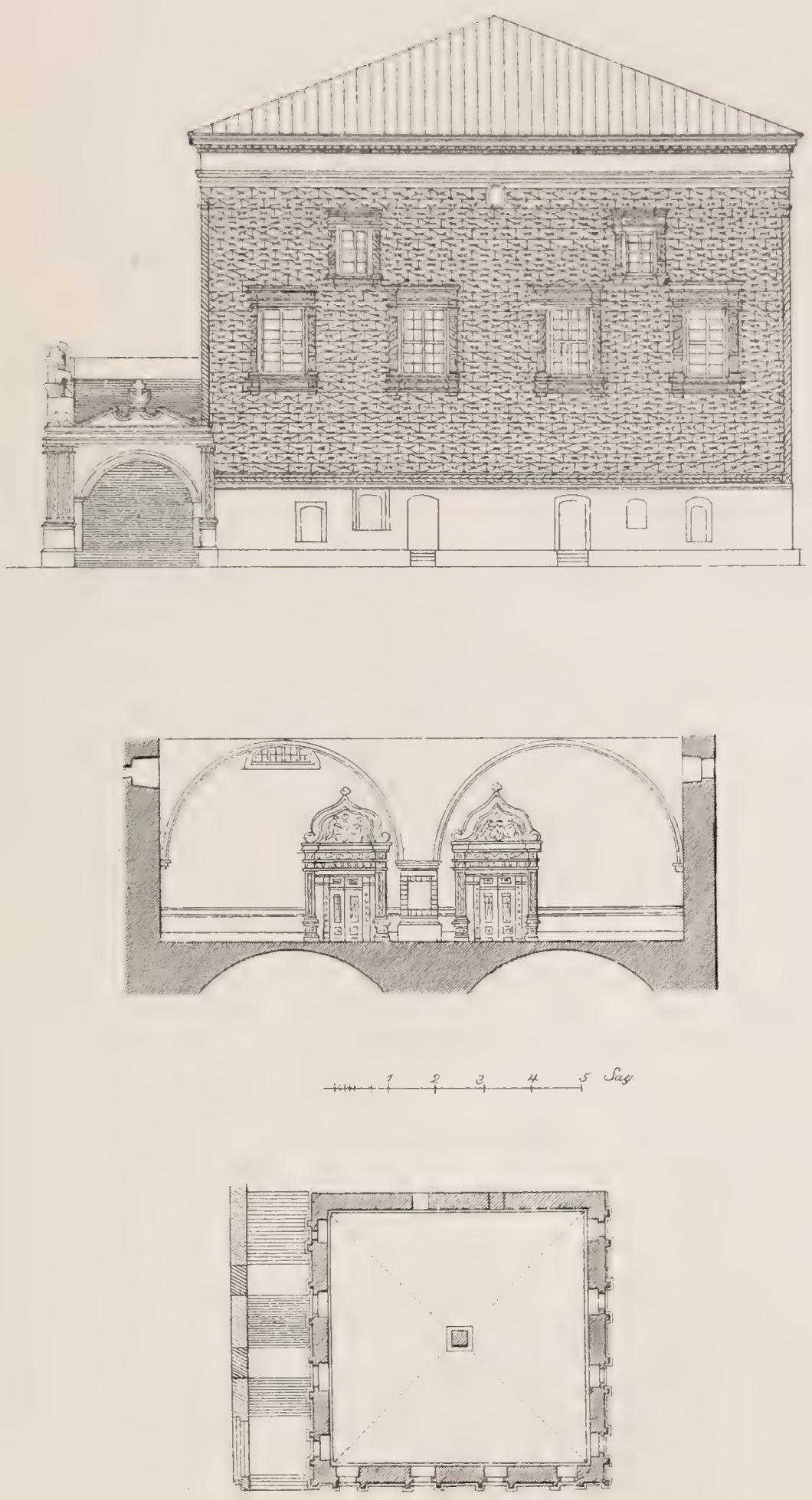

$+1+1345$ iag.

GRANOVITAPA FALATA OU GRANDE CHAMBRE JE PIERTE A MOSCOU,

CONNTRUITE EN 1840 


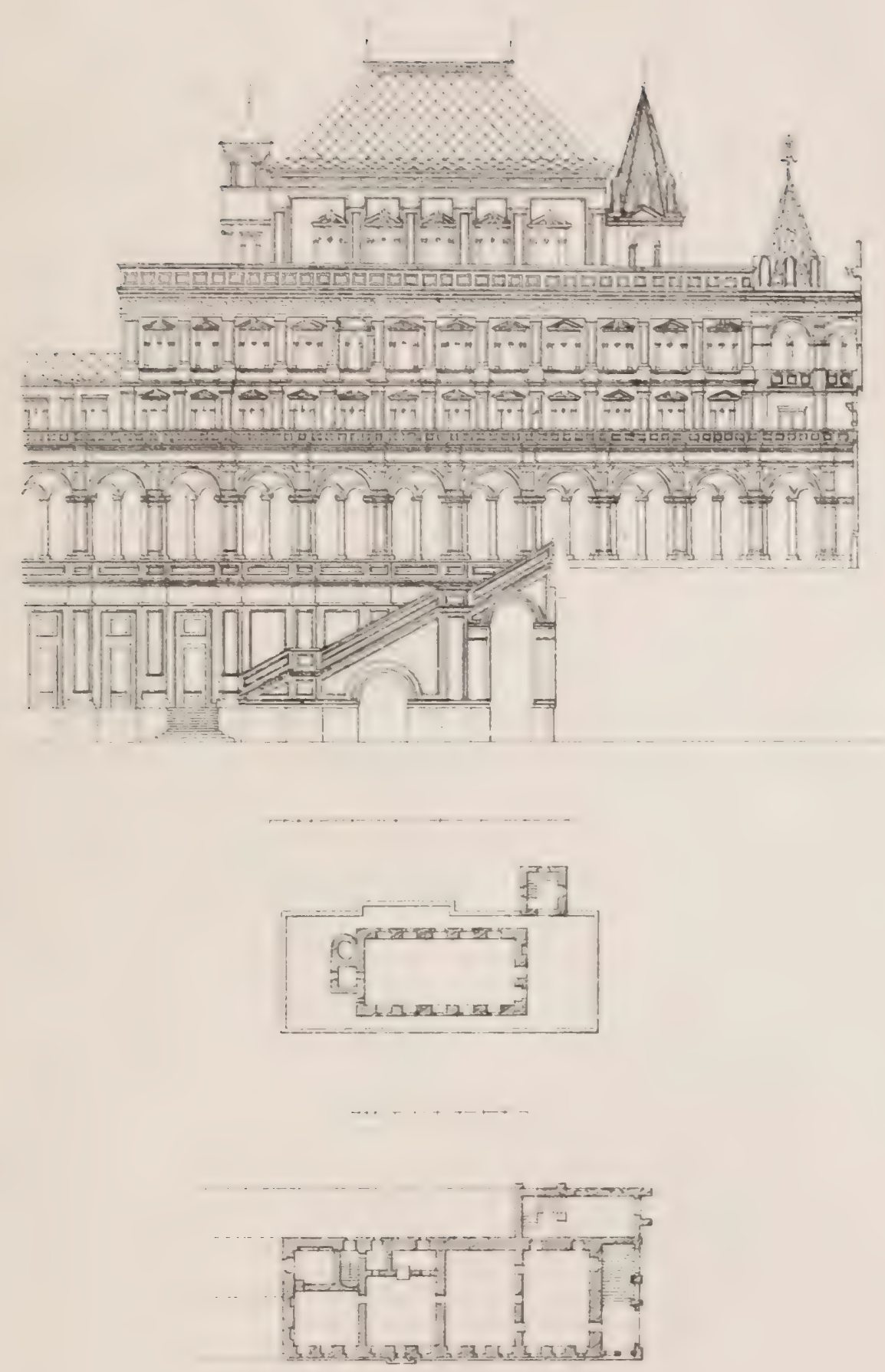



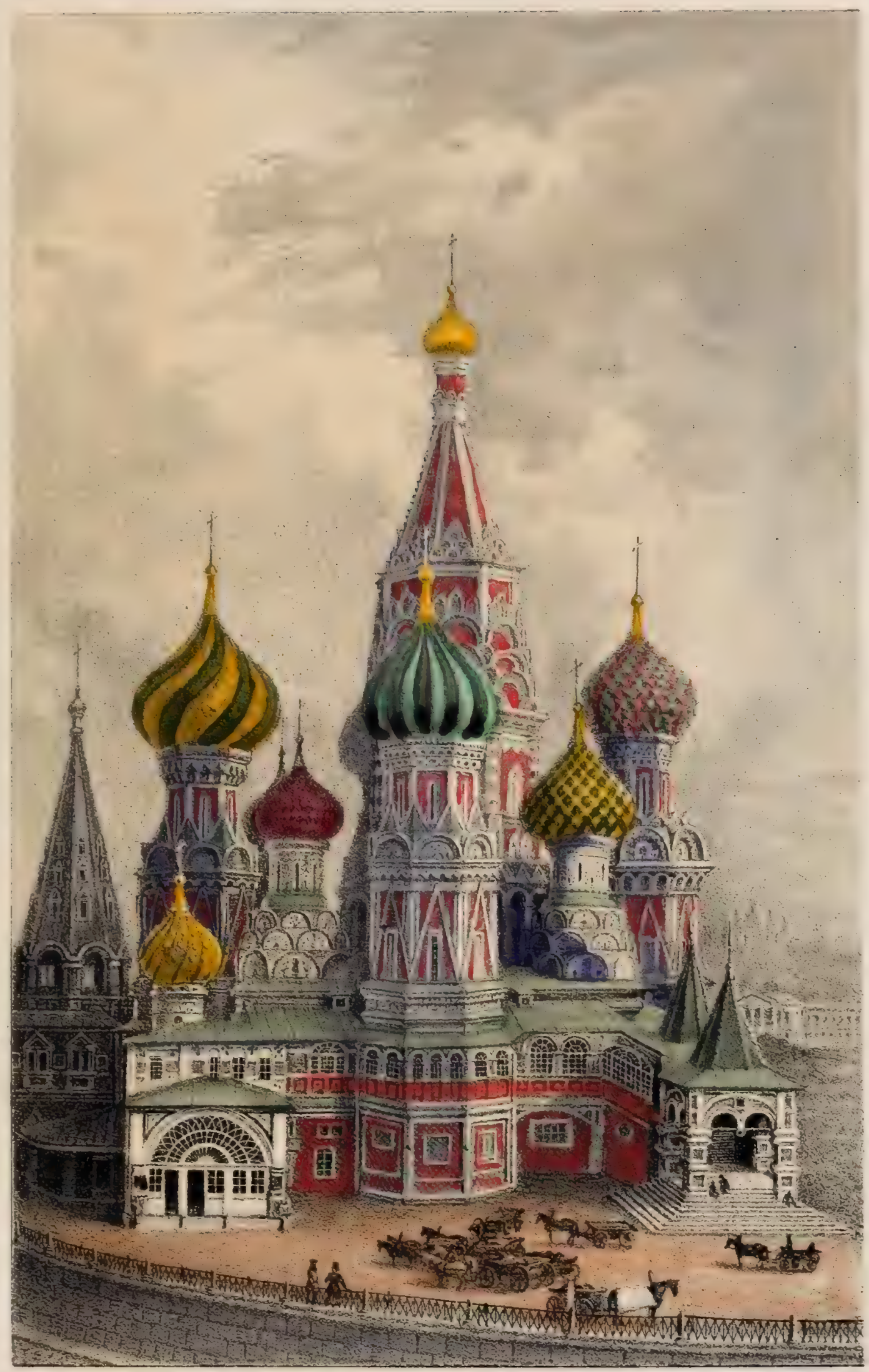

EGISE DE ST BASILE LE BIENHEUTREJX

(Vassily Biaćénnoy) A MOSCOJ 



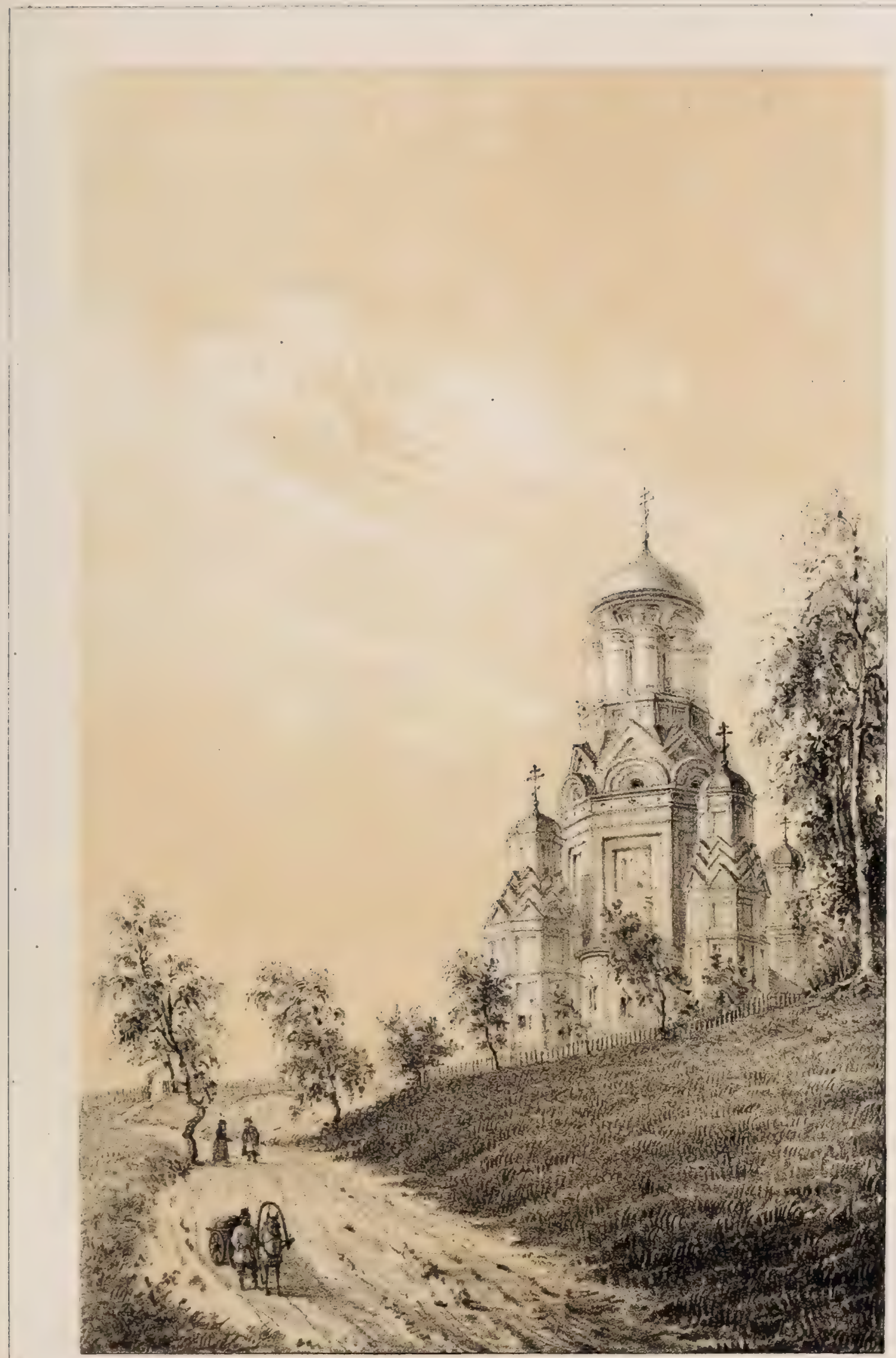

EGIISE DE LA DECOLLATTON DE SE JEAN BAPTISTE AU VILJAGE DIAKOVO, PRESS DE MOSCOU 



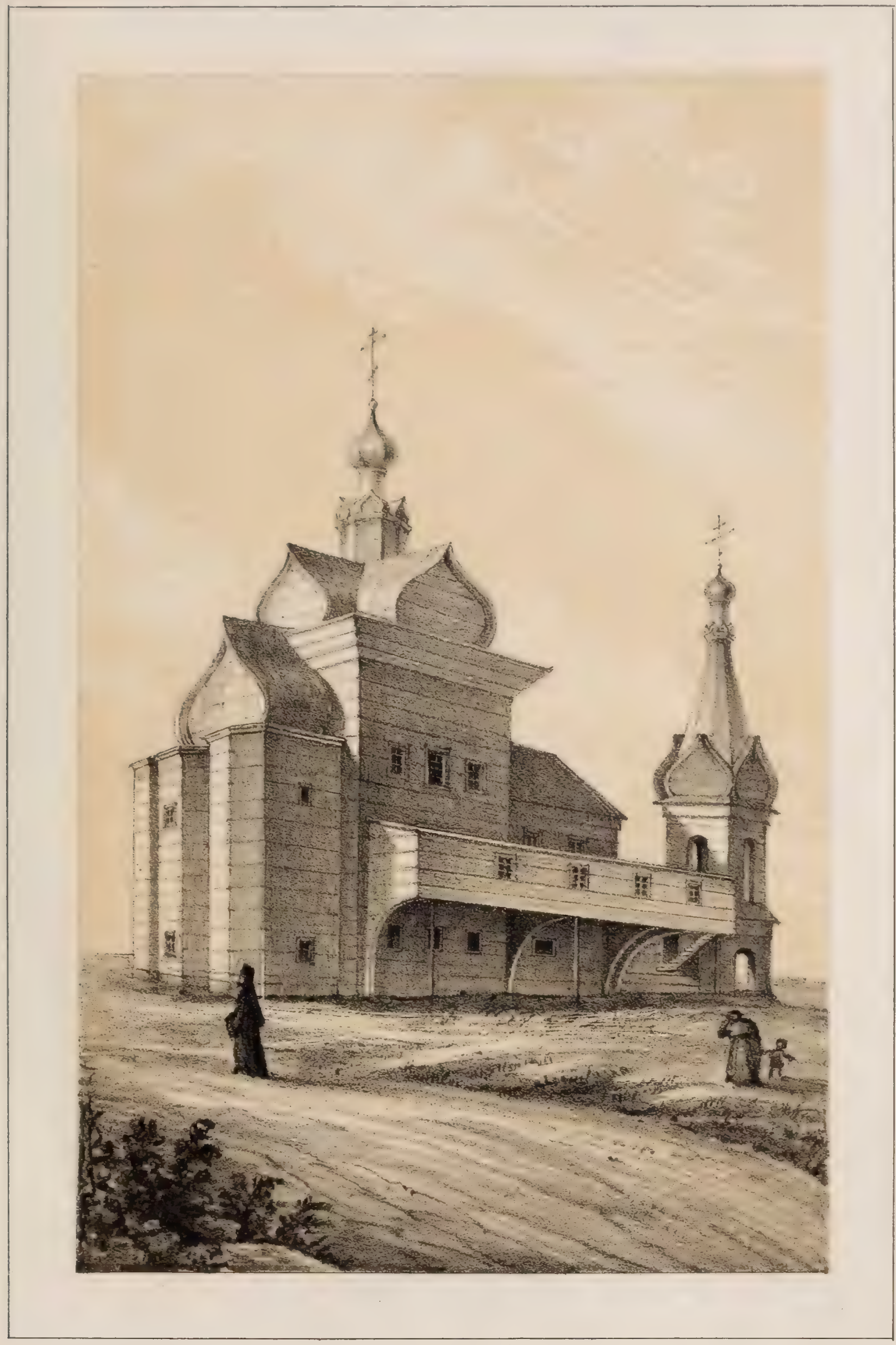

ECLISE DE LERMTTACE DE GETHSENANNE.

PRES DU COUVENT DE St SERGE A TROTTZA. 



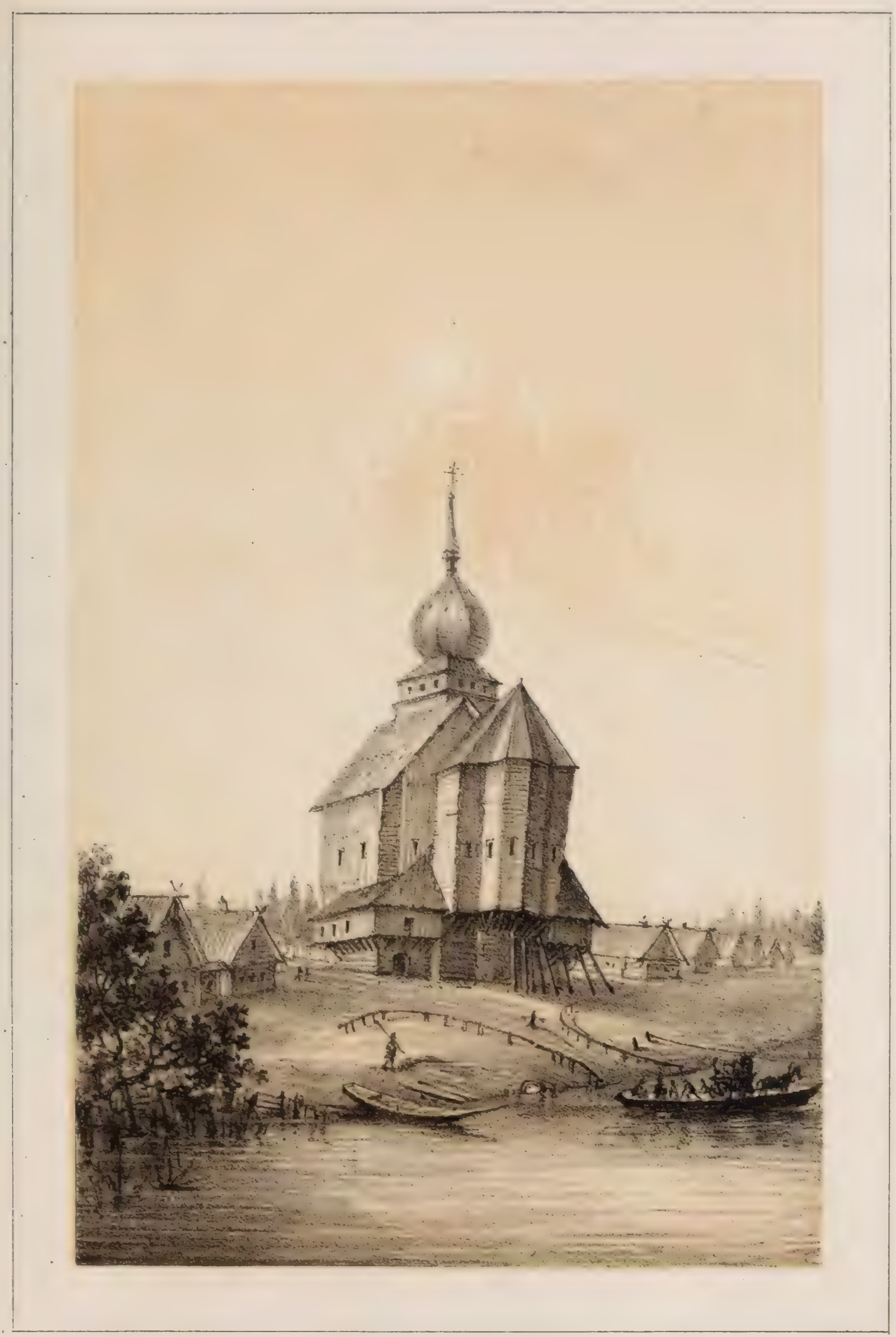

BCLISE SITURE DANS IES ENVIRONS DR LA VILUR DE ROSTOV. 



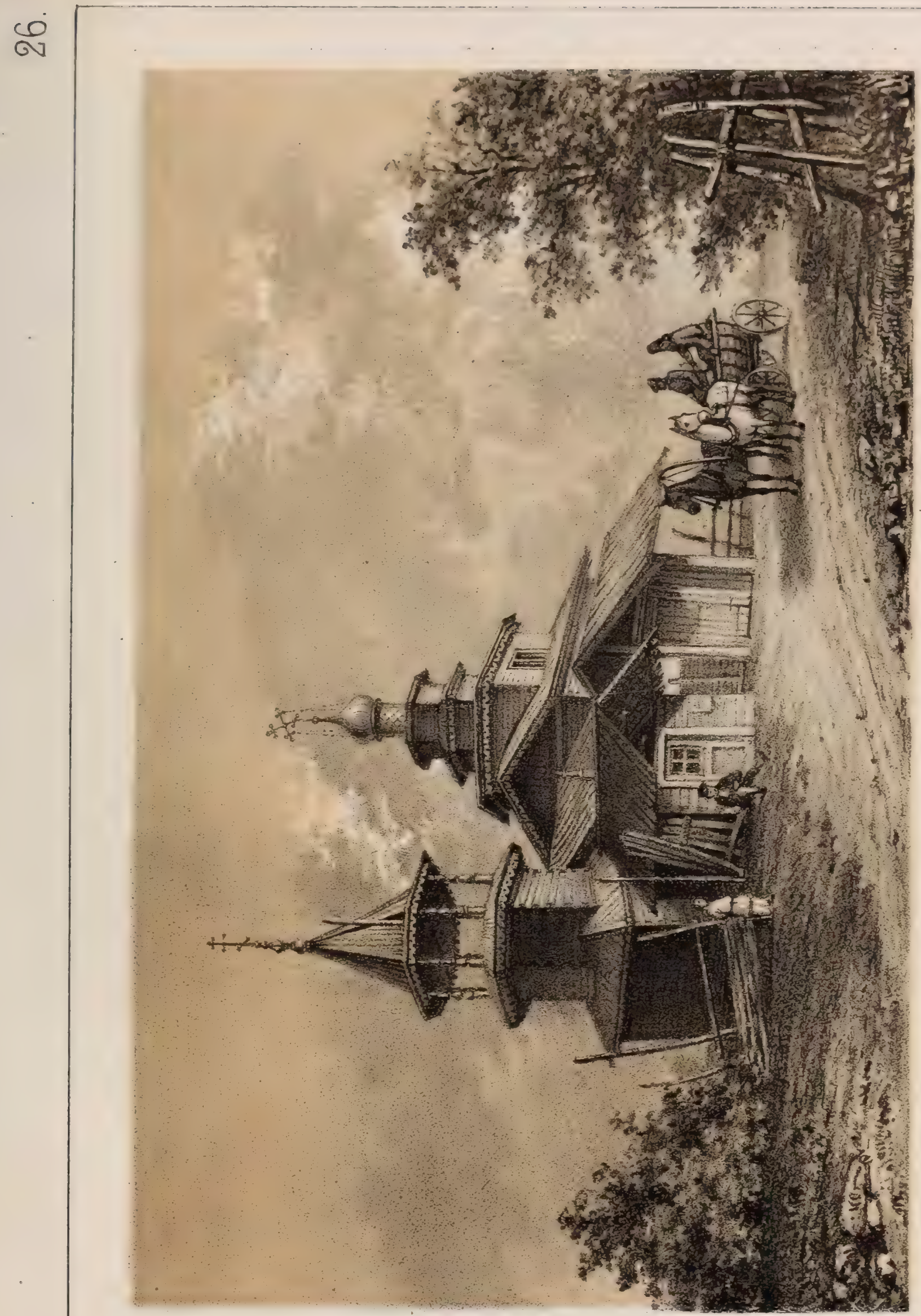




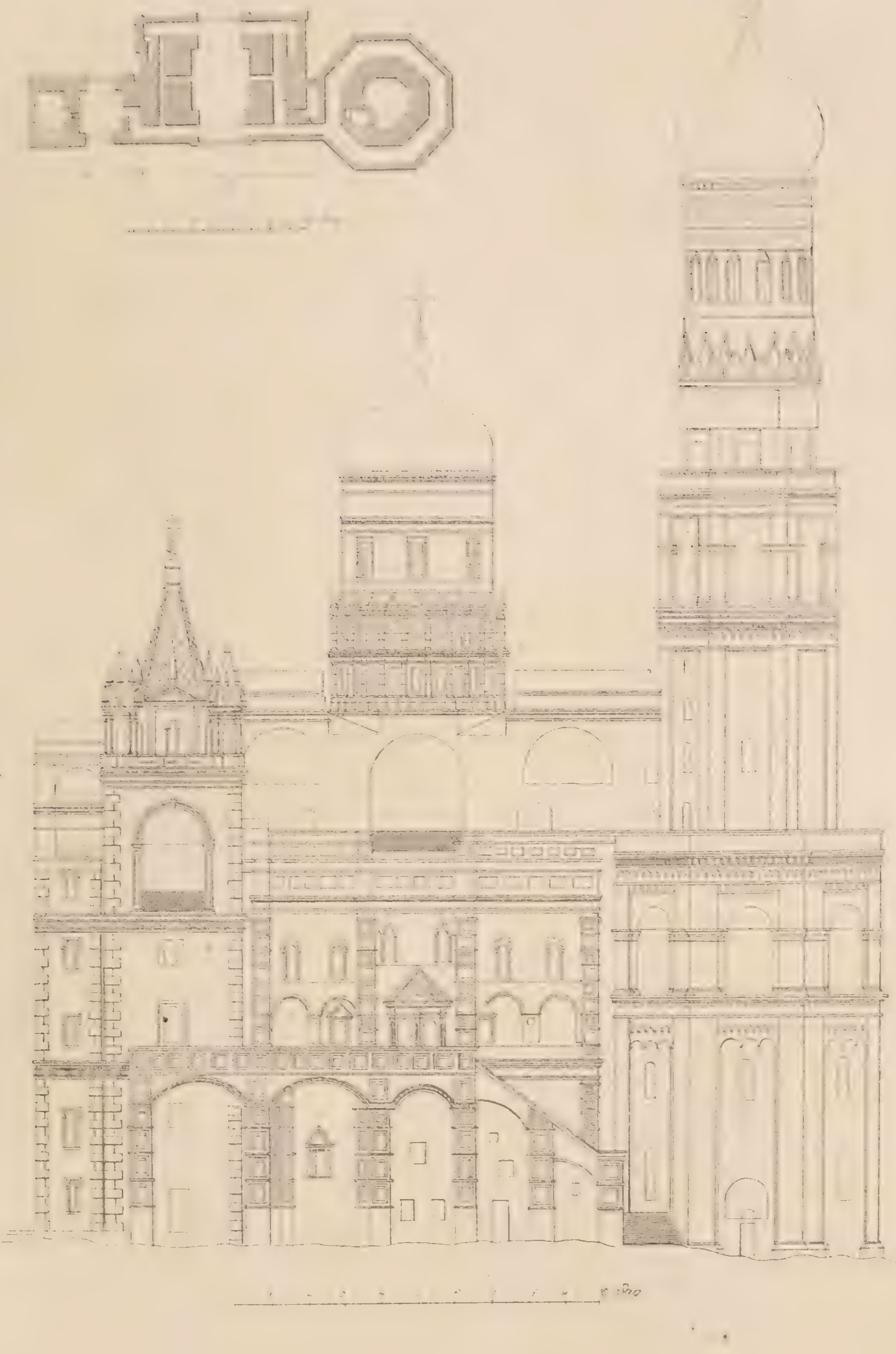

TOUR D'TVAN VBLTKI

AVANT SA RECONSTRUUCTION À TA FIN DU XVII SIECIR 



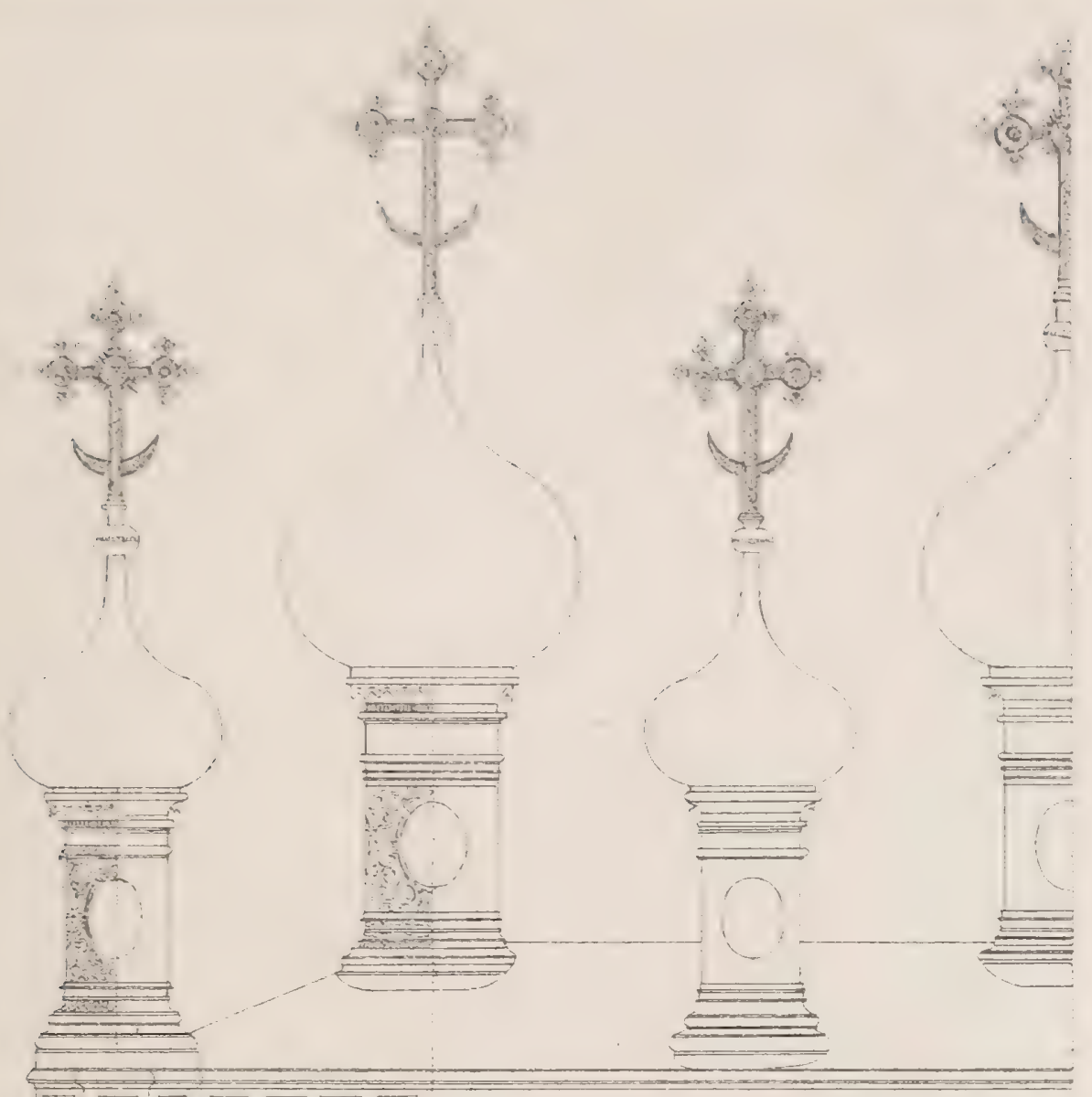

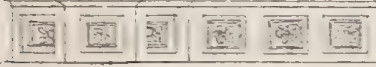

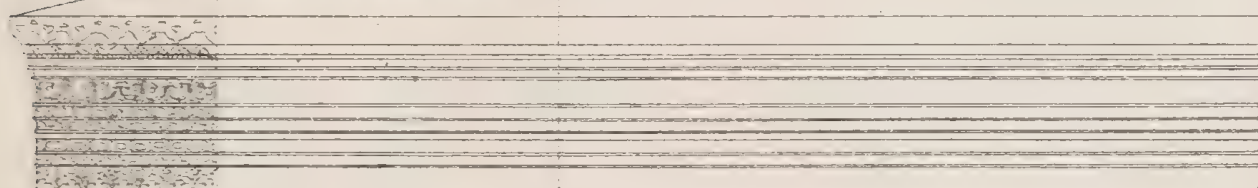

$=2 x^{2}+3$
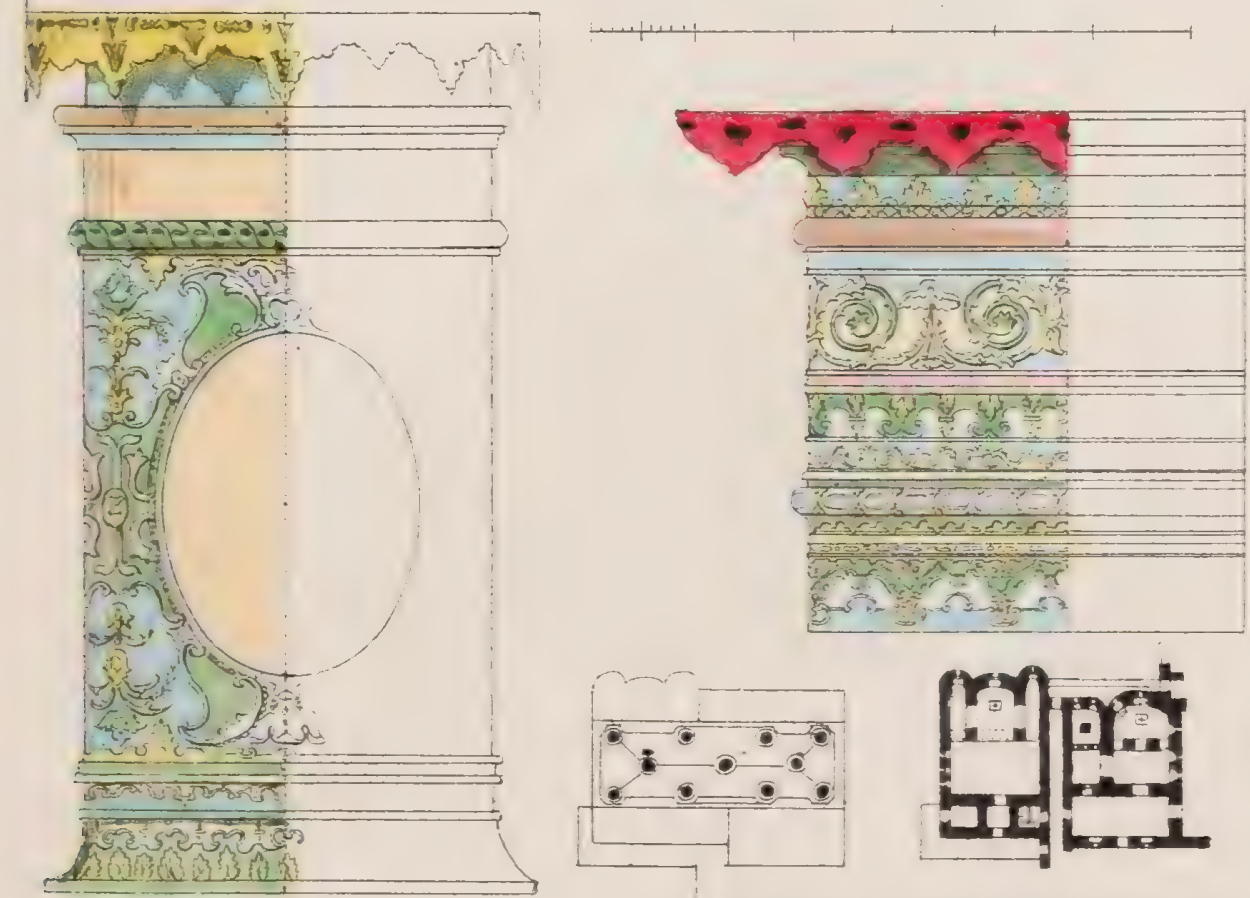

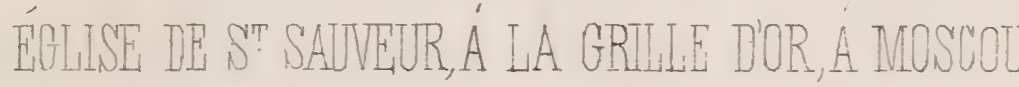



จู

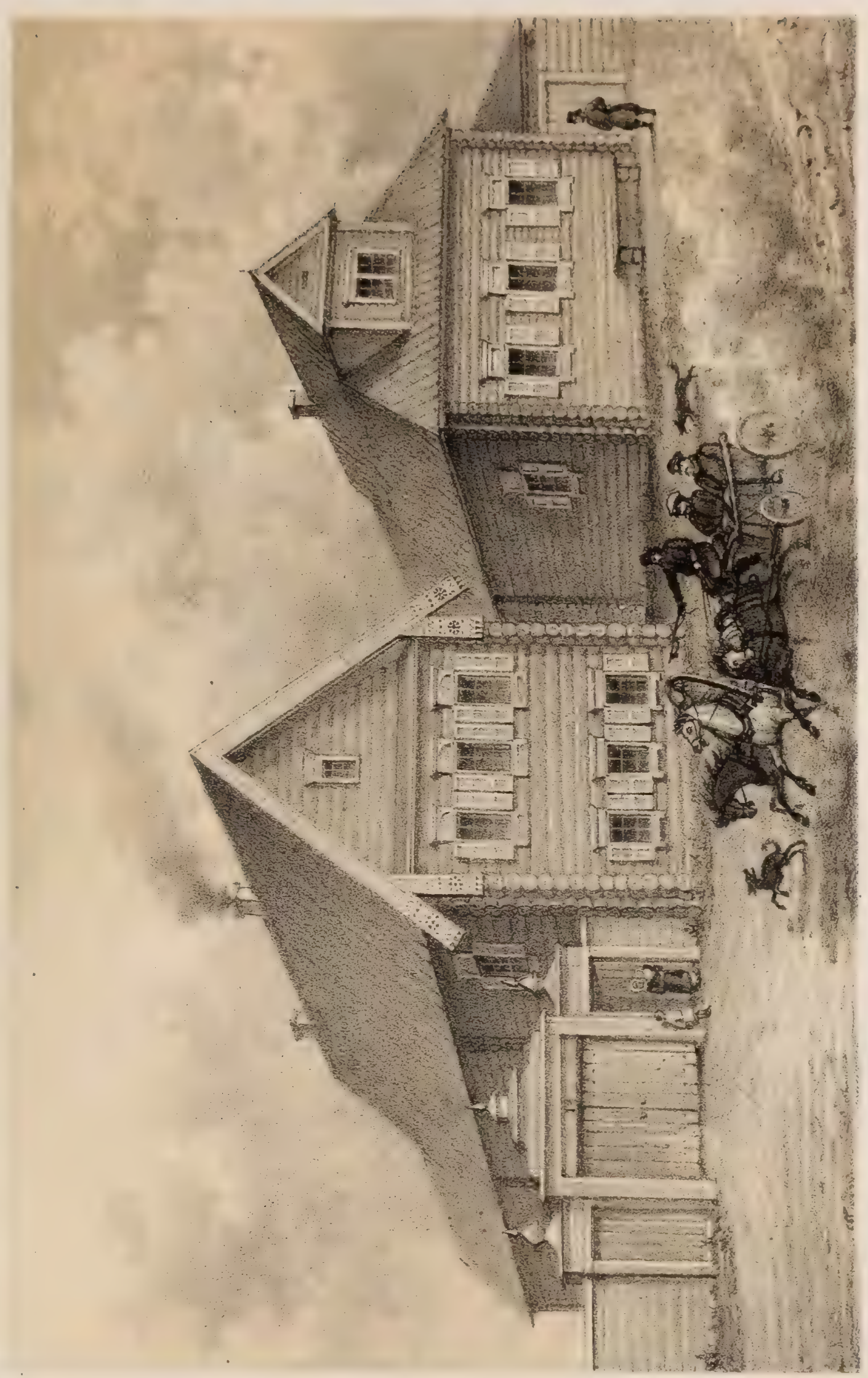

Ex
02
$0 \Omega$
$\square$
$\square$

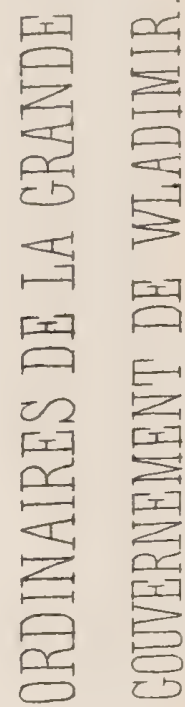

2
2
$z$ 

ले

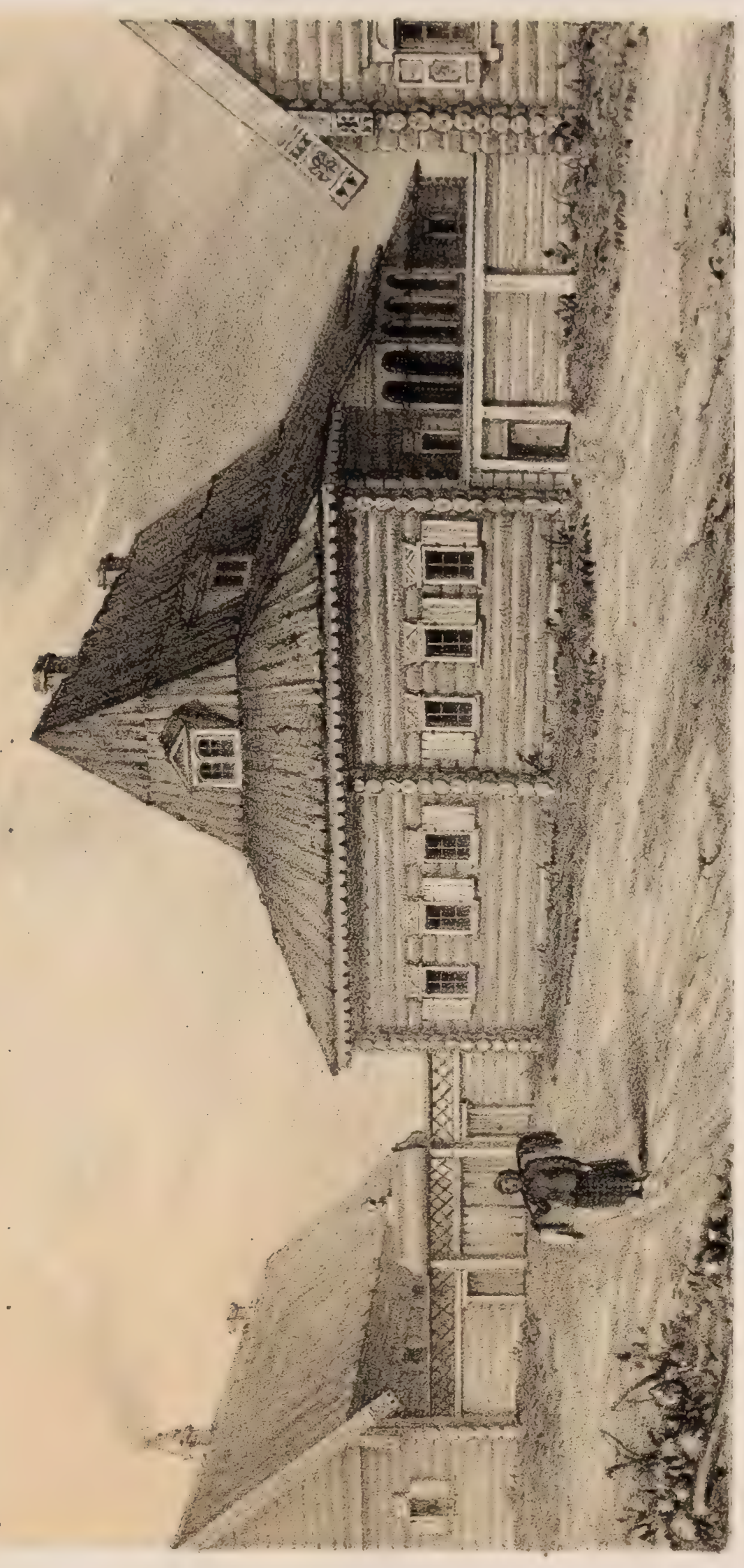

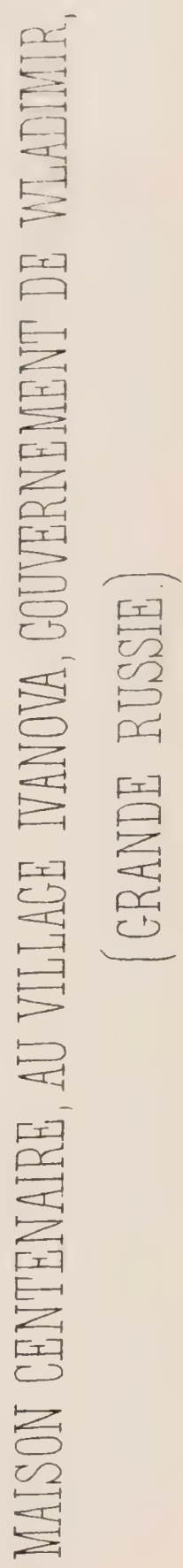





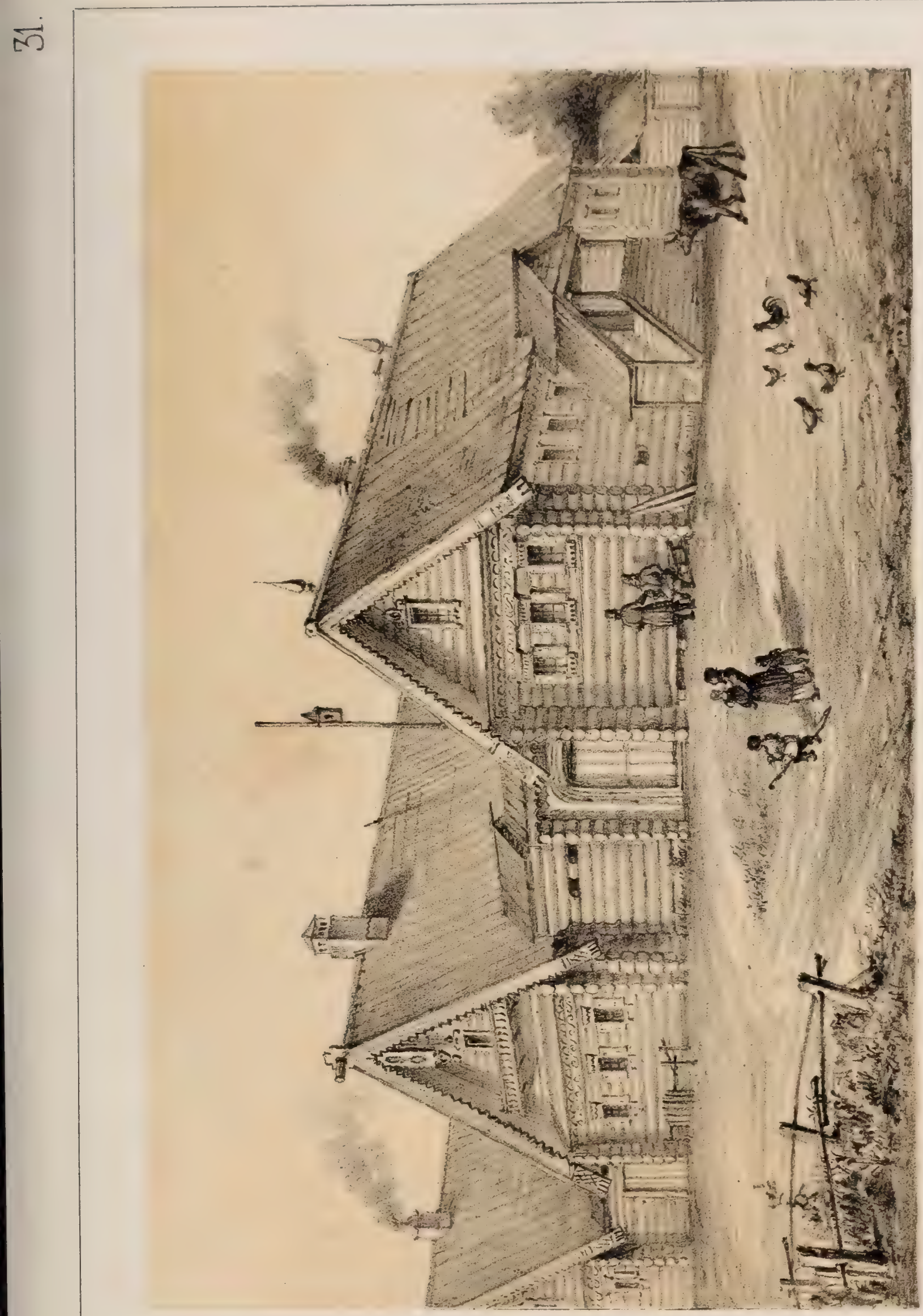

送 

จำ

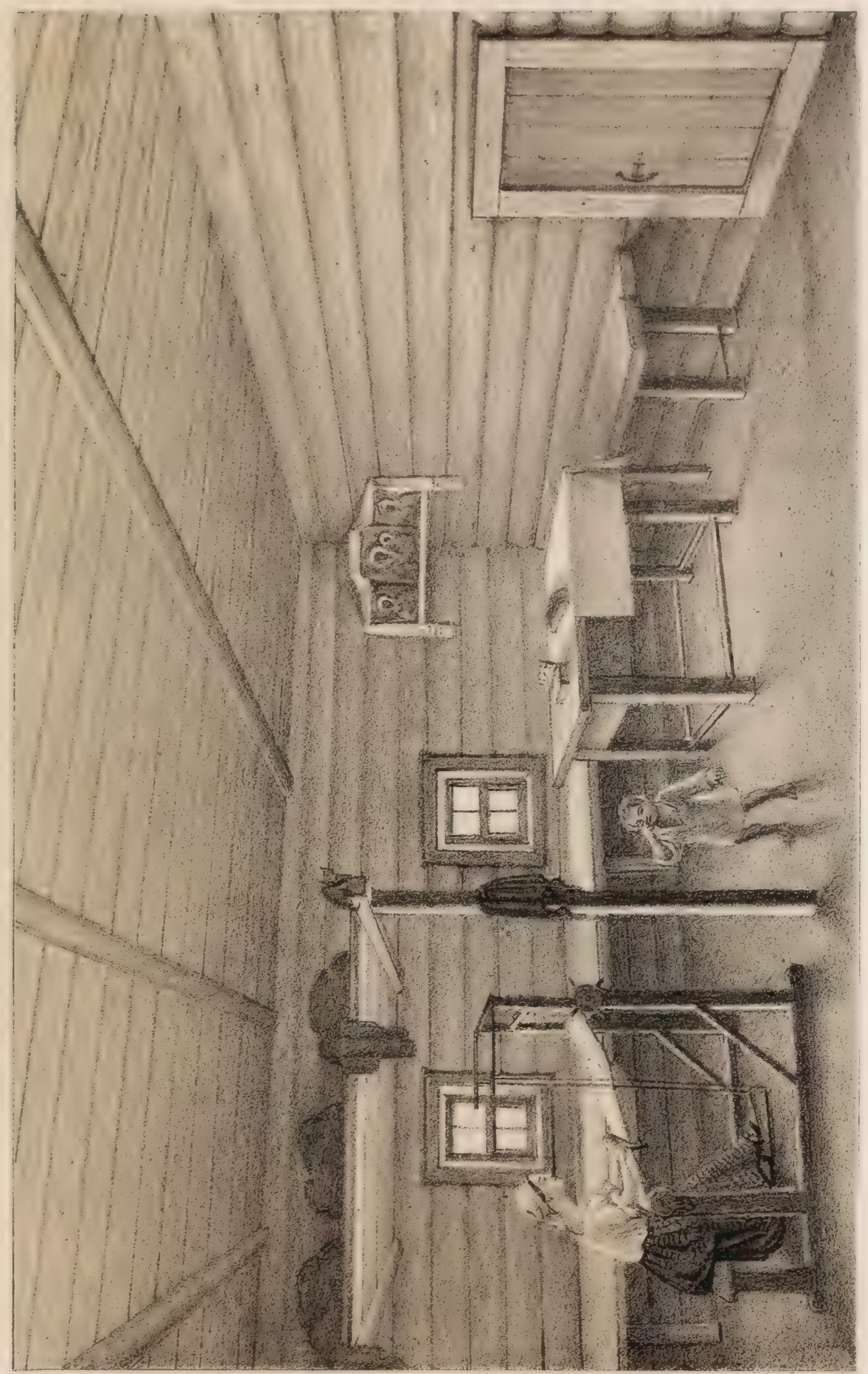

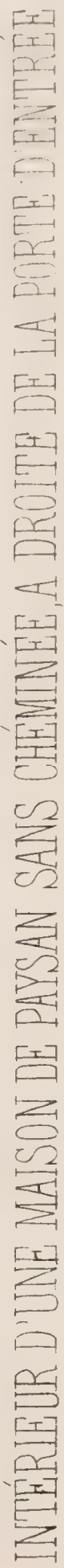



13

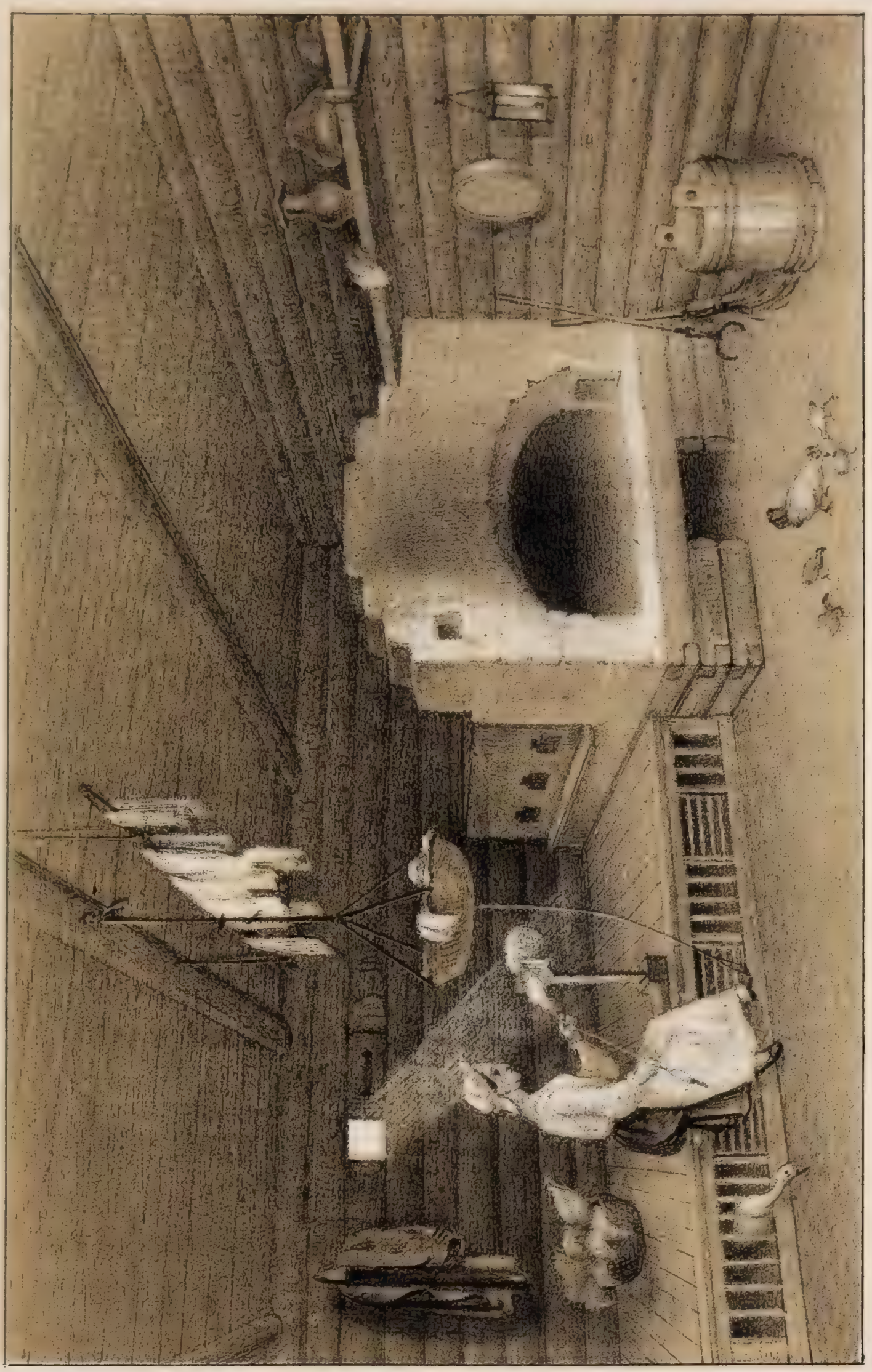

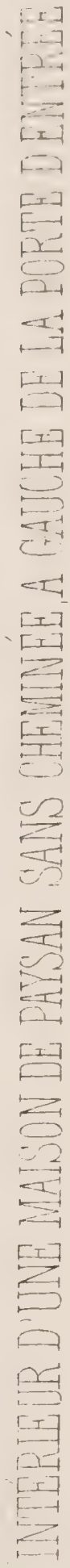





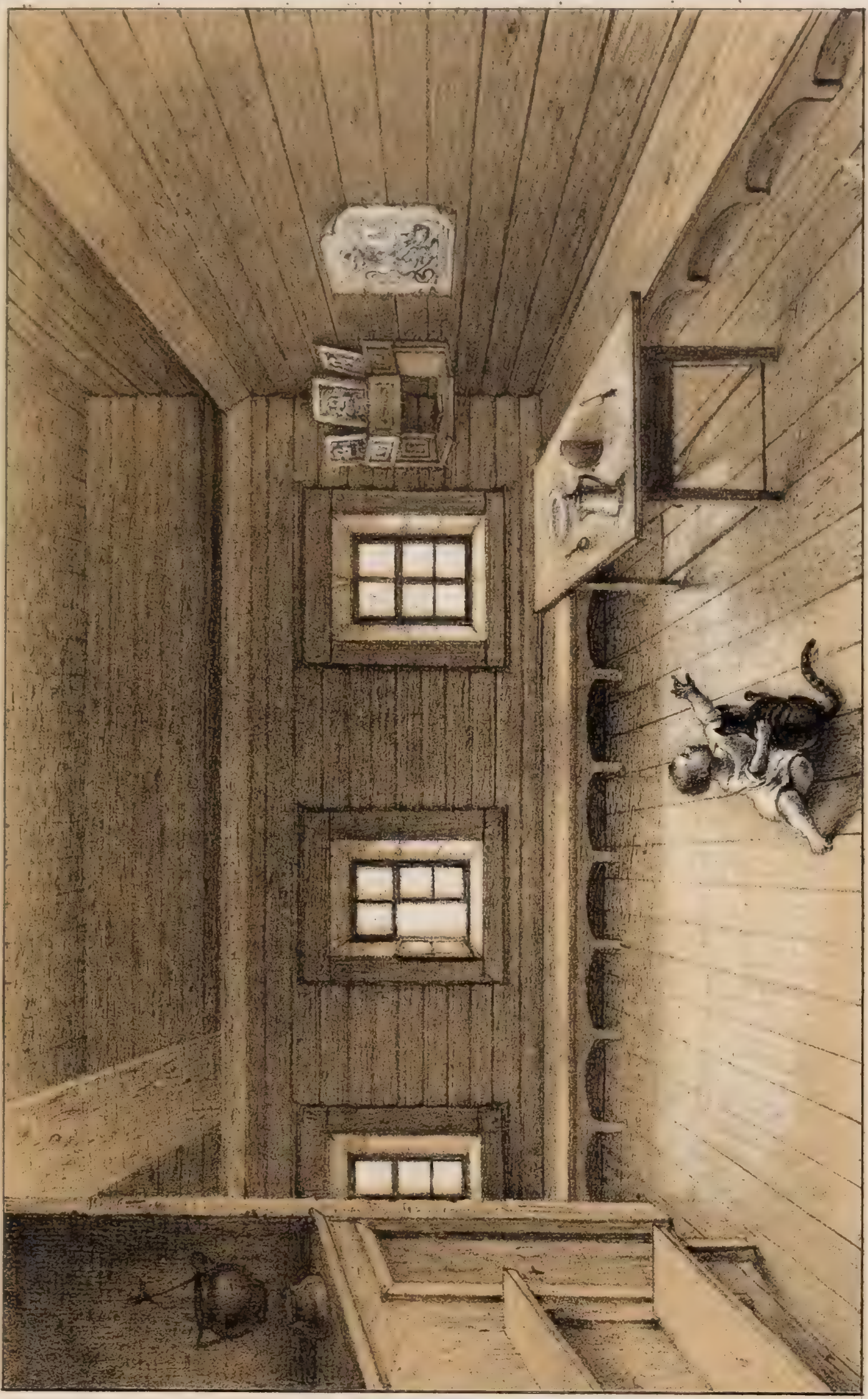

年 

m

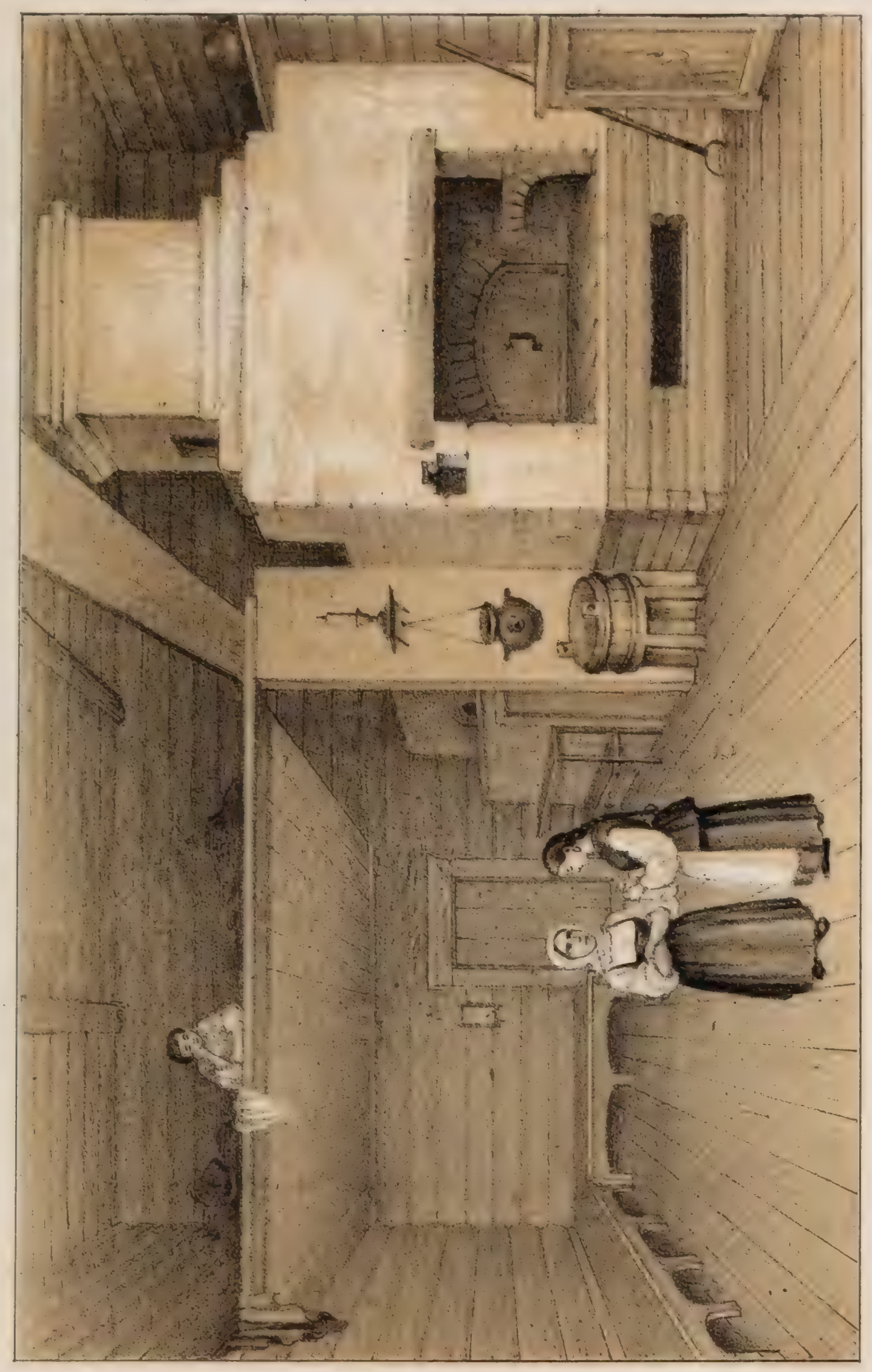

量 



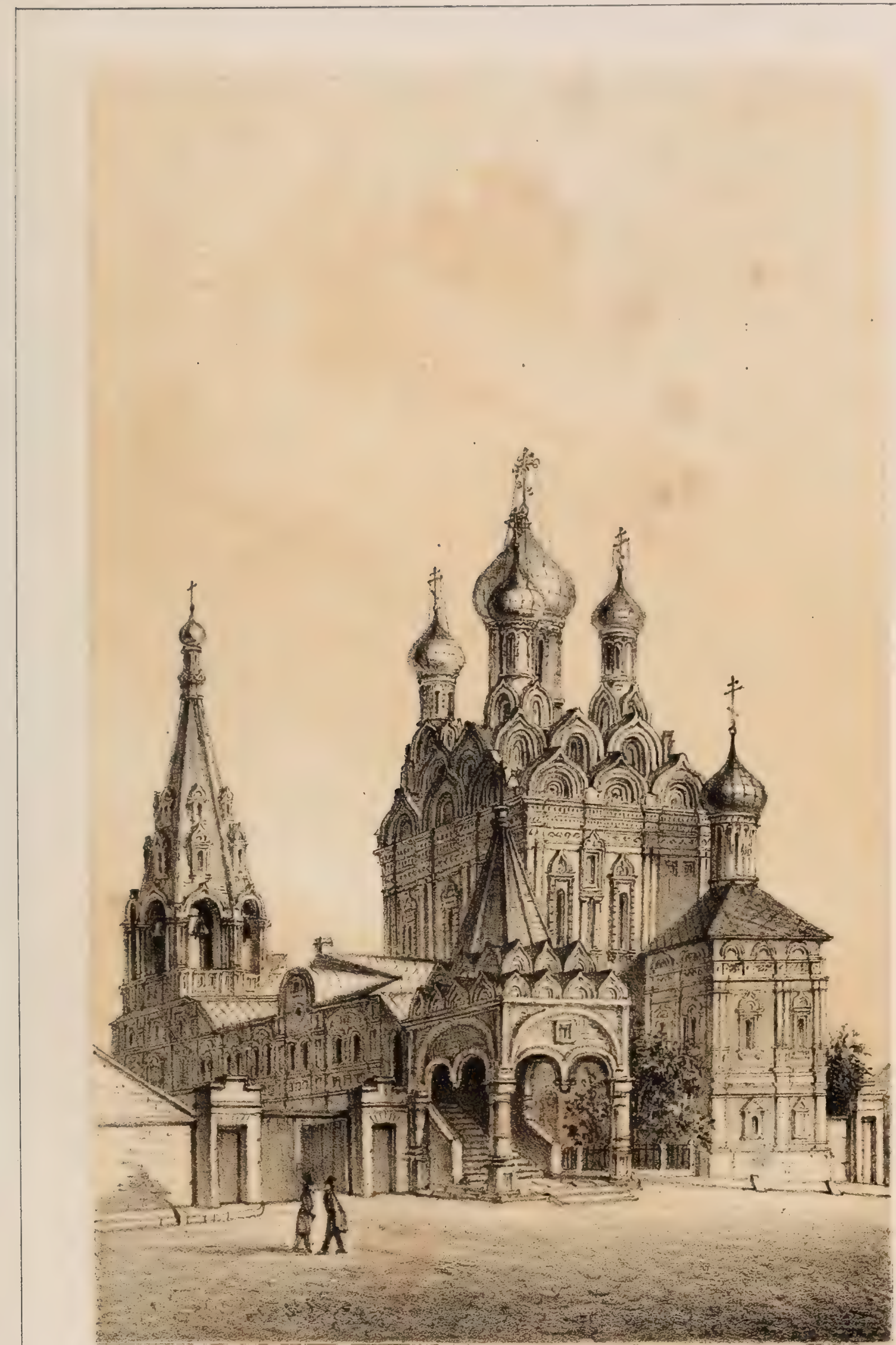

- EGIISE DE NOTRE DAME DE GF́ORGTE, 



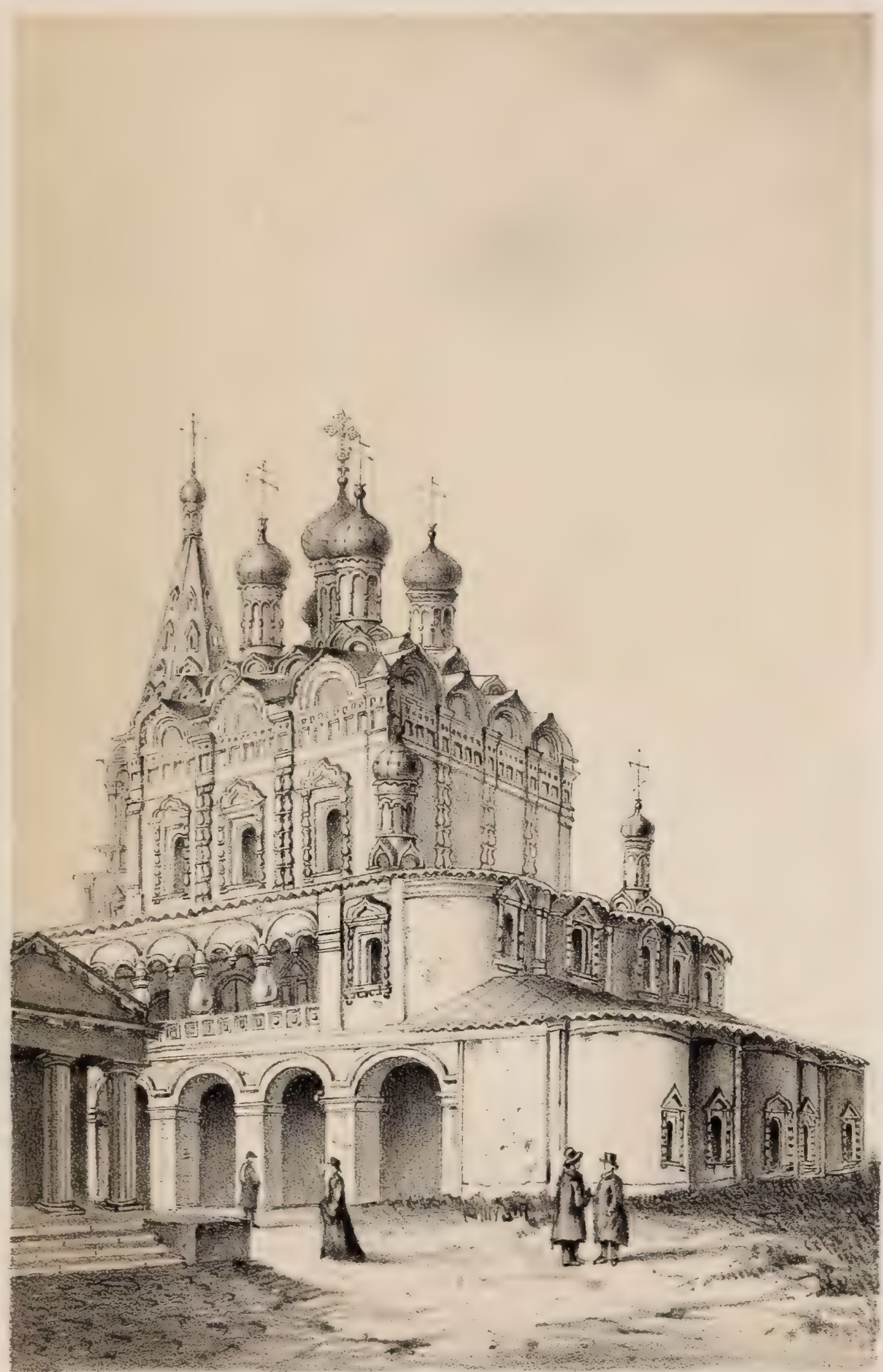

EGIISE DE St. NICOLAS AUX COLONNES A MOSCOU. 



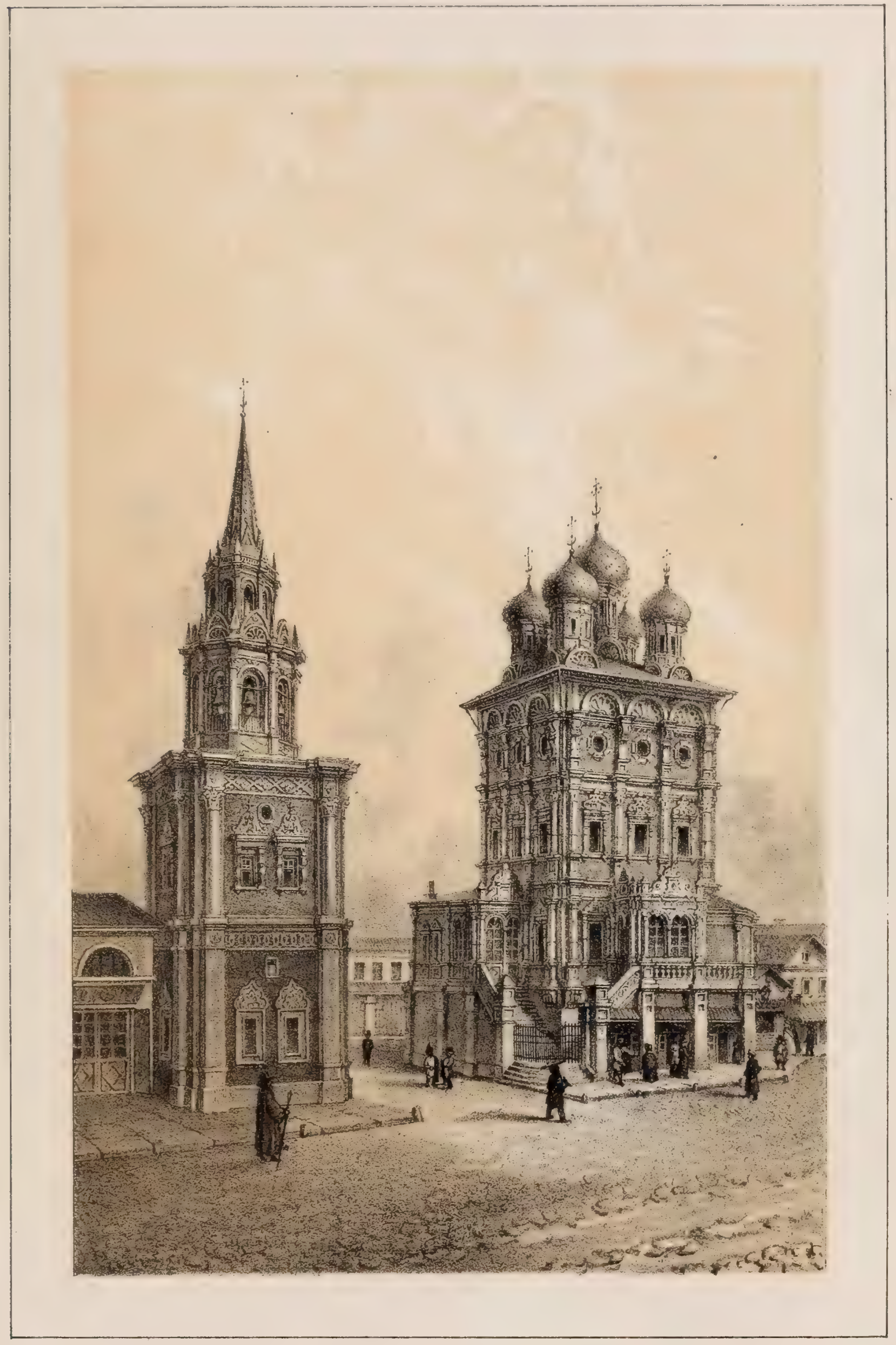

\section{EGLISE DE SE NICOIAS, A LA GRANDE CROIX.




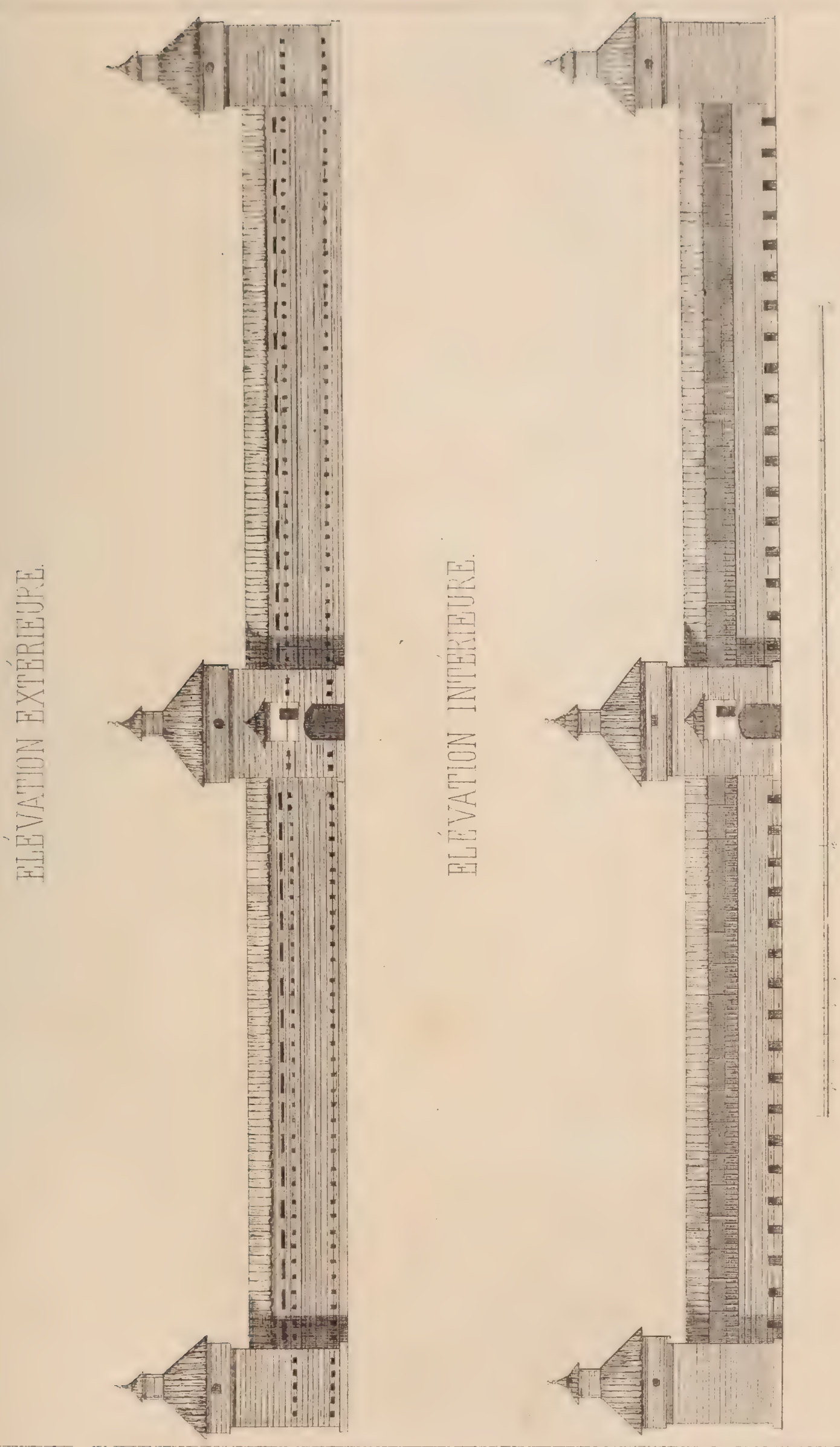



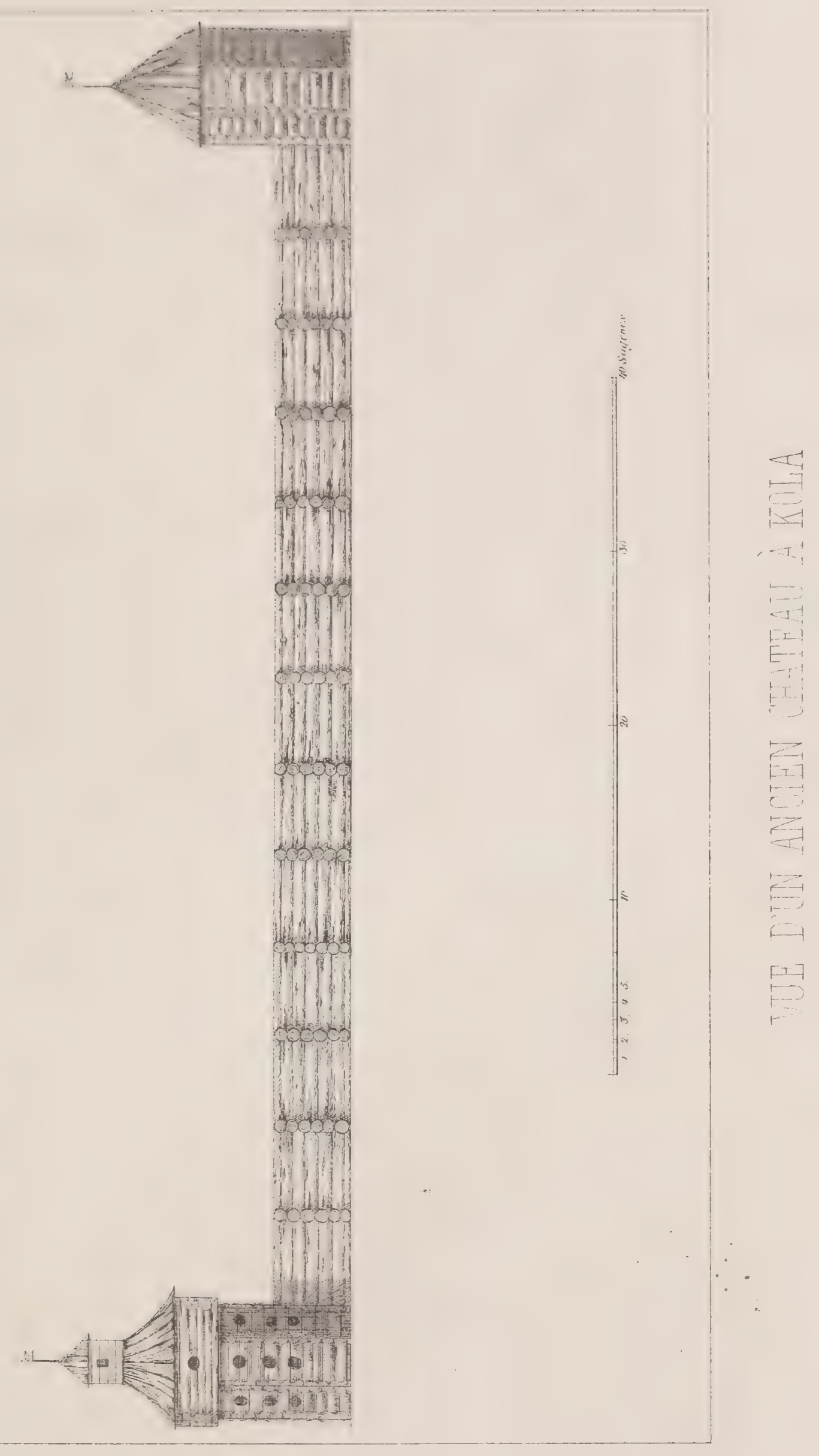





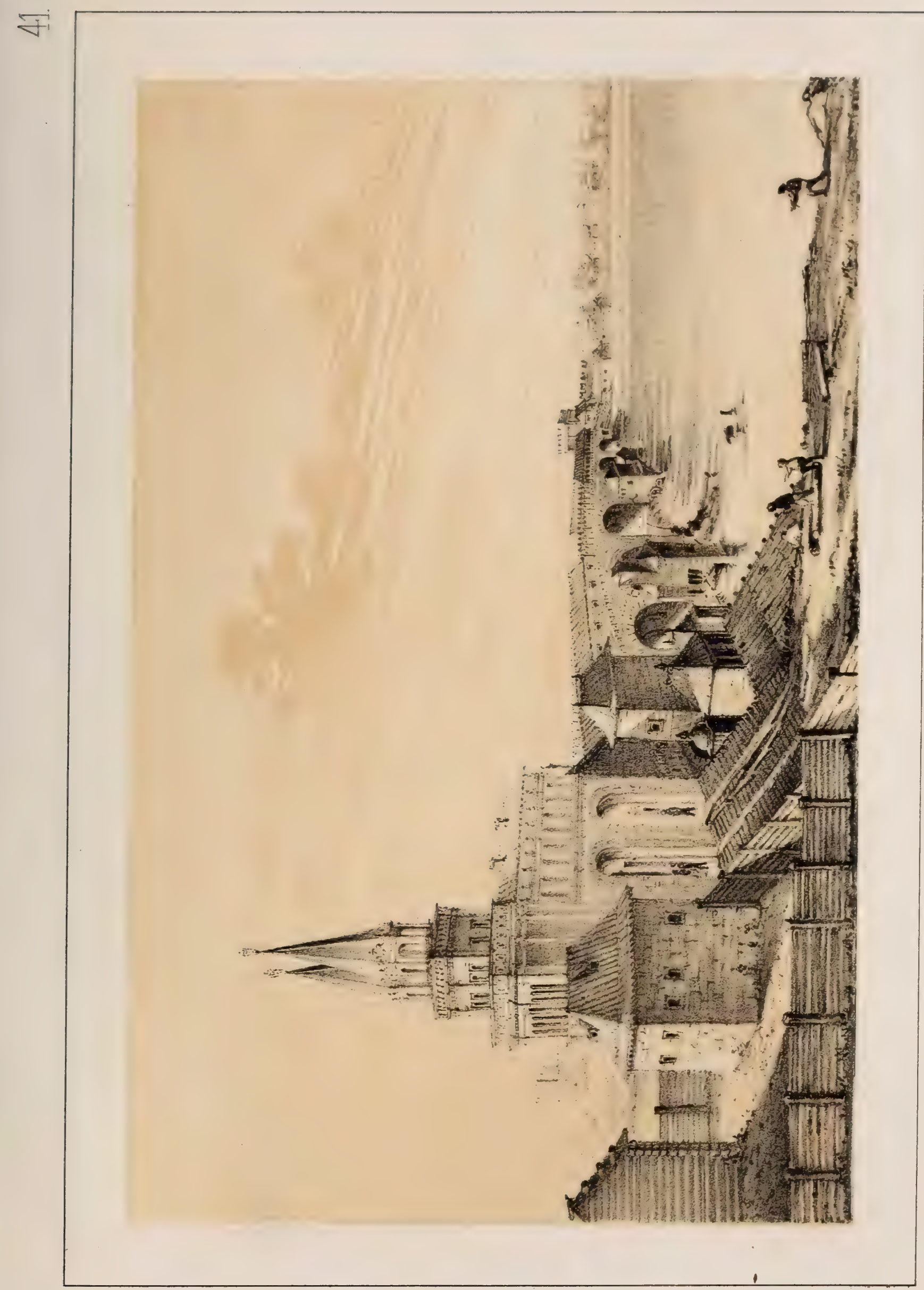

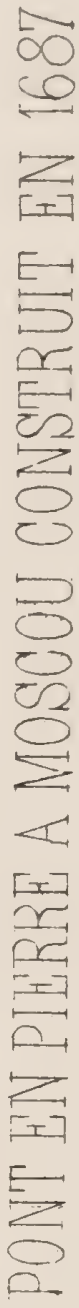





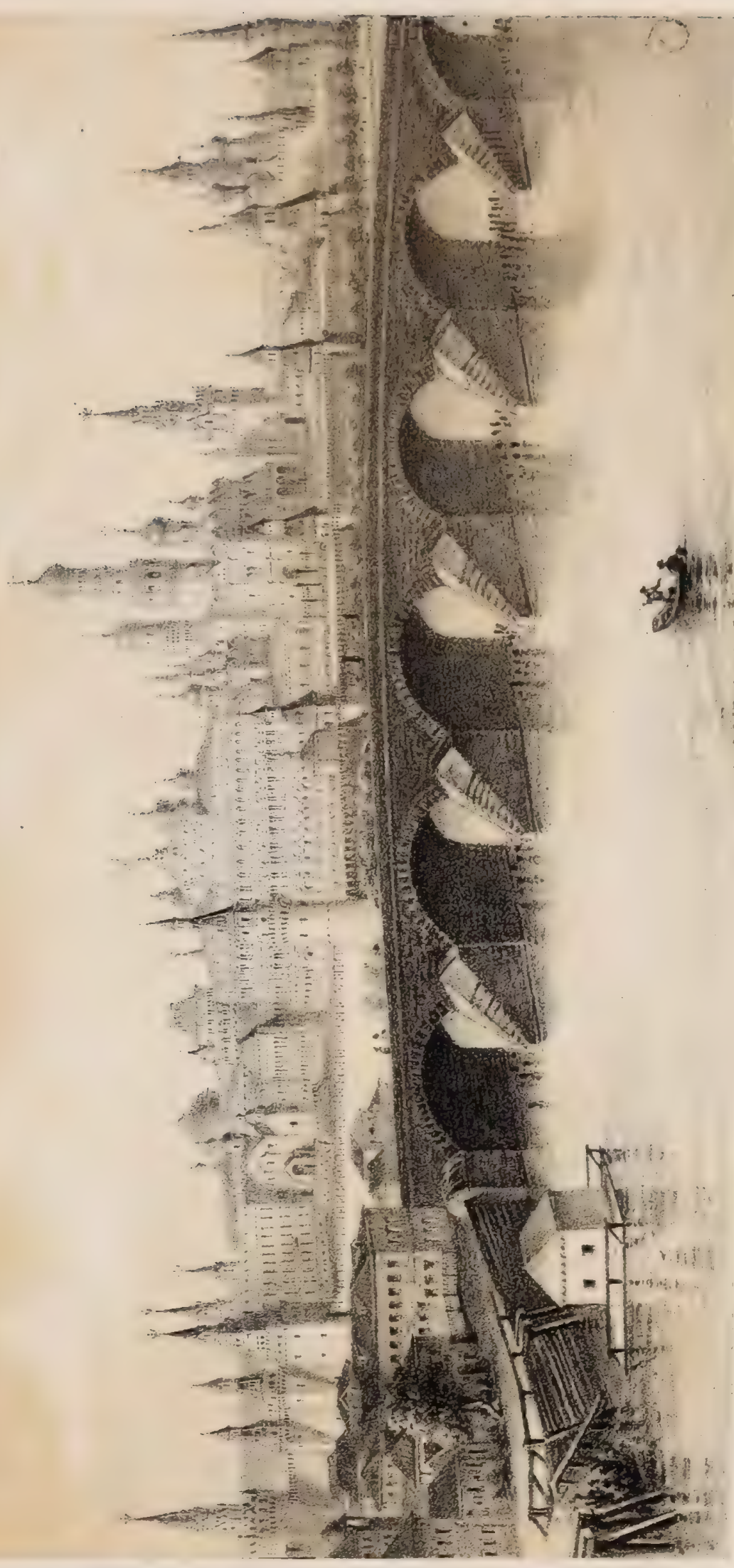

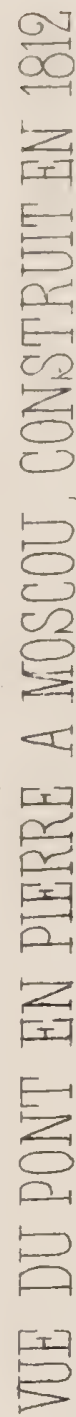





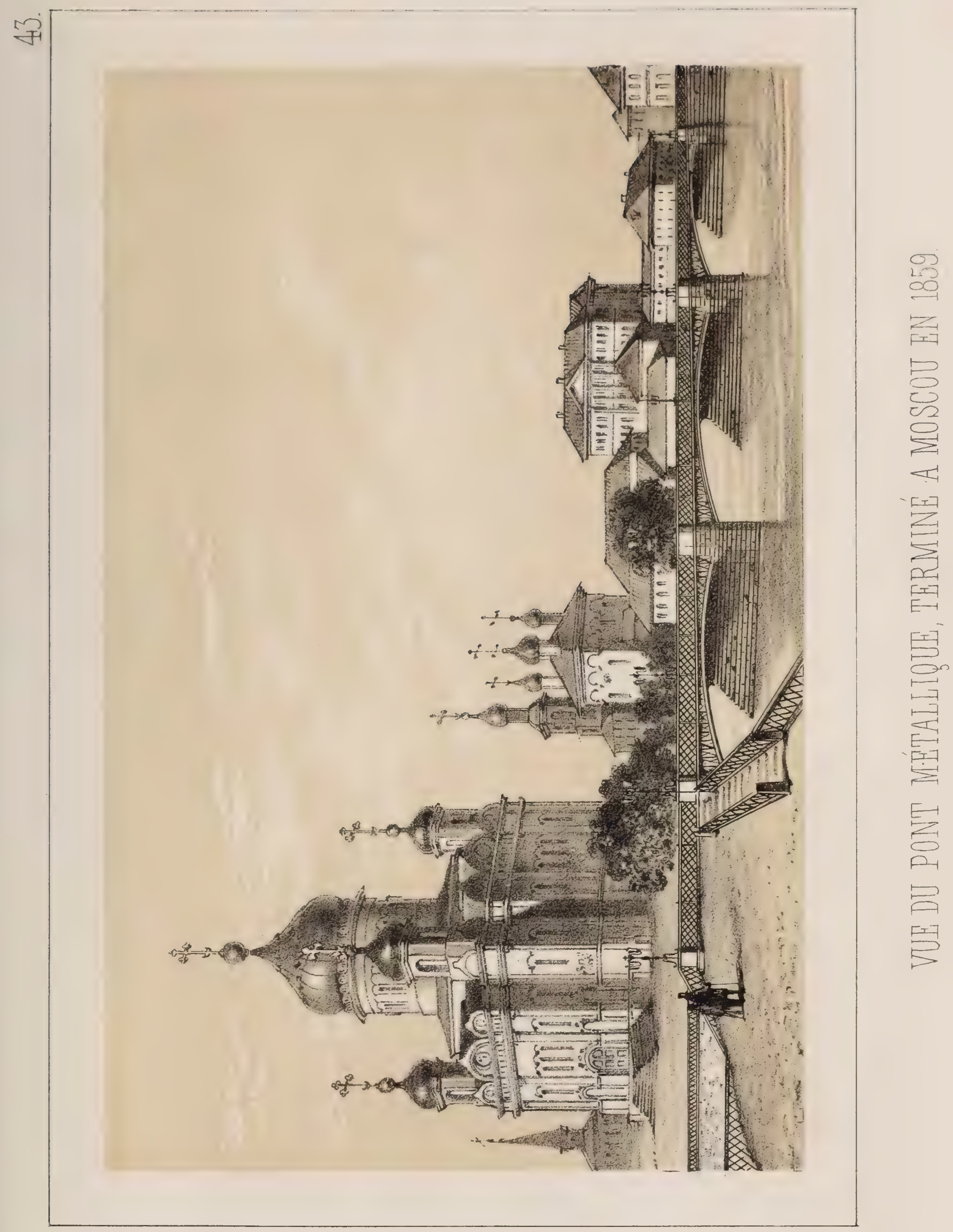





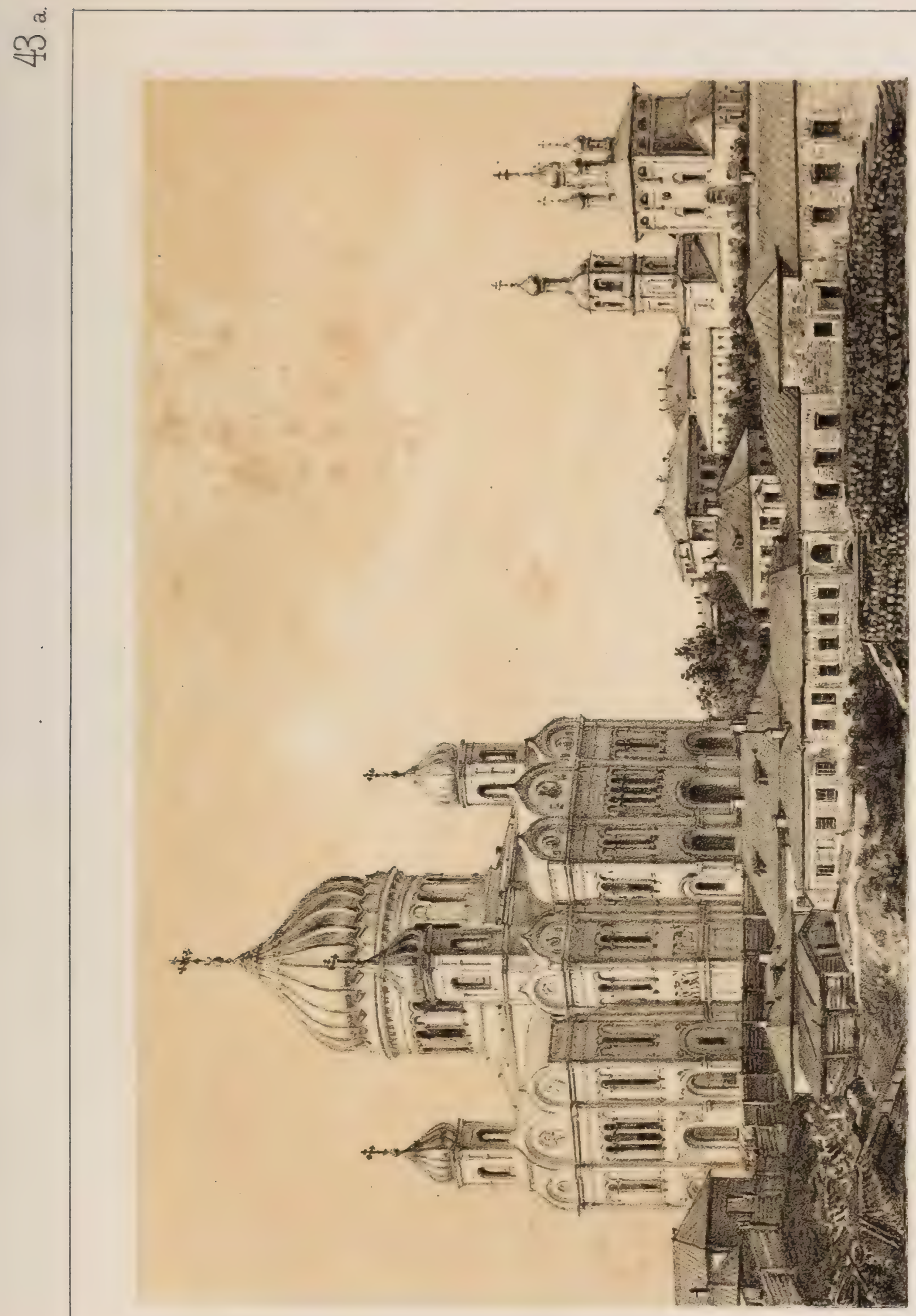

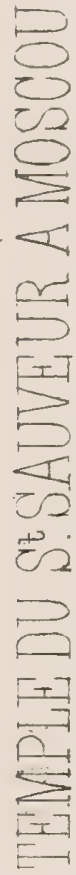





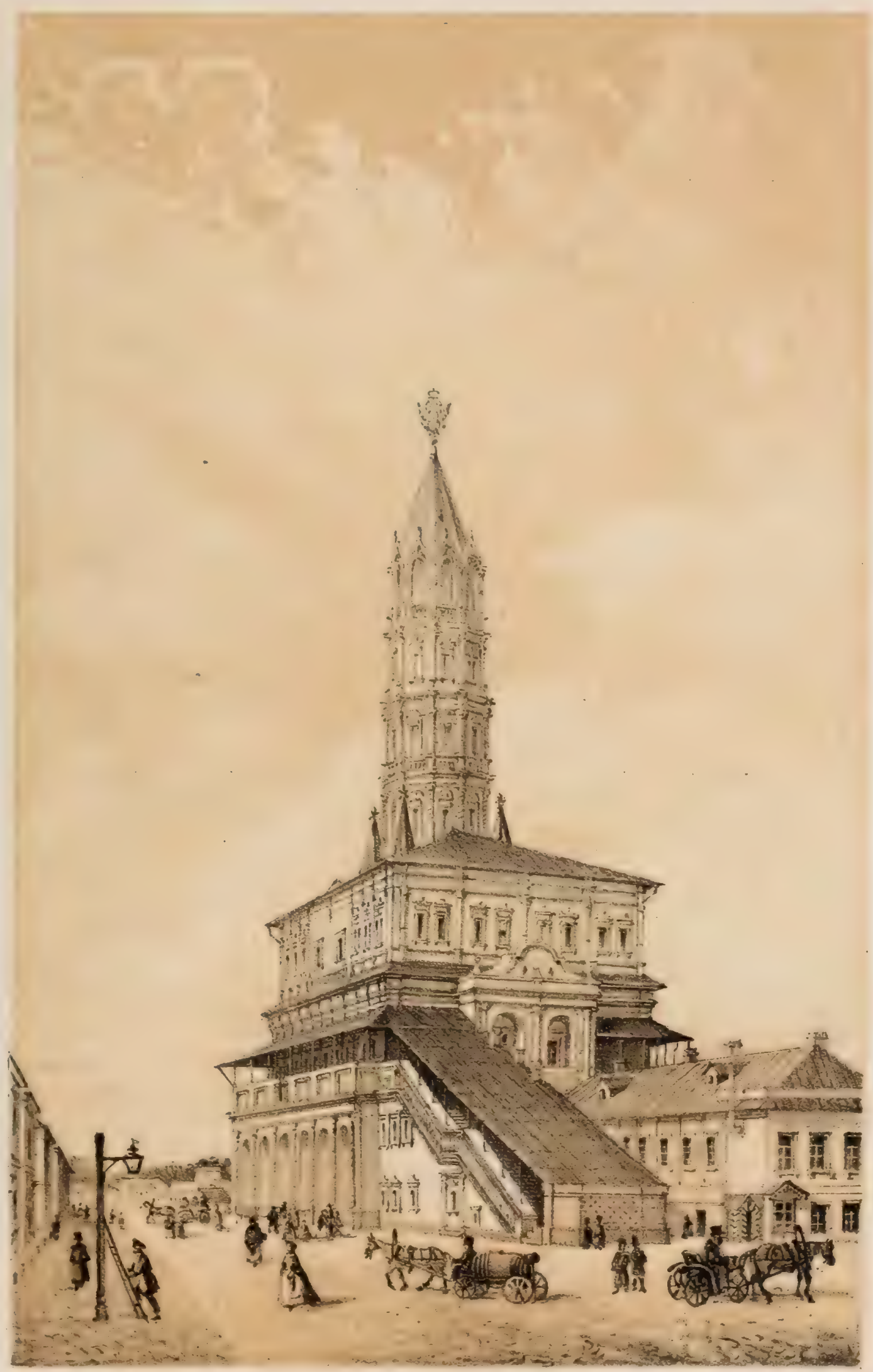





\section{BVIISE DE SE ANDRE, A KIEV.}





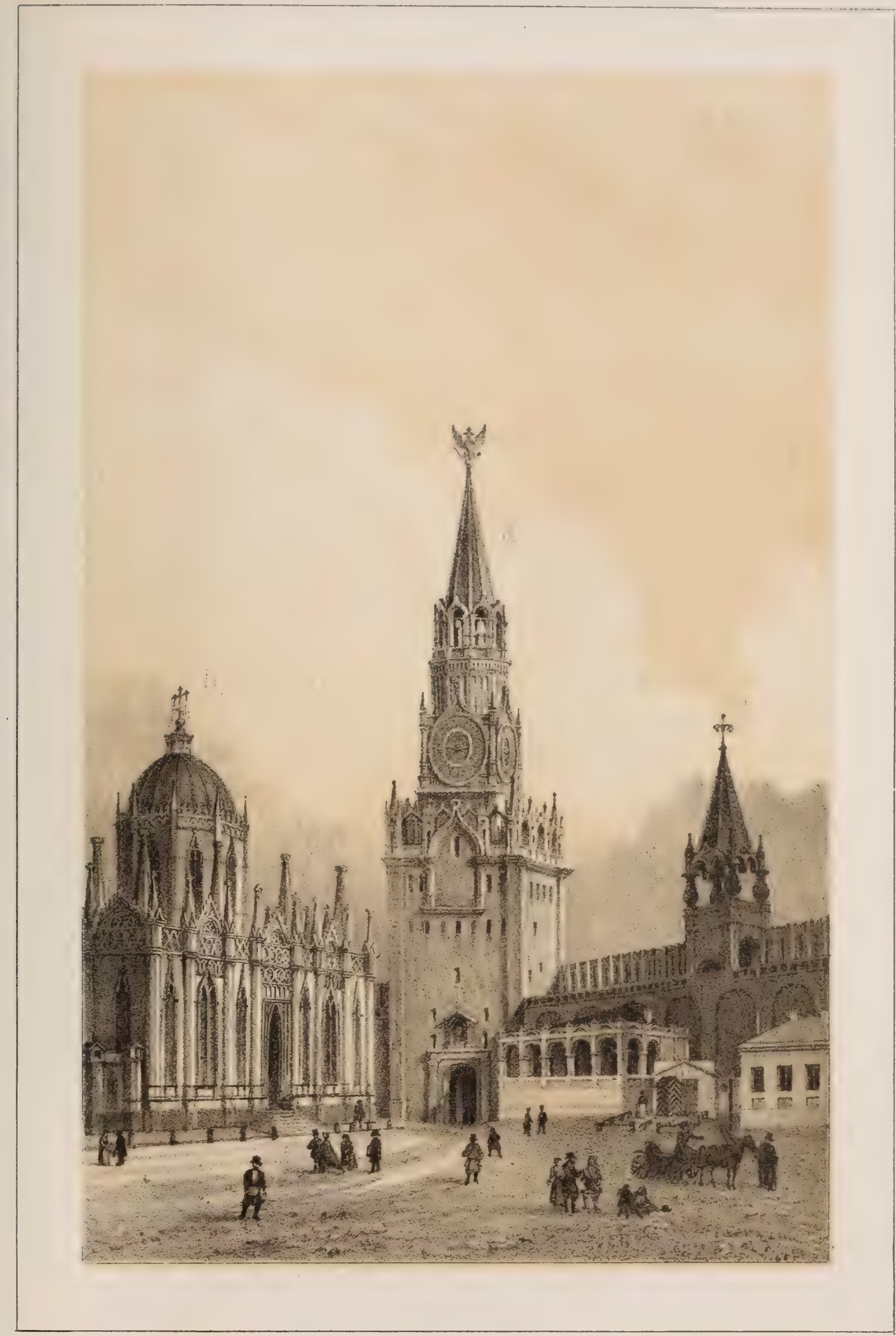

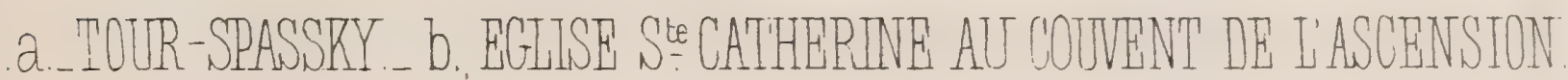
C. PETITE TOUR DES TLARS. 



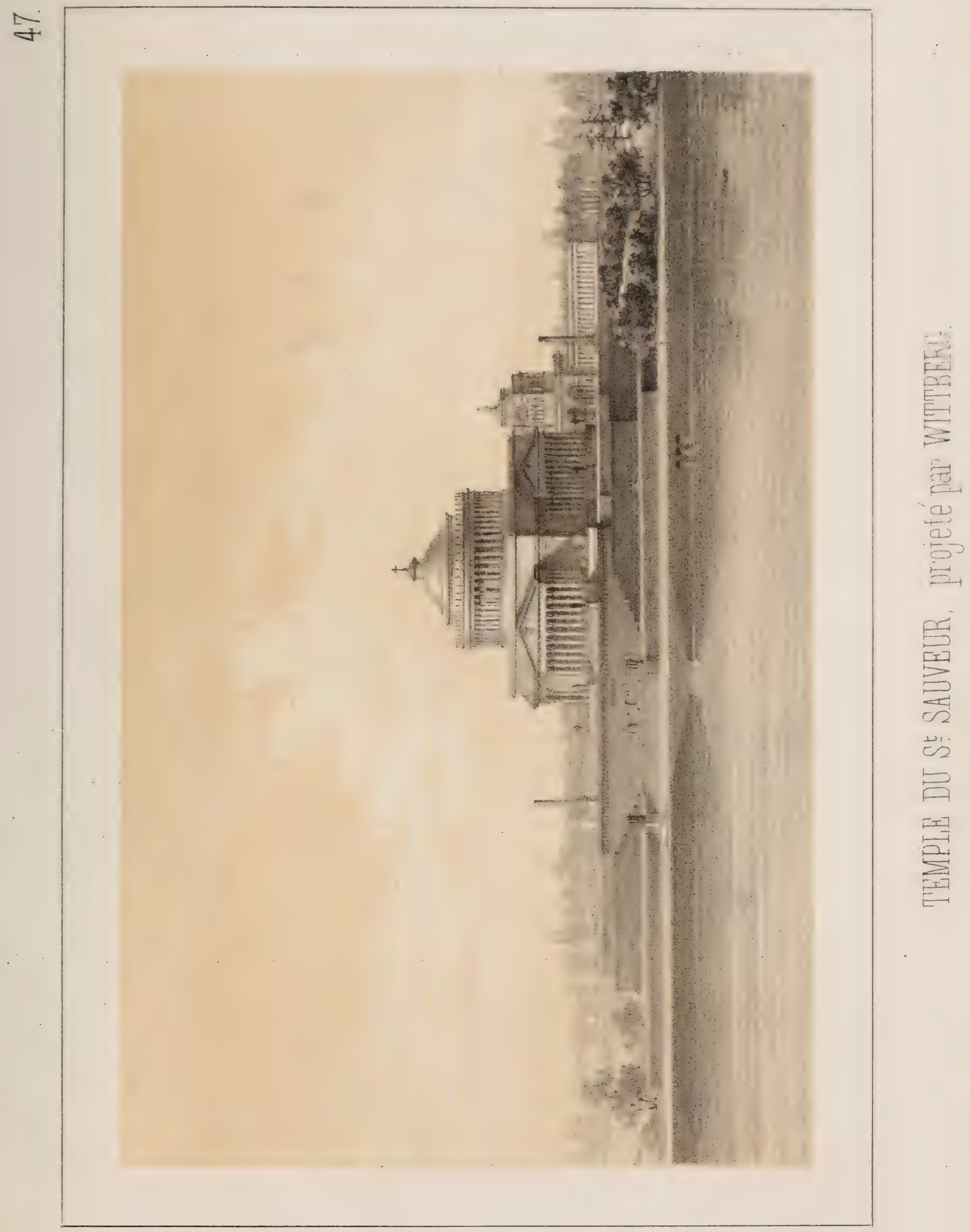





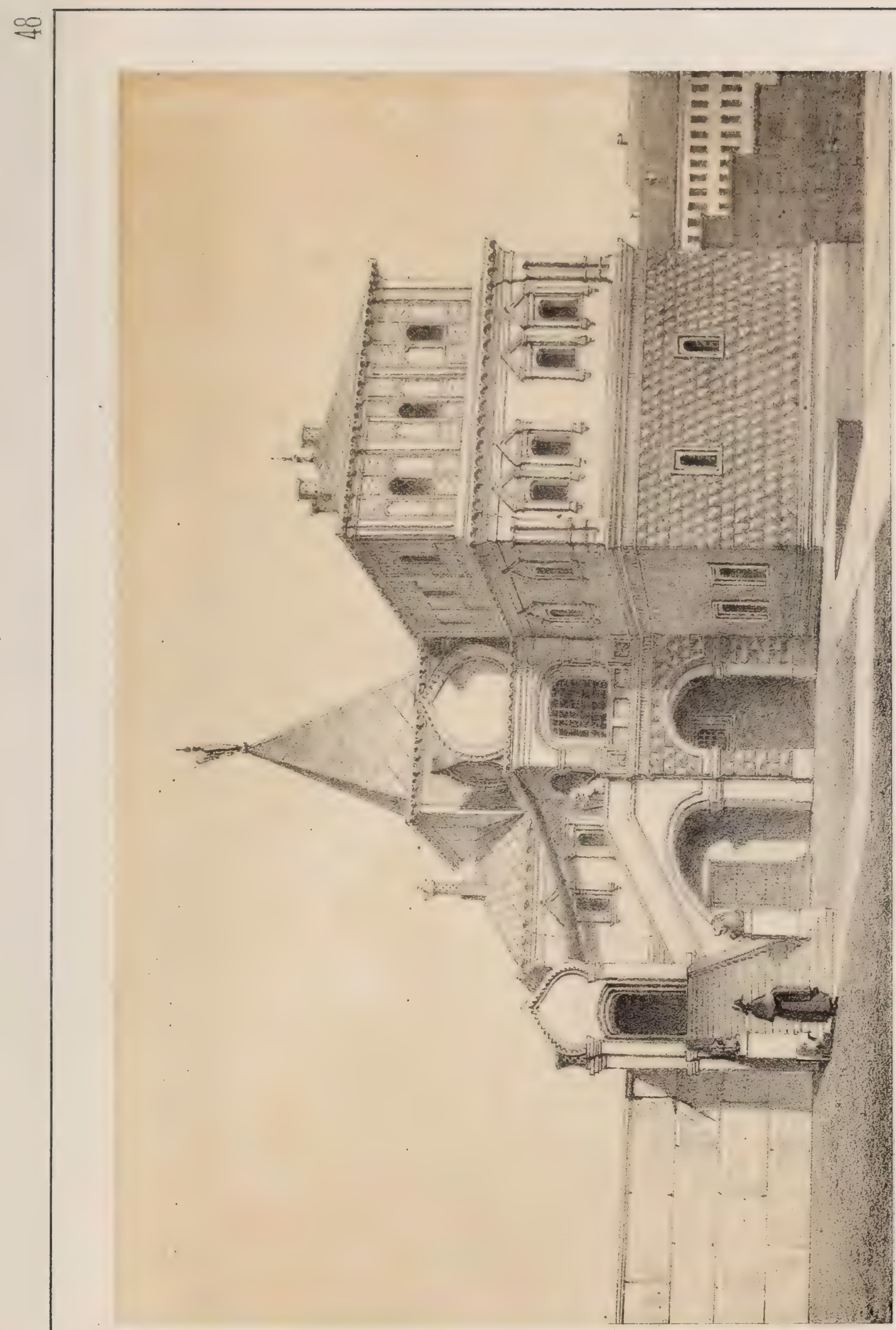

(I) 


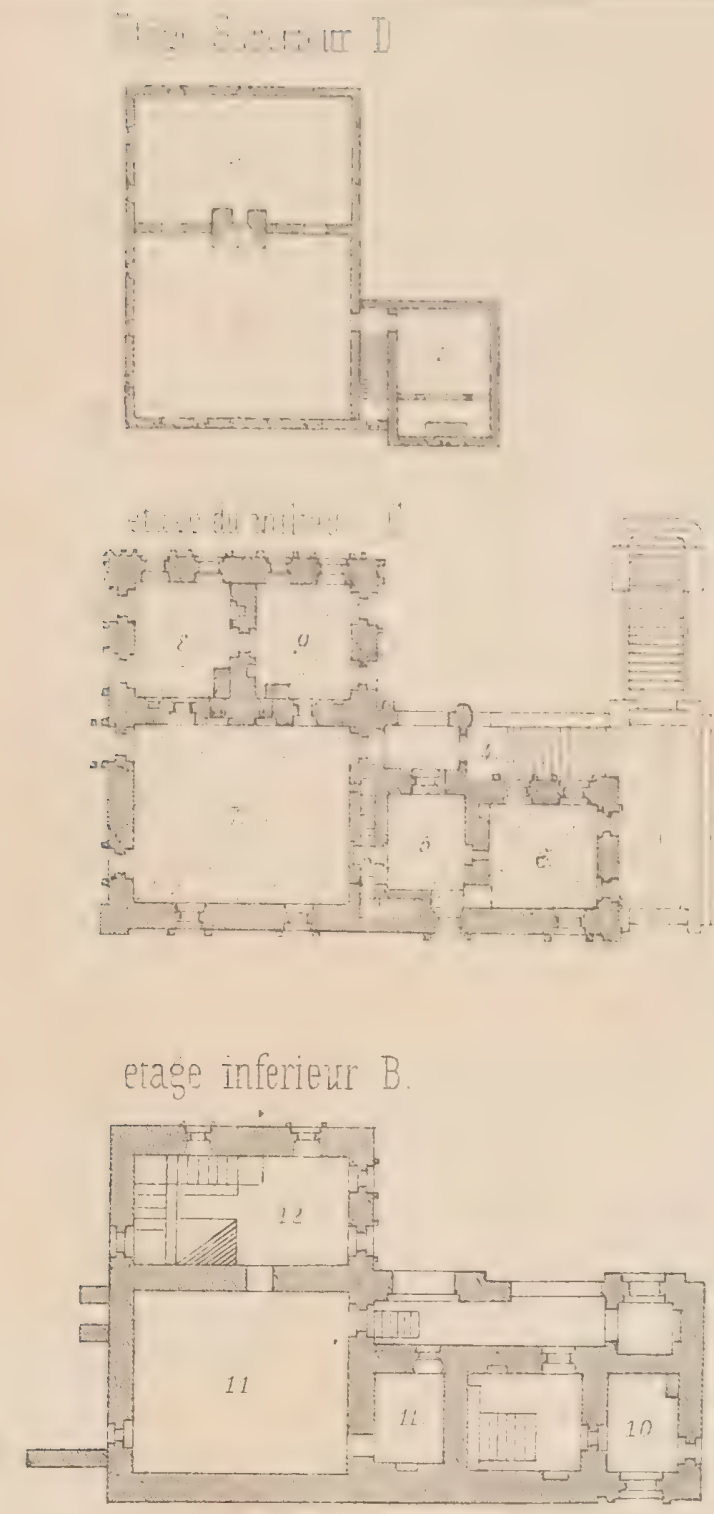

Sous - sol A
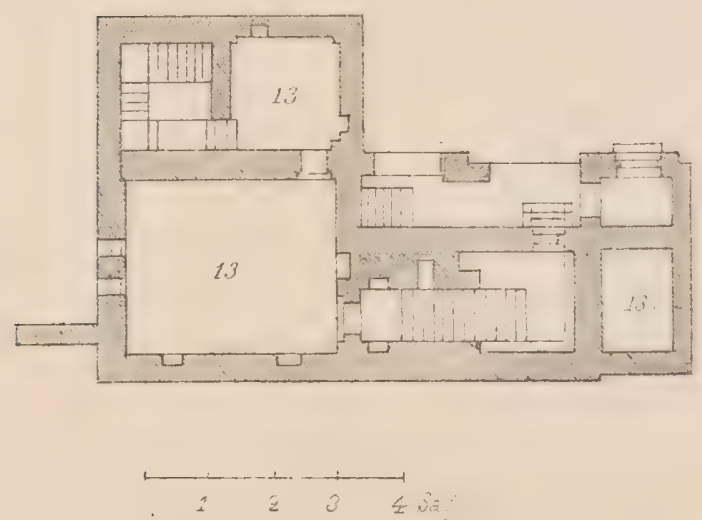

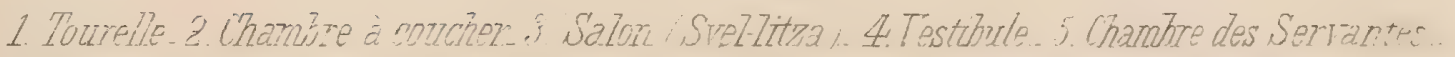

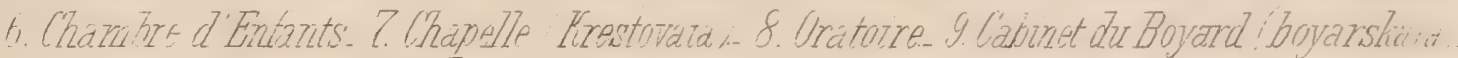

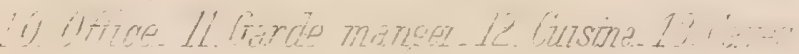





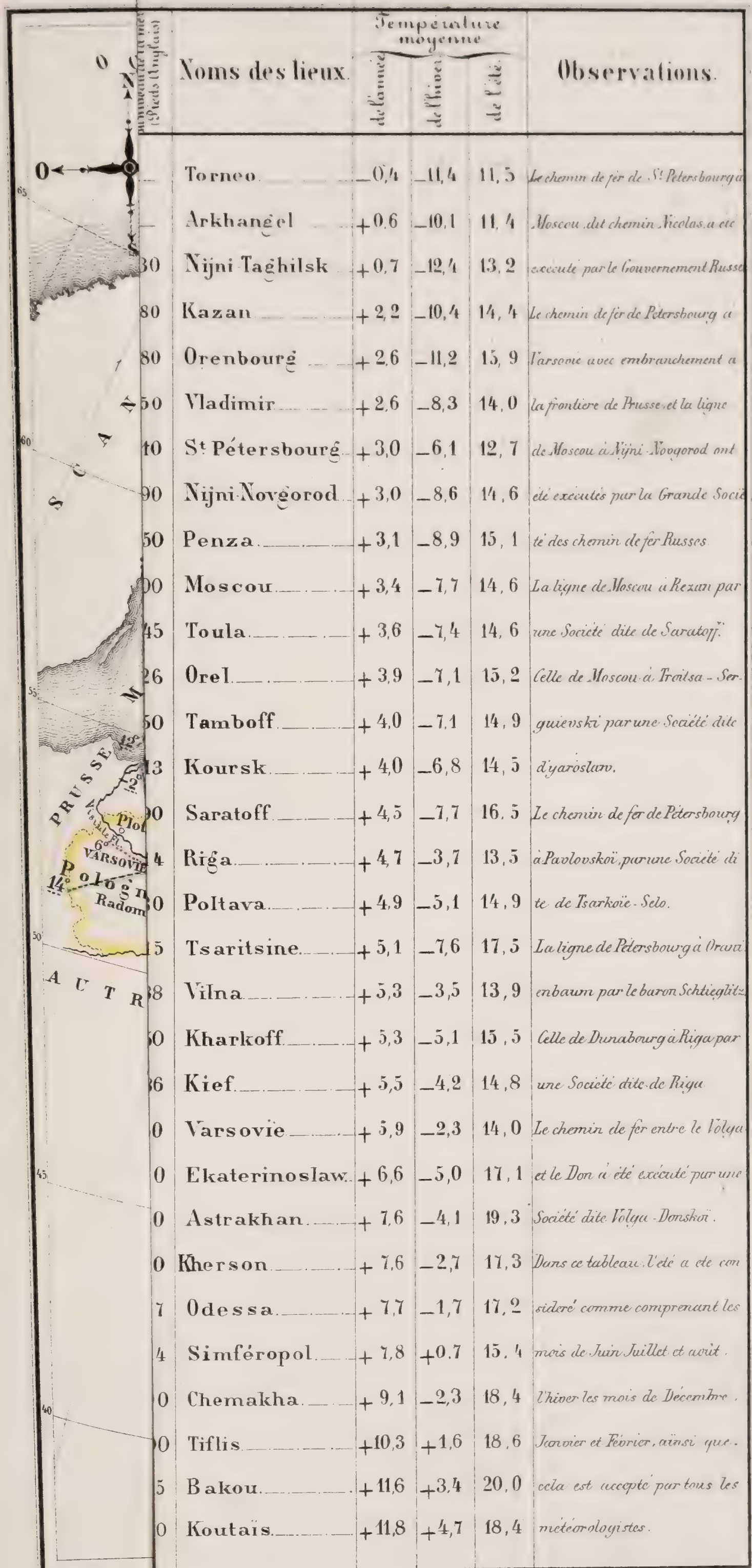





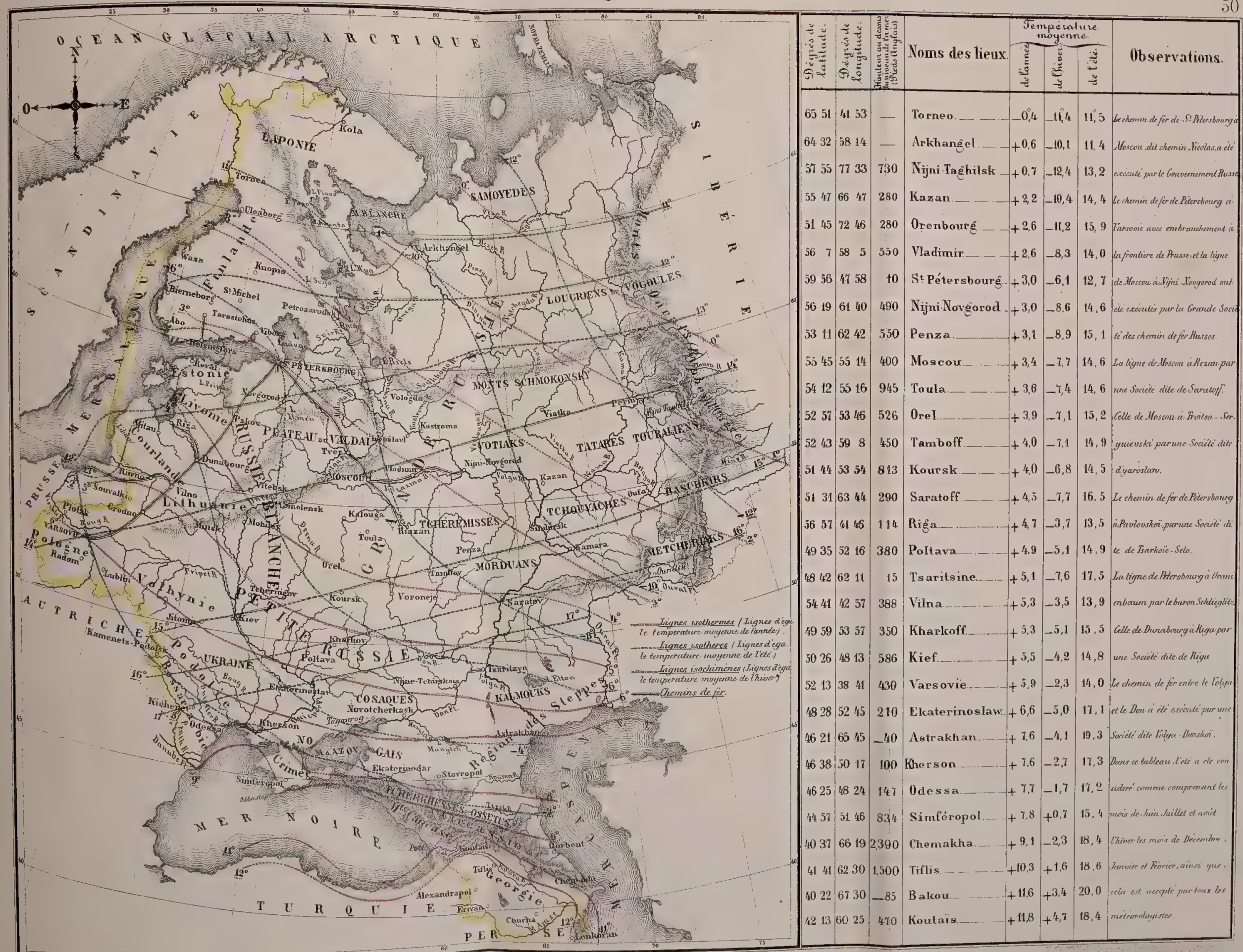





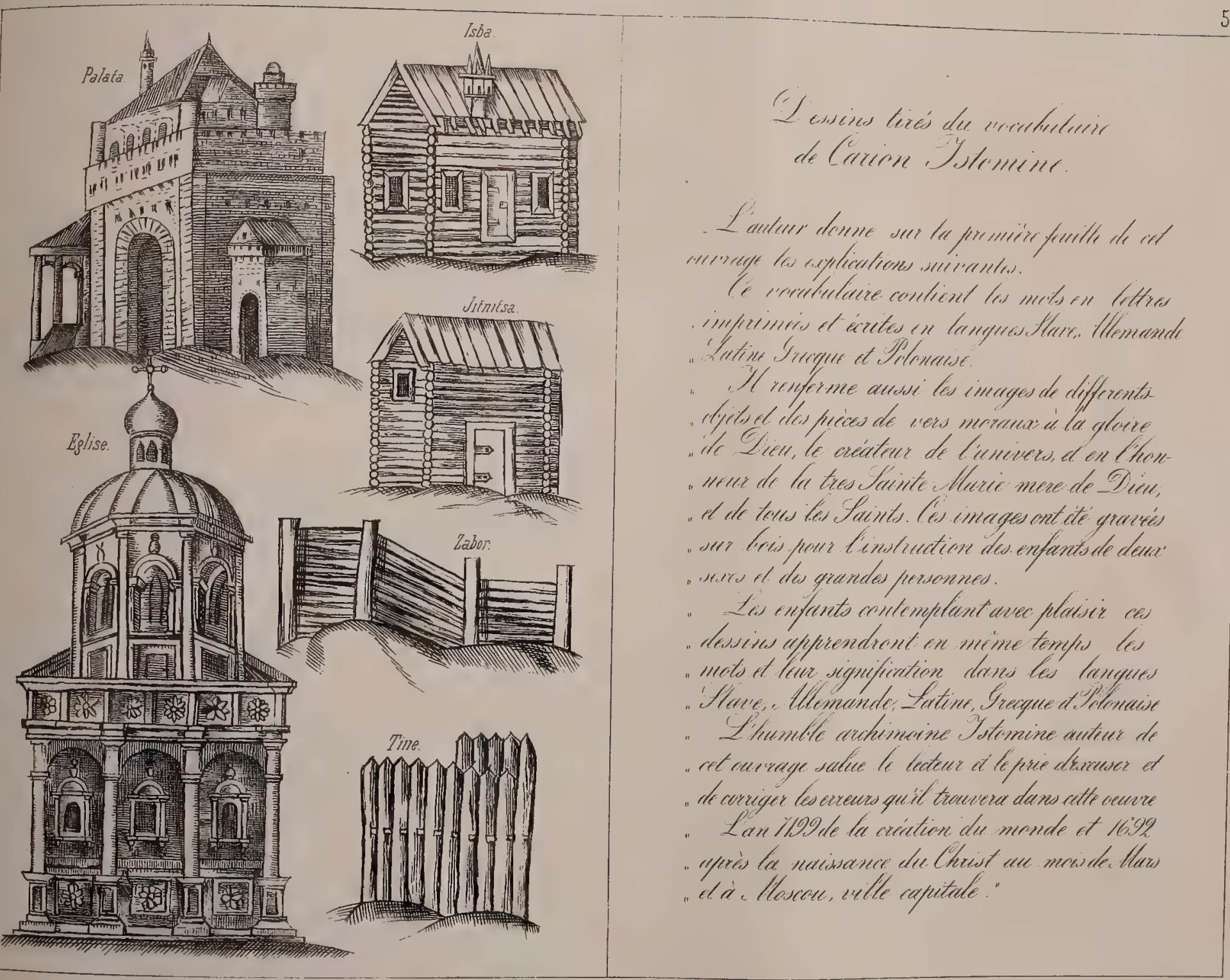



a

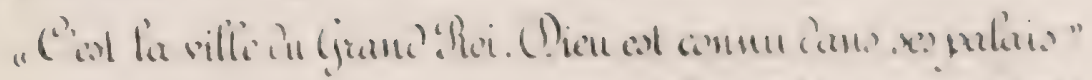

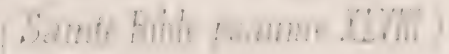

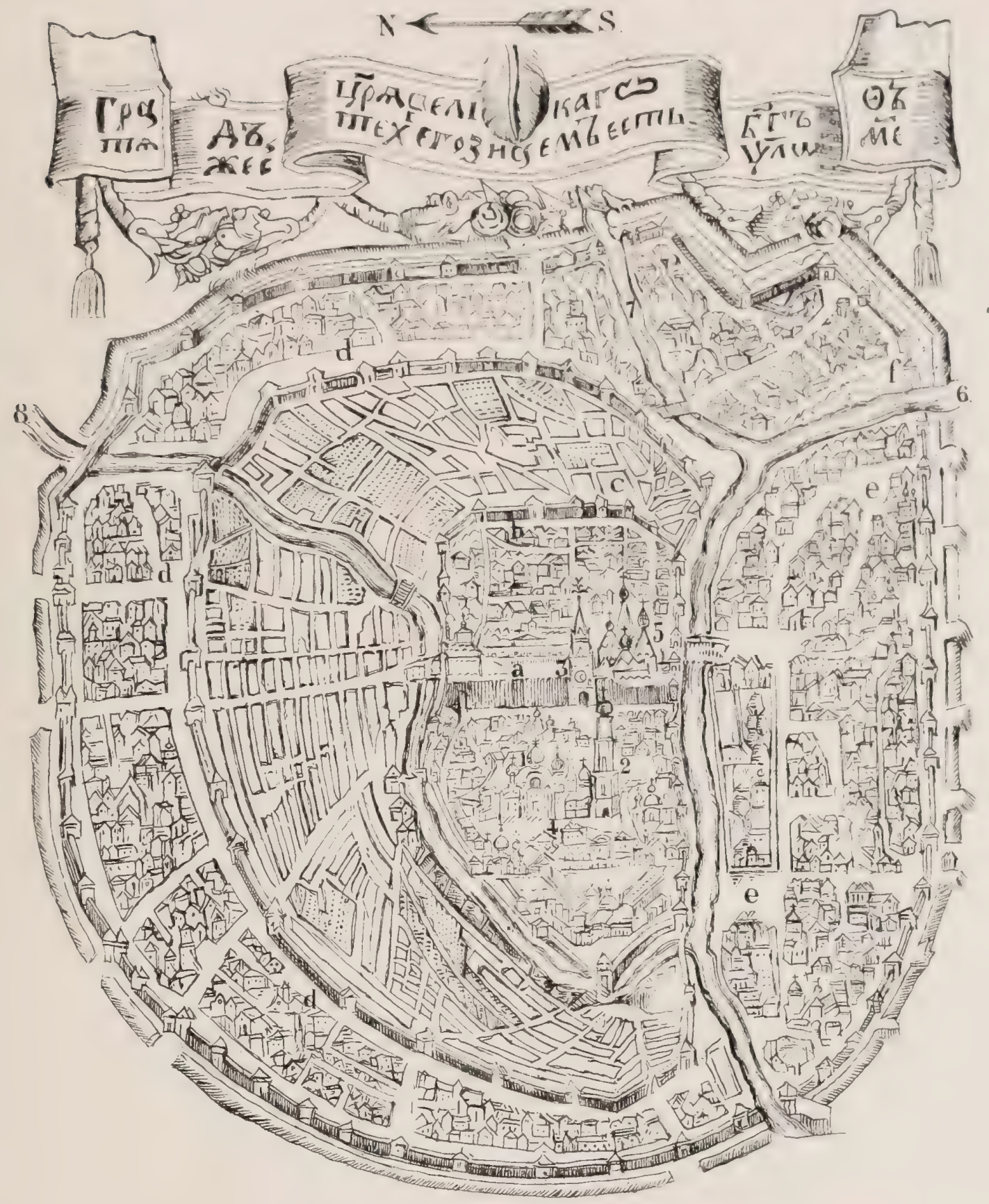

a Kremlin b. Kitai zorod, c Belö̈ ̧̧orod, d Zemlianoi gुorod, e. Quantier au dela de la rn.

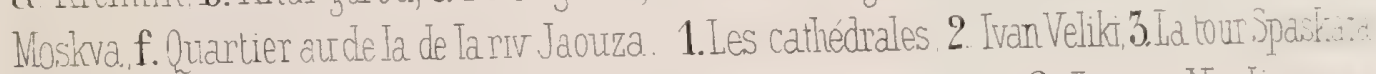
4. Les teremas 5. Vassily blapeni 6. La niv Moskva, 7. La niv. Jaoutza, 8. La niv Neginmaza

13. Sa fleihe au dessus du plan ne se trouve pus sur le dessin original fauteur a srun whle de Pajouter pour indiquer la pasition de lie ville. 



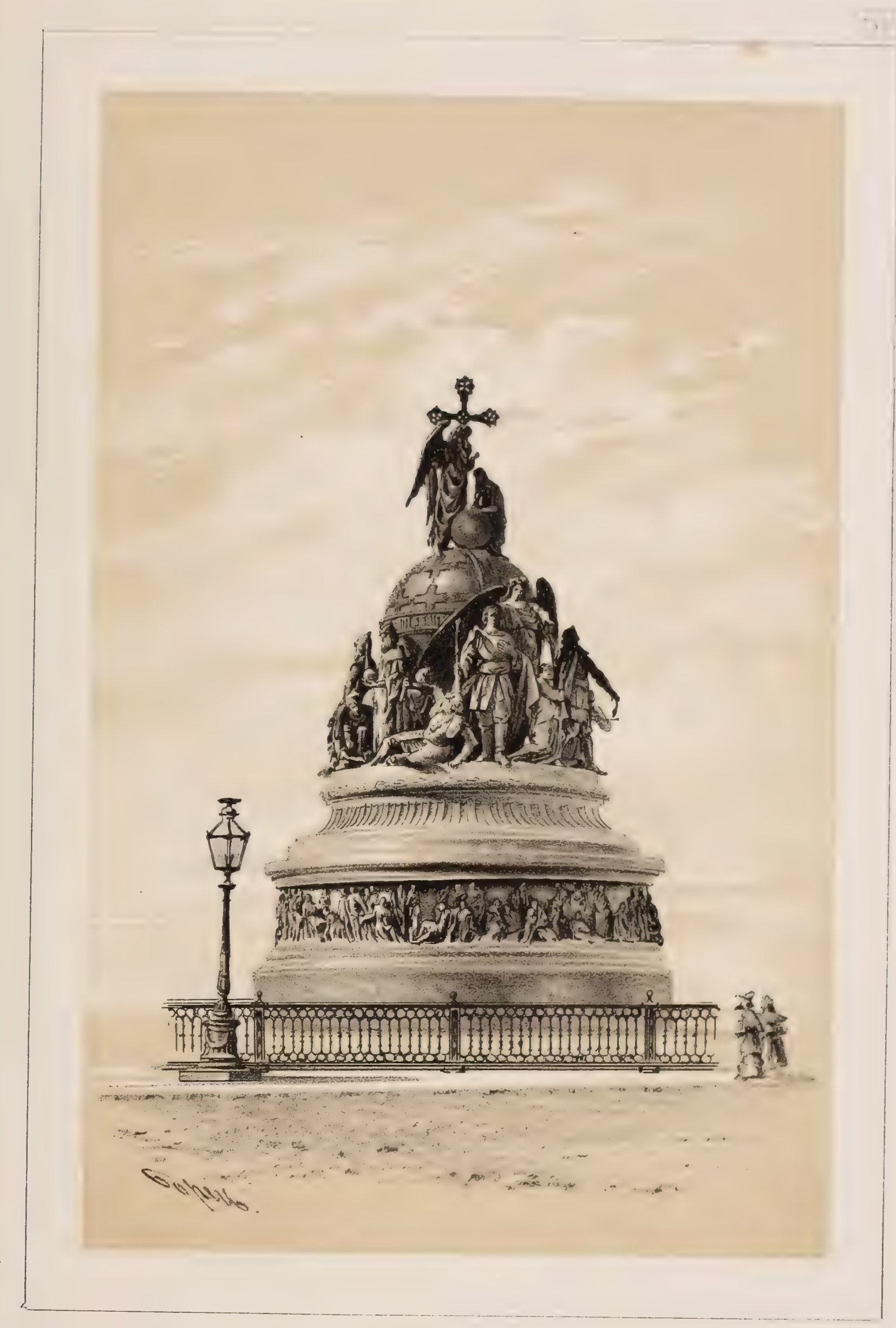

MONUMENT COMMÉMORATIP MILIENATRE,

ÉLEVÉ EN 1862 À NOVGOROD. 




